\title{
DESENVOLVIMENTO VEGETATIVO E NODULAÇÃO DE PLANTAS DE SOJA EM FUNÇÃO DE NITROGÊNIO E FÓSFOR̉O APLICADOS NA SEMEADURA EM CONDIÇÕES CONTROLADAS
}

\author{
FÁBIO ÁLVARES DE OLIVEIRA \\ Engenheiro Agronômo
}

Orientador: Prof. Dr. QUIRINO AUGUSTO DE CAMARGO CARMELLO

Dissertação apresentada à Escola Superior de Agricultura "Luiz de Queiroz", da Universidade de São Paulo, para obtenção do título de Mestre em Agronomia, Área de Concentração: Solos e Nutrição de Plantas.

PIRACICABA

Estado de São Paulo - Brasil

Dezembro - 1996 


\section{Dados Internacionais de Catalogação na Publicação (CIP) \\ DIVISĀO DE BIBLIOTECA E DOCUMENTAÇÃO - Campus “Luiz de Queiroz"/USP}

Oliveira, Fábio Álvares de

Desenvolvimento vegetativo e nodulaçāo de plantas de soja em funçāo de nitrogênio e fósforo aplicados na semeadura em condiçōes controladas / Fábio Álvares de Oliveira. - Piracicaba, 1996.

$$
85 \text { p. : il. }
$$

Dissertação (mestrado) - - Escola Superior de Agricultura Luiz de Queiroz, 1996.

Bibliografia.

1. Bactéria fixadora de nitrogênio 2. Nitrogênio em soja - Fixação 3. Soja - Adubação fosfatada 4. Soja - Nodulação 5. Soja - Nutriçāo 1. Titulo

CDD 633.34 
DESENVOLVIMENTO VEGETATIVO E NODULAÇÃO DE PLANTAS DE SOJA EM FUNÇÃO DE NITROGÊNIO E FÓSFORO APLICADOS NA SEMEADURA EM CONDIÇÕES CONTROLADAS

FÁBIO ÁLVARES DE OLIVEIRA

Aprovada em: 17.12 .1996

Comissão julgadora:

Prof. Dr. Quirino Augusto de Camargo Carmello ESALQ/USP Prof. Dr. Luís Ignácio Prochnow ESALQ/USP Dr. Roberto Tetsuo Tanaka Instituto Agronômico

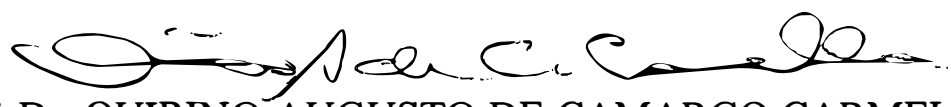

Prof. Dr. QUIRINO AUGUSTO DE CAMARGO CARMELLO Orientador 
Aos meus pais, Hélio e Mafalda e irmãos, Marcelo e Rodrigo, pelo apoio e incentivo

\section{DEDICO}

A toda minha família, pela confiança 


\section{AGRADECIMENTOS}

Fica aqui registrado meus sinceros agradecimentos a todos que contribuiram de forma direta e indireta para a realização deste trabalho, em especial às seguintes instituições e pessoas:

A ESCOLA SUPERIOR DE AGRICULTURA "LUIZ DE QUEIROZ" (ESALQ/USP) por minha formação e todas as condições proporcionadas;

A COORDENADORIA DE APOIO À PESQUISA DE ENSINO SUPERIOR (CAPES), pela concessão da bolsa de estudos;

A todos os professores do Curso de Pós-graduação em Solos e Nutrição de Plantas, por todo ensinamento, em especial aos do Setor de Nutrição Mineral de Plantas do Departamento de Química da ESALQ/USP, Dr. Antonio Roque Dechen e Dr. Francisco Antonio Monteiro pela amizade;

Ao Departamento de Ciência do Solo da ESALQ/USP, na pessoa do professor Dr. Márcio R. Lambais pela cessão da casa-de-vegetação para a condução do experimento;

Aos pesquisadores científicos da Seção de Leguminosas do Instituto Agronômico de Campinas Dr. Hipólito A. A. Mascarenhas e Dr. Roberto Tetsuo Tanaka pelas sugestões na elaboração do trabalho e ao Dr. Manoel A. de C. Miranda, pelo fornecimento das sementes;

À professora Dra. Siu Mui Tsai do Departamento de Microbiologia do Centro de Energia Nuclear na Agricultura (CENA/USP) pelo fornecimento do inoculante;

Aos funcionários do Setor de Nutrição Mineral de Plantas do Departamento de Química da ESALQ/USP, Fernando Éder Ré, Lúcia Helena S. Pavan Forti, Edinéia Cristina S. Mondoni, pela realização das análises de terra, Lurdes A. Dário de González, Nivanda Maria de Moura, pelo auxílio na realização das análises do material vegetal, 
além das funcionárias Sueli Maria Amaral de Campos Bovi e Mirtes Ventura Sesso, pelo auxílio e amizade;

Aos funcionários do Departamento de Ciência do Solo da ESALQ/USP, Dorival Grisotto e Jair Ferrer da Silva pela amizade e auxílio durante a condução do experimento;

Às bibliotecárias Kátia M. de Andrade Ferraz e Eliana M. Garcia Sabino pelo auxílio na organização das referências bibliográficas;

Aos amigos Alberto C. de C. Bernadi, José Humberto Andia, Gabriel V. B. de Almeida, César Hiroshi Kameoka, Carlos Giovani Tonet, Flávio Guanaes Bonini, Vanderlei Nestor Koefender e Rodrigo Ozello Baratti que sempre me incentivaram e auxiliaram na instalação e colheita do experimento;

A todos os colegas do Curso de Pós-graduação em Solos e Nutrição de Plantas e amigos do Curso de graduação em Engenharia Agronômica pelo companheirismo e amizade;

Em especial ao professor Dr. Quirino Augusto de Camargo Carmello pela amizade e orientação segura. 


\section{SUMÁRIO}

RESUMO. viii

SUMMARY xi

1. INTRODUÇÃO

2. REVISÃO DE LITERATURA. 3

3. MATERIAL E MÉTODOS.......................................................................... 15

3.1. Local de condução do experimento e características do solo............................... 15

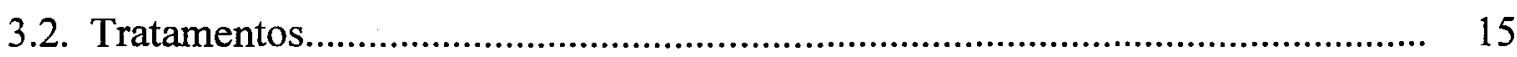

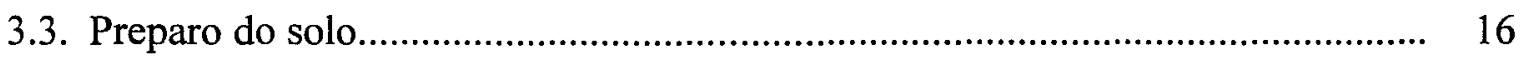

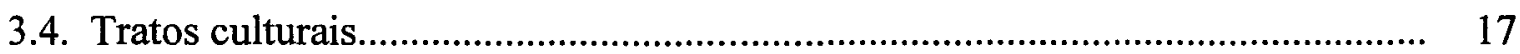

3.5. Avaliações e determinações........................................................................ 18

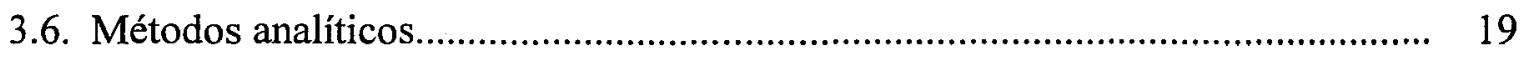

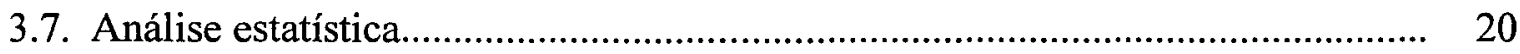

4. RESULTADOS E DISCUSSÃO.................................................................... 21

4.1. Nodulação.......................................................................................................... 21

4.1.1. Efeito do fator cultivar........................................................................... 24

4.1.2. Efeito do fator dose de nitrogênio................................................................. 26

4.1.3. Efeito do fator dose de fósforo...................................................................... 29

4.1.4. Efeito da interação entre os fatores dose de nitrogênio e dose de fósforo......... 30

4.2. Massa de material vegetal seco............................................................................. 34

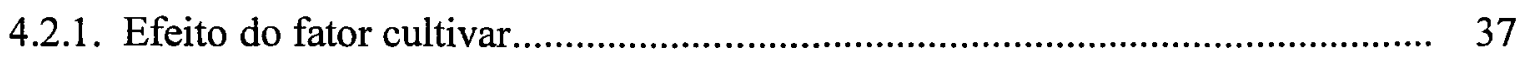

4.2.2. Efeito do fator dose de nitrogênio.............................................................. 40

4.2.3. Efeito do fator dose de fósforo......................................................................

4.2.4. Efeito da interação entre os fatores cultivar e dose de fósforo.......................... 45

4.2.5. Efeito da interação entre os fatores dose de nitrogênio e dose de fósforo......... 48

4.3. Teores foliares e quantidade acumulada total de $\mathrm{N}$ e $\mathrm{P}$ pelas plantas.................. 49

4.3.1. Efeito do fator cultivar.................................................................................. 53 
4.3.2. Efeito do fator dose de nitrogênio.............................................................. 54

4.3.3. Efeito do fator dose de fósforo................................................................. 57

4.3.4. Efeito da interação entre os fatores cultivar e dose de fósforo......................... 59

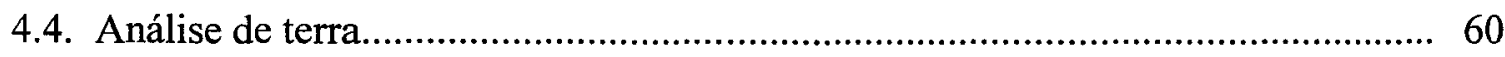

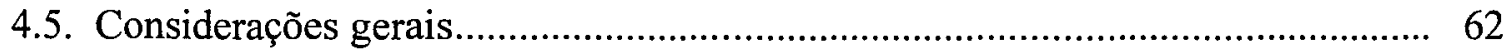

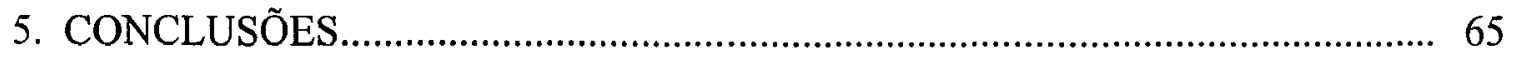

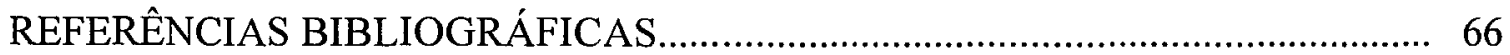

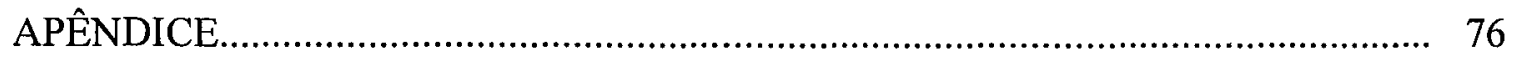




\title{
DESENVOLVIMENTO VEGETATIVO E A NODULAÇÃO DE PLANTAS DE SOJA EM FUNÇÃO DE NITROGÊNIO E FÓSFORO APLICADOS NA SEMEADURA EM CONDIÇÕES CONTROLADAS
}

\author{
Autor: FÁBIO ÁLVARES DE OLIVEIRA \\ Orientador: Prof. Dr. QUIRINO AUGUSTO DE CAMARGO CARMELLO
}

\section{RESUMO}

Hoje, a cultura tecnificada da soja (Glycine max (L.) Merrill) é considerada auto-suficiente quanto à necessidade de $\mathrm{N}$, dispensando assim, os gastos com a adubação mineral desse nutriente, que é inibidor da fixação simbiótica do $\mathrm{N}_{2}$. Porém, o $\mathrm{N}$-mineral, é necessário para o desenvolvimento inicial das plantas e, para o processo de associação simbiótica, apresentando até mesmo efeitos benéficos, quando em concentrações adequadas. Se a demanda por $\mathrm{N}$ na fase inicial da associação for maior do que a quantidade disponível, a não adubação pode atrasar o processo de infecção e assim prejudicar também a fixação.

O fósforo apresenta também grande relação com o desenvolvimento inicial das plantas, com o processo de estabelecimento da simbiose e com a fixação do $\mathrm{N}_{2}$, uma vez que essas etapas exigem gastos de energia, disponível na forma de moléculas de ATP.

Considerando esses aspectos, foi conduzido um experimento em casa-devegetação entre os meses de janeiro e março de 1996, para verificar a influência da aplicação de doses de $\mathrm{N}$-mineral em três níveis de adubação fosfatada na semeadura, sobre a nodulação e o crescimento radicular e também da parte aérea de dois cultivares de soja inoculada, avaliados em dois estágios de crescimento das plantas. Utilizou-se 
para isso o delineamento experimental no sistema de fatorial em blocos casualizados, contendo 4 níveis de nitrogênio, sendo o nível 0 , aquele onde não se aplicou o nutriente e três doses correspondentes a 5,7; 11,4 e 17,1 $\mathrm{mg} \mathrm{kg}^{-1}$ de N, 3 níveis de fósforo, 15,2; 22,7 e 30,3 mg kg ${ }^{-1}$ de $\mathrm{P}_{2} \mathrm{O}_{5}$ e dois cultivares de soja, "IAC-8" e "IAC-14", com três repetições cada tratamento e duas épocas de avaliação, quatro e oito semanas após a emergência, necessitando-se portanto, o dobro do número de vasos do fatorial, num total de 144. Os vasos das duas avaliações contiveram quatro plantas cada e apresentaram volumes diferentes de um latossolo vermelho amarelo, textura média e baixa concentração em fósforo, corrigido para $\mathrm{V}=70 \%$.

Os cultivares IAC-8 e IAC-14 apresentaram crescimento diferenciado. O desenvolvimento inicial do cultivar IAC-8, assim como a sua nodulação, foram superiores aos do cv. IAC-14. No entanto, oito semanas após a emergência, esses cultivares não apresentaram diferenças quanto à massa de material seco das raízes e a diferença da massa de material seco da parte aérea dos dois cultivares foi reduzida mostrando um maior crescimento do cultivar IAC-14 nessa fase. A massa de material seco dos nódulos não variou significativamente, porém os cultivares apresentaram diferenças quanto à nodulação. O cultivar IAC-8 produziu uma maior quantidade de nódulos, contudo, os nódulos produzidos pelo cultivar IAC-14 apresentaram a massa de material seco médio por nódulo significativamente superior à do cultivar IAC-8.

Quatro semanas após a emergência, a aplicação de $\mathrm{N}$ acima de $5,7 \mathrm{mg} \mathrm{kg}^{-1}$ inibiu a nodulação. O N-mineral inibiu a formação dos nódulos e o desenvolvimento dos poucos formados, reduzindo a fixação inicial, que não foi compensada pela adubação. Desse modo, a quantidade de $\mathrm{N}$ disponível para as plantas diminuiu, reduzindo o desenvolvimento inicial das raízes e da parte aérea.

$\mathrm{O}$ efeito do $\mathrm{N}$-mineral sobre a nodulação não foi verificado oito semanas após a emergência, porém, as plantas adubadas com 5,7 e 11,4 $\mathrm{mg} \mathrm{kg}^{-1}$ de $\mathrm{N}$ apresentaram tendência de formação de um maior número e massa de material seco dos nódulos que as plantas do tratamento no qual não se aplicou $\mathrm{N}$-mineral na semeadura. $\mathrm{O}$ 
desenvolvimento vegetativo das plantas foi incrementado pela aplicação de $\mathrm{N}$ na semeadura, verificando-se respostas lineares significativas para o crescimento da parte aérea e das raízes.

A aplicação de fósforo na semeadura aumentou a nodulação $\mathrm{e} \quad \mathrm{o}$ desenvolvimento da parte aérea e das raízes nas duas épocas avaliadas. O fósforo apresentou, ainda, tendência de redução da inibição da nodulação por $\mathrm{N}$-mineral com a aplicação de $30,3 \mathrm{mg} \mathrm{kg}^{-1}$.

$\mathrm{O} \mathrm{N}$ aplicado diminuiu a nodulação inicial, porém, foi benéfico para as plantas, que apresentaram nodulação e crescimento vegetativo, no início do florescimento, equivalentes às plantas do tratamento no qual não se aplicou $\mathrm{N}$ e, nódulos mais jovens, que podem deslocar o período de maior eficiência da fixação, para uma época mais próxima do final do ciclo. 


\title{
VEGETATIVE DEVELOPMENT AND NODULATION IN \\ SOYBEAN PLANTS IN FUNCTION OF NITROGEN AND \\ PHOSPHORUS APPLIED AT SOWING IN CONTROLLED \\ CONDICTIONS
}

\author{
Author: FÁBIO ÁLVARES DE OLIVEIRA \\ Adviser: Prof. Dr. QUIRINO AUGUSTO DE CAMARGO CARMELLO
}

\section{SUMMARY}

Nowadays, the technical soybean (Glycine max (L.) Merrill) culture is considered self-sufficient as for the $\mathrm{N}$ demand. It does not require, therefore, expenses with mineral $\mathrm{N}$ fertilization, which is inhibitory to the symbiotic $\mathrm{N}_{2}$ fixation. However, the mineral $\mathrm{N}$ is an essential nutrient to the plants in the early development and to the symbiotic association process, presenting also, beneficial effects, when its concentration is adequate. If the $\mathrm{N}$ demand at the beginning of the symbiotic association is greater than the available amount, the $\mathrm{N}$ non-fertilization can delay the infection process and thus, damage the $\mathrm{N}_{2}$ fixation too.

The phosphorus presents, as well, a great relationship with the plants in the early development, with the symbiosis establishing process and $\mathrm{N}_{2}$ fixation, because all those stages demand energy, available in the ATP molecule form.

Considering those aspects, an experiment was carried out, in green-house condictions, from january until march in the year 1996, in order to verify the influence of the $\mathrm{N}$ application on three phosphorus fertilization levels at sowing, to the nodulation and shoot and root growth of two inoculated soybean cultivars, evaluate in two stages of the plants development. It was used a experimental delineation in the fatorial system in 
randomized blocks, with $4 \mathrm{~N}$ levels, one non-applied $\mathrm{N}$ treatment and three $\mathrm{N}$ rates corresponding to 5,$7 ; 11,4$ and $17,1 \mathrm{mg} \mathrm{kg}^{-1}$ of $\mathrm{N}, 3$ phosphorous levels, 15,2; 22,7 and $30,3 \mathrm{mg} \mathrm{kg}{ }^{-1}$ of $\mathrm{P}_{2} \mathrm{O}_{5}$ and two soybean cultivars, "IAC-8" e "IAC-14", with 3 repetitions to each treatment and two evaluation stages, four and eight weeks after the outgrowth, using for this, the twice number of pots of the fatorial, in a totality of 144 . The pots in the two evaluations contained four plants each one and presented different capacity of an Oxisol, media texture and phosphorous in low concentration, amended to $\mathrm{V}=70 \%$.

The IAC-8 and IAC-14 cultivars presented different growth. The early development of IAC-8 plants thus, as its nodulation were higher than the "IAC-14" plants. Therefore, eight weeks after the outgrowth, those cultivars presented no differences to the root dry matter mass and the difference of the two shoot cultivars dry matter mass was decreased showing, at this stage, a higher "IAC-14" growth. The nodule dry matter mass did not change significantly, however, the cultivars presented differences in the nodulation. The "IAC-8" plants produced a higher nodule amount, but, the "IAC-14" nodules presented a dry matter mass per nodule significantly higher than the IAC-8 cultivar.

Four weeks after the outgrowth, the $\mathrm{N}$ application above $5,7 \mathrm{mg} \mathrm{kg}^{-1}$ inhibitted the nodulation. The mineral $\mathrm{N}$ inhibitted the nodule forming and the development of the few formed ones, decreased the early fixation, which was not compensated by the fertilization. Thus, the available $\mathrm{N}$ amount for the plants decreased, delaying the shoot and root early development.

The mineral $\mathrm{N}$ effect on the nodulation was not verified eight weeks after the outgrowth, but, the plants fertlized with 5,7 and $11,4 \mathrm{mg} \mathrm{kg}^{-1}$ of $\mathrm{N}$ showed a tendency of forming more nodules and dry matter mass than the plants on the mineral- $\mathrm{N}$ non-applied treatment. The vegetative plant development was increased by the $\mathrm{N}$ application at sowing, being verified significantly linear responses to the shoot and root growing.

The phosphorus application at sowing increased the nodulation and the shoot and root development in the two evaluated stages. The phosphorus presented, besides, a 
reduction tendency to the nodulating inhibition by mineral $\mathrm{N}$, with the $30,3 \mathrm{mg} \mathrm{kg}^{-1}$ application.

The $\mathrm{N}$ applied rate decreased the early nodulation, however, was beneficial to the plants, which presented at the early flowering, equivalent nodulation and vegetative growth with the plants of the non-applied treatment, and younger nodules, which can change the stage of higher fixation efficiency to a time nearer to the end of the cycle. 


\section{INTRODUÇÃO}

A cultura da soja (Glycine max (L.) Merrill) é citada hoje como auto-suficiente quanto à necessidade de nitrogênio $(\mathrm{N})$, uma vez que sua associação simbiótica com a bactéria Bradyrhizobium japonicum forma nódulos radiculares altamente eficientes para a fixação do $\mathrm{N}$ atmosférico $\left(\mathrm{N}_{2}\right)$ até formar amônia. Sendo assim, apenas a aplicação de material contendo inóculo da bactéria nas sementes é recomendada para garantir o suprimento de $\mathrm{N}$ para todo o ciclo da cultura, dispensando portanto, o uso de fertilizante mineral contendo esse nutriente.

Além da aplicação do N-mineral ser considerada desnecessária, as pesquisas apontam essa prática como inibidora da fixação simbiótica do $\mathrm{N}_{2}$. Sempre que os campos de cultivo de soja foram adubados com N-mineral, apesar de haver algum aumento no teor de $\mathrm{N}$ das plantas, o total de $\mathrm{N}$ proveniente da fixação diminuiu. No entanto, essas pesquisas revelaram-se contraditórias, quanto aos resultados de produção de grãos, apontando tanto ganhos quanto perdas, em relação à testemunha inoculada $\mathrm{e}$ não adubada. Apesar disso, nos casos em que houve resposta à adubação, o aumento de produção não foi suficiente para cobrir os custos da operação.

A presença de altos teores de N-mineral no solo, como ocorre após uma adubação, é inibidora da fixação simbiótica de $\mathrm{N}_{2}$. As bactérias do gênero Bradyrhizobium tem a capacidade de viver livremente no solo, quando esse apresentar níveis consideráveis de $\mathrm{N}$, não necessitando assim, dispensar energia para se associar às raízes das leguminosas para fixar um nutriente que já está disponível no solo.

O nitrogênio porém, é um nutriente necessário para o processo de associação simbiótica, apresentando até mesmo efeitos benéficos, quando em concentrações 
adequadas. Se a demanda por $\mathrm{N}$ na fase inicial da associação for maior do que a quantidade disponivel, a não adubação pode atrasar o processo de infecção, e assim prejudicar também a fixação. Isso explica porque as plantas de soja tornam-se muitas vezes cloróticas, no início do crescimento.

Outro nutriente que apresenta grande relação com o processo de estabelecimento da simbiose e também com a fixação do $\mathrm{N}_{2}$ é o fósforo (P), uma vez que essas etapas exigem gastos de energia, disponível na forma de moléculas de ATP.

$\mathrm{O} \mathrm{N}$ e o $\mathrm{P}$ do solo podem exercer influência sobre a velocidade de estabelecimento da simbiose. A aplicação desses nutrientes promove um melhor estabelecimento da planta, que desenvolve com maior rapidez a parte aérea e as raízes, e assim garantem o suprimento dos demais nutrientes. $\mathrm{O} \mathrm{N}$ aplicado supre as necessidades da planta, porém pode retardar o início da fixação. Esse fato pode porém, ser até benéfico para as plantas, porque esse atraso pode deslocar o período de maior eficiência da fixação, até bem próximo do final do ciclo.

Com base nessa hipótese, efetuou-se um estudo em casa-de-vegetação, para verificar a influência da aplicação de N-mineral em três níveis de adubação fosfatada na semeadura, sobre a nodulação, o crescimento radicular e da parte aérea, além da absorção e do acúmulo de $\mathrm{N}$ e $\mathrm{P}$ de dois cultivares de soja inoculada, avaliados em dois estágios de crescimento. 


\section{REVISÃO DE LITERATURA}

A soja é a leguminosa que apresenta maior sucesso no programa de desenvolvimento da fixação simbiótica do nitrogênio atmosférico. Os processos de seleção de genótipos definiram algumas estirpes da bactéria da espécie Bradyrhizobium japonicum com alto poder de infestação e fixação de nitrogênio, quando em simbiose com raízes de plantas de soja.

Dependendo da interação entre o genótipo da planta hospedeira e da estirpe do rizóbio, além do potencial de produção e da disponibilidade de $\mathrm{N}$ no solo, Vest et al. (1973) afirmaram que a simbiose soja - B. japonicum fixa entre 100 e $160 \mathrm{~kg} \mathrm{ha}^{-1} \mathrm{de} \mathrm{N}$. Esses valores foram suficientes para se ter uma produção em torno de $2000 \mathrm{~kg} \mathrm{ha}^{-1}$ (Vernetti ${ }^{1}$ citado por Novo, 1995). Para rendimentos da ordem de $2750 \mathrm{~kg} \mathrm{ha}^{-1}$, Weber (1966) afirmou serem necessários $215 \mathrm{~kg} \mathrm{ha}^{-1}$ de $\mathrm{N}$, havendo portanto grande influência do $\mathrm{N}$ do solo sobre a produção.

Mascarenhas et al. (1983) afirmaram que a fixação simbiótica garante o fornecimento de 25 a $60 \%$ do $\mathrm{N}$ total exigido pelas plantas adultas. Para Franco et al. (1978) esse percentual situou-se entre 40 e $50 \%$ do $\mathrm{N}$ total da planta, sendo o restante proveniente das reservas cotiledonares e do solo, parecendo assim haver necessidade de complementação com a aplicação de $\mathrm{N}$-mineral.

\footnotetext{
${ }^{1}$ VERNETTI, F.J. Inoculação da soja. Pelotas: Ministério da Agricultura, Departamento Nacional de Pesquisa Agropecuária do Sul, 1971. 31p. (Boletim técnico, 75).
} 
A eficiência da fixação simbiótica do $\mathrm{N}$ está relacionada com a compatibilidade entre os vários genótipos apresentados tanto pelas plantas quanto pelas bactérias. Nangju (1980) verificou diferenças nas respostas de cultivares de soja ao rizóbio, quanto à nodulação, crescimento, exsudação de $\mathrm{N}$-amínico e rendimento de grãos.

Patterson \& Larue (1983) observaram que as diferenças apresentadas pelos cultivares de soja em relação à fixação de $\mathrm{N}_{2}$ estavam relacionadas com os grupos de maturação, sendo que os cultivares tardios fixavam mais $\mathrm{N}_{2}$ que os precoces, por apresentarem um período vegetativo maior. Os nódulos apresentam ciclo médio de vida de 60 dias e desse modo, os primeiros nódulos formados entram em senescência no período de maior exigência de $\mathrm{N}$ pela planta, entre o florescimento e o início do enchimento dos grãos. Além disso, a partir do início da fase reprodutiva da planta, a emissão de novos pelos radiculares é bastante reduzida, e sendo essa a região de infecção da bactéria, a formação de novos nódulos também é reduzida. Com isso, o número e o peso de nódulos por planta reduziu-se, diminuindo assim a atividade total da nitrogenase nas plantas.

A nitrogenase é o complexo enzimático responsável pela fixação de $\mathrm{N}_{2}$ atmosférico em amônia e é formado por duas proteínas, sendo uma de maior peso molecular contendo ferro e molibdênio, sendo por isso chamada de Mo-Fe-proteína, e uma outra de menor peso molecular que apresenta ferro em sua constituição, sendo desse modo, chamada de Fe-proteína.

Klucas (1974) verificou que após o florescimento, em torno de 58 a 75 dias após o plantio (dap), inicia-se a queda na atividade da nitrogenase. Lawn \& Brun (1974) confirmaram que a atividade total da nitrogenase na planta diminuiu após esse período, devido à redução da distribuição de fotossintatos ao sistema radicular e aos nódulos, uma vez que a planta priorizaria a formação das vagens e, posteriormente o enchimento dos grãos.

Segundo Rosolem (1984), o período de maior exigência de $\mathrm{N}$ ocorre entre o florescimento e o início do enchimento dos grãos. Nessa época, o sistema radicular deve 
estar totalmente formado e apresentar uma boa nodulação, para garantir o suprimento de todos os nutrientes.

Nelson \& Weaver (1980) verificaram que 79\% do N proveniente do solo foi absorvido antes do início de formação das vagens. Após esse período, a fixação apresentou grande capacidade de suprimento de $\mathrm{N}$, já que o teor foliar do nutriente não diminuiu.

De acordo com Muller (1981), as plântulas podem manifestar sintomas de deficiência de $\mathrm{N}$, como clorose nas primeiras folhas, caso o fornecimento de $\mathrm{N}$ não seja adequado nesse período.

$\mathrm{O} \mathrm{N}$ do solo é importante para a nutrição da soja quando são esperadas produções elevadas porém, sua concentração no solo está ligada à inibição da fixação. Segundo Bezdicek et al. (1978), quando o $\mathrm{N}$-mineral estava abundante no solo, promoveu a diminuição da nodulação das raízes de plantas leguminosas, reduzindo a quantidade de $\mathrm{N}$ fixado.

Todos os estágios do processo de nodulação pareceram ser inibidos pela presença de concentrações moderadas de nitrato $\left(\mathrm{NO}_{3}\right)^{2}$, nitrito $\left(\mathrm{NO}_{2}{ }^{-}\right)$e uréia $\left(\mathrm{CO}\left(\mathrm{NH}_{2}\right)_{2}\right)$, evidenciados pelo número reduzido de infecções, tempo para o aparecimento do primeiro nódulo e número e o peso dos nódulos formados, segundo Gibson \& Nutman (1960). Beard \& Hoover (1971) verificaram uma correlação inversa entre o número de nódulos formados e a dose de $\mathrm{N}$-amoniacal aplicada na semeadura.

A concentração de $\mathrm{N}$-mineral que influencia o processo de fixação simbiótica de $\mathrm{N}_{2}$ varia em função da sua forma presente no solo. A revisão da literatura indicou que o nitrato é mais prejudicial do que o amônio $\left(\mathrm{NH}_{4}{ }^{+}\right)$nos processos de nodulação (Lie, 1974) e na fixação do $\mathrm{N}_{2}$ (Harper, 1987).

$\mathrm{O}$ nitrato inibe a fixação simbiótica de $\mathrm{N}_{2} \mathrm{em}$ diferentes etapas. A inibição do processo de formação dos nódulos é justificada por um efeito prejudicial na infecção dos pelos radiculares. Esse efeito é atribuído à destruição catalítica do ácido indolacético (AIA), responsável pelo encrespamento dos pelos radiculares e pela formação do "cajado 
de pastor", pelo íon nitrito, primeiro produto da redução do nitrato absorvido (Tanner \& Anderson, 1963). O nitrato provocou ainda, mudanças químicas na superfície dos pelos radiculares, reduzindo a concentração de lecitinas disponíveis para ligar o rizóbio ao pelo radicular (Gibson, 1981).

$\mathrm{O}$ efeito do nitrato sobre o desenvolvimento dos nódulos manifesta-se, pela diminuição no tamanho das células dos nódulos (Franco \& Neves, 1992). A adição de N ao sistema provoca um desbalanço no metabolismo do $\mathrm{C}$ e N, aumentando a competição pelos fotossintatos disponíveis, prejudicando a síntese de proteínas e a redução do $\mathrm{N}_{2}$ (Raggio et al., 1965 e Gibson \& Pagam, 1977). Esse aumento na disponibilidade de N . para a parte aérea promove seu crescimento e reduz a quantidade de fotossintatos que chegam ao sistema radicular e aos nódulos, aumentando assim a competição entre os nódulos e os núcleos de assimilação de N-mineral (Oghoghorie \& Pate, 1971 e Rabie et al., 1980).

Cho \& Harper (1991) relacionaram o efeito do N-mineral sobre o desenvolvimento dos nódulos radiculares através da concentração de isoflavonóides na raiz. A presença de $\mathrm{N}$-mineral reduz a concentração desses isoflavonóides, tendo o nitrato, um efeito redutor mais acentuado que o amônio e a uréia, para uma mesma concentração.

A atividade da nitrogenase é reduzida pelo nitrato (Phillips, 1974). Mahon (1977) verificou que a respiração das raízes e de nódulos que apresentavam fixação de $\mathrm{N}_{2}$, foi reduzida quando em presença de nitrato, ocasionada também pela competição pelos fotossintatos que chegavam em quantidades reduzidas aos nódulos (Small \& Leonard, 1969 e Sprent, 1979). Sloger (1985) demonstrou que a interrupção no suprimento de fotossintatos para os nódulos diminuiu a atividade da nitrogenase. Por outro lado, a adição de açúcar ao meio de crescimento da leguminosa, aumentando a fonte de carbono, reduziu o efeito inibitório do nitrato (Wong, 1980), confirmando a influência da relação $\mathrm{C} / \mathrm{N}$ na formação dos nódulos e na atividade da nitrogenase. 
Stephens \& Neyra (1983) justificaram a inibição da nitrogenase devido ao aumento na disponibilidade de nitrato, pelo acúmulo de nitrito nos nódulos. O nitrito liga-se de maneira reversível à proteína Mo-Fe, além de oxidar o Fe da leghemoglobina, alterando sua ligação com $\mathrm{O}_{2}$ e sua função de transporte (Harper, 1987 e Franco \& Neves, 1992). Todos esses fatores ligados à presença do nitrato estão ainda relacionados à integridade dos nódulos e à aceleração no processo de senescência dos mesmos (Harper, 1987).

Os prejuízos causados pelo $\mathrm{N}$-mineral ao processo de fixação simbiótica são observados a partir de determinadas concentrações no solo. Gibson \& Harper (1985) determinaram que, a partir de $0,5 \mathrm{mM} \mathrm{NO}_{3}{ }^{-}$na solução, já ocorrem efeitos sobre a nodulação. No entanto, Holsten et al. (1971) verificaram fixação de $\mathrm{N}_{2}$ por B. japonicum associado com células de raízes de soja em meio de cultura, com $60 \mathrm{mM}$ de N-mineral, mostrando que a associação simbiótica não é completamente inibida, mesmo pelas mais elevadas concentrações de $\mathrm{N}$-mineral.

Allos \& Bartholomew (1959) mostraram que o número e o tamanho dos nódulos em raízes de leguminosas não são reduzidos, até que a quantidade de $\mathrm{N}$ adicionada seja igual ao total necessário para o máximo crescimento das plantas.

A nodulação desenvolve-se melhor na presença de baixas quantidades de Nmineral, como é o caso dos solos, do que na sua completa ausência, como em meio de cultura contendo solução sem fonte de N. Child \& Larue (1974) concluíram que, baixos níveis, tanto de nitrato quanto de amônio, foram necessários para se ter uma boa atividade da nitrogenase em associações de células de soja - $R$. japonicum.

O nível de $\mathrm{N}$-mineral do solo atua de modo benéfico, para a seleção de estirpes de maior infectividade. La Favre \& Eaglesham (1987) observaram um efeito diferencial das estirpes inoculadas individualmente, na formação de nódulos em plantas de soja cultivadas em solução nutritiva com doses crescentes de nitrato. Somente as estirpes com baixa infectividade foram inibidas pela presença do nitrato. 
A variabilidade genética da soja influencia a infecção dos pelos radiculares pelo rizóbio, e tem efeito diferencial sobre a fixação de nitrogênio, quando em presença de fertilização nitrogenada (Hardarson et al., 1984). Esses aspectos incentivaram o aumento nas pesquisas, para a obtenção de cultivares tolerantes ao nitrato (Herridge \& Betts, 1985).

Ruschel et al. (1980) observaram que plantas de soja, crescendo em níveis baixos de nitrato, apresentavam atividade da nitrogenase superior àquela apresentada por plantas desenvolvidas na ausência do íon. Eaglesham et al. (1983) afirmaram que uma pequena quantidade de $\mathrm{N}$ aplicada na semeadura da soja estimulou a fixação simbiótica em plantas cultivadas na ausência completa de $\mathrm{N}$ externo.

Harper (1974) verificou que as plantas de soja, crescendo em níveis baixos de nitrato apresentaram maiores taxas de fixação de $\mathrm{N}_{2}$, quando comparadas com plantas crescendo na ausência completa de $\mathrm{N}$-mineral. $\mathrm{O}$ autor destacou que o $\mathrm{N}$-mineral do solo é essencial, no período anterior ao completo estabelecimento da simbiose, para obter-se plântulas vigorosas.

Segundo Fonseca (1985), a habilidade da soja em estabelecer uma simbiose eficiente com bactérias do gênero Bradyrhizobium reduz a demanda por $\mathrm{N}$-mineral do solo, contudo, o potencial de crescimento da planta e de fixação de nitrogênio não podem ser maximizados na ausência completa de fontes de N-mineral. Gallardo (1989) verificou que as plantas de soja cultivadas em solução nutritiva com concentração de 1 $\mathrm{mM} \mathrm{NO}_{3}{ }^{-}$, tiveram resposta significativa na produção de material seco da parte aérea e de nódulos, além das concentrações de $\mathrm{N}$ e $\mathrm{P}$, quando comparadas ao tratamento em ausência de nitrato.

Hatfield et al. (1974) demonstraram a importância do $\mathrm{N}$ do solo para o crescimento inicial da soja, mesmo na presença de inoculação adequada, já que as plantas cuja única fonte de $\mathrm{N}$ foi a fixada simbioticamente tiveram, após seis semanas, menor crescimento que as plantas com fornecimento de $\mathrm{N}$ durante as quatro primeiras semanas, não havendo diferenças no desenvolvimento dos nódulos para os dois grupos. 
De acordo com Hardy et al. (1971), a fixação de $\mathrm{N}$ atmosférico inicia-se três a cinco semanas após o plantio, mas como as quantidades necessárias para as plantas são muito baixas até essa fase, o suprimento de $\mathrm{N}$ é garantido pelas reservas cotiledonares e do solo. Contudo, em solos extremamente deficientes, uma dose de $\mathrm{N}$-mineral aplicada na semeadura estimula o desenvolvimento inicial e a fixação simbiótica.

Segundo Gibson ${ }^{2}$, citado por Bonetti (1982), as respostas da soja ao N-mineral foram observadas raramente, ocorrendo somente quando foram utilizadas doses elevadas do nutriente e, por isso, não se obteve viabilidade econômica.

$\mathrm{O}$ nível de $\mathrm{N}$-mineral considerado adequado para a soja é o disponível no solo mais uma quantidade de fertilizante, que garante uma concentração na qual observa-se um efeito mínimo na nodulação, sendo para muitos casos, a adubação não recomendada.

Harper \& Hageman (1972) verificaram que a aplicação de uma pequena quantidade de $\mathrm{N}$ na semeadura $\left(20 \mathrm{~kg} \mathrm{ha}^{-1}\right.$ de $\left.\mathrm{N}\right)$ não teve efeito na massa nodular ou na atividade da nitrogenase. Em solos com elevado teor de $\mathrm{N}$-mineral, no entanto, ocorreu uma diminuição no efeito da inoculação e da adubação com N-mineral (Bell \& Nutman, 1971).

A aplicação de N-mineral via fertilizante mostrou-se benéfica para áreas de solo com material vegetal de difícil decomposição, devido à alta relação $\mathrm{C} / \mathrm{N}$. Nesse caso, como todo o $\mathrm{N}$ do solo está imobilizado, pode haver prejuízo ao desenvolvimento inicial da cultura de soja e o fertilizante promove o efeito "priming" ou seja, favorece a mineralização do $\mathrm{N}$ contido na fração orgânica. como demonstraram Westerman \& Kurtz (1973), através de correlações positivas entre mineralização e $\mathrm{N}$-adicionado.

Vargas et al. (1982) não obtiveram respostas da aplicação de até $30 \mathrm{~kg} \mathrm{ha}^{-1}$ de $\mathrm{N}$, em solo de cerrado, com a incorporação de $26 \mathrm{t} \mathrm{ha}^{-1}$ de material seco, para ter aumentos na produção de grãos.

No caso de solos com baixas quantidades de matéria orgânica, muitos produtores de soja costumam utilizar uma aplicação de pequena quantidade de $\mathrm{N}$ na

\footnotetext{
2 GIBSON. A.H. Limitation to dinitrogen fixation by legumes. In: INTERNATIONAL SYMPOSIUM OF NITROGEN FIXATION, 1, 1976. Proceedings. Washington: Pullman, 1976. p. 400-28.
} 
semeadura, para garantir um melhor crescimento inicial das plantas. Esse tipo de adubação, conhecida como "starter" ou de arranque, não mostra, aumentos de produtividade, de acordo com as pesquisas.

Sij et al. (1979) estudaram as respostas à aplicação de $0,16,8$ e $50,4 \mathrm{~kg} \mathrm{ha}^{-1}$ de $\mathrm{N}$ na forma de sulfato de amônio na semeadura, quanto à altura e ao peso fresco das plantas e a expansão da área foliar nas primeiras sete semanas após a emergência. Avaliaram o desenvolvimento inicial das plantas de soja, visando uma maior competitividade com as plantas invasoras, mas no entanto, não foram encontradas diferenças em nenhuma das avaliações.

Hathcock ${ }^{3}$ citado por Franco et al. (1978) não obteve aumentos de produção em dois solos com menos de $15 \mathrm{~g} \mathrm{dm}^{3}$ de M.O., para vários níveis de $\mathrm{N}$ aplicados no plantio. Embora não se tenha comprovado aumentos de produtividade com a adubação de arranque, Rosolem (1984) afirmou ser prudente realizá-la, em solos ácidos com baixos teores de M.O. $\left(<15 \mathrm{~g} \mathrm{dm}^{3}\right)$.

Bonetti (1982) afirmou que, para as condições de cultivo de soja em casa-devegetação, doses baixas de $\mathrm{N}\left(40 \mathrm{~kg} \mathrm{ha}^{-1}\right.$ de $\left.\mathrm{N}\right)$ parecem não prejudicar a nodulação e a atividade da nitrogenase e podem apresentar respostas positivas. Teores de $\mathrm{N}$-mineral no solo entre 25 e $80 \mathrm{mg} \mathrm{kg}^{-1}$ promoveram as melhores nodulações e produção de vagens, reforçando a idéia da necessidade de doses de arranque de $\mathrm{N}$.

Santiago (1989), aplicando de 5 a $30 \mathrm{~kg} \mathrm{ha}^{-1}$ de $\mathrm{N}$ na semeadura, destacou a inibição da fixação inicial, o aumento da produção de material seco da parte aérea e a redução do $\mathrm{N}$ fixado biologicamente presente na parte aérea, quando foram utilizadas doses crescentes de $\mathrm{N}$-mineral na forma de sulfato de amônio.

Sanders (1969) verificou uma redução da nodulação, pela aplicação de $\mathrm{N}$ na semeadura, logo no início do desenvolvimento das plantas. No entanto, no início do florescimento, a influência da aplicação de $\mathrm{N}$ na nodulação foi menor, mostrando uma recuperação das plantas adubadas. Apesar disso, as produções de material seco das raizes

\footnotetext{
${ }^{3}$ HATHCOCK, B.R. Effects of applied nitrogen on juvenile growth and nodulation of soybeans.

Tennessee Farm and Home Science Progress Report, v. 96, p. 32 - 3, 1975.
} 
e da parte aérea dessas plantas foram menores do que as das plantas do tratamento onde o $\mathrm{N}$ não foi aplicado.

Ruschel et al. (1975) estudaram a participação do N-mineral do solo, de doses de sulfato de amônio e da fixação biológica de $\mathrm{N}_{2}$ no $\mathrm{N}$ total acumulado pelas plantas. As colheitas feitas aos 35 e 55 dap, mostraram que o $\mathrm{N}$ proveniente do solo e do fertilizante foram mais utilizados. Isso sugeriu que, a atividade do sistema redutor de nitrato, precedeu o início da atividade da nitrogenase.

Existe uma correlação inversa entre as atividades da nitrogenase e da redutase do nitrato durante o ciclo da soja, parecendo razoável sugerir-se que, a energia requerida em ambos os processos seja suficientemente grande para impedir que, altas atividades ocorram simultaneamente (Franco et al., 1978 e Ruschel et al., 1980).

Hanway \& Weber (1971) verificaram que, a aplicação de fertilizante nitrogenado no florescimento, não impediu a translocação do $\mathrm{N}$ para a semente. Para que esse fato tenha ocorrido, independente do teor de $\mathrm{N}$ no solo, a possível razão pareceu ser, a diminuição da atividade da redutase do nitrato nesta fase de maior atividade da nitrogenase.

Franco et al. (1979) observaram que, os processos de assimilação e redução do nitrato e de fixação de $\mathrm{N}_{2}$ são sucessivos, com contribuições de $\mathrm{N}$ em períodos definidos, durante o desenvolvimento da planta.

Sinclair \& Wit (1976), constataram que, o aumento no suprimento de nitrato na solução nutritiva, aumentou a absorção e o acúmulo de $\mathrm{N}$ pelas partes vegetativas das plantas, o que prolongou o período de crescimento dos grãos, em função da maior disponibilidade de $\mathrm{N}$ para ser translocado durante esse processo.

Além de distinguir a época preferencial para cada fonte de $\mathrm{N}$, alguns trabalhos demostraram que a aplicação do $\mathrm{N}$ na semeadura atrasou o início da nodulação e, desse modo, retardou também o início da diminuição da atividade da nitrogenase, que manteve-se alta até os períodos mais próximos do final do ciclo. 
Saito et al. (1981) observaram, para o feijoeiro cultivado em casa-de-vegetação, que as plantas inoculadas e adubadas com $\mathrm{N}$-mineral tiveram o desenvolvimento dos nódulos retardado, alcançando peso máximo aos 45 dap, época em que os nódulos nas plantas que não foram adubadas já encontravam-se em senescência.

Paz (1978), estudando os níveis de nitrato para o feijoeiro, também observou um efeito linear de retardamento no desenvolvimento dos nódulos, quando avaliados aos 25 dap, em função das doses de nitrato aplicadas. No entanto, aos 45 dap, as doses de 0,3 $\mathrm{mM} \mathrm{NO}_{3}{ }^{-}$na solução mostraram-se benéficas para o peso dos nódulos, sendo que as doses maiores não diferiram da ausência de nitrato.

A questão da aplicação de $\mathrm{N}$ para a cultura da soja é bastante discutida, mas para o $\mathrm{P}$, existe a concordância sobre seus efeitos benéficos, tanto para o crescimento das plantas, quanto para o desenvolvimento dos nódulos. Mooy \& Pesek (1966) afirmaram que o bom suprimento de P na semeadura, garante um bom desenvolvimento radicular e da parte aérea, além de estimular a formação dos nódulos radiculares. O P contribui para aumentar o número e o peso dos nódulos, além de estimular o enraizamento e crescimento das plantas.

Para que a planta possa fixar $\mathrm{N}$ convenientemente, é necessário também, um suprimento adequado de $\mathrm{P}$, pois como em todos os processos fisiológicos das plantas, o processo de redução do $\mathrm{N}_{2}$ até amônia requer grande quantidade de energia metabólica, na forma de ATP. Concordando com isso, Whiteaker et al. (1976) observaram o aumento da atividade da nitrogenase com a aplicação de fósforo.

A adubação fosfatada tem um papel relevante na nodulação, na fixação simbiótica, na quantidade acumulada e no teor de $\mathrm{N}$ das plantas (Andrew \& Robins, 1969a e Kolling et al., 1974). Paz (1978) observou aumentos na produção de material seco das raízes e nódulos, com doses crescentes de $\mathrm{P}_{2} \mathrm{O}_{5}$. Bonetti et al. (1984) demonstraram que os nódulos necessitam de uma alta quantidade de $\mathrm{P}$, porque esse nutriente contribui para aumentar o número, o peso e a atividade dos nódulos e consequentemente, $\mathrm{o}$ acúmulo de $\mathrm{N}$ na planta. 
O fósforo aumenta a fixação, devido ao estímulo de crescimento da planta hospedeira (Robson et al., 1981) ou por desempenhar papéis específicos sobre a multiplicação bacteriana na rizosfera e, também sobre a iniciação, o desenvolvimento e a atividade dos nódulos (Bethenfalvay \& Yoder, 1981; Jakobsen, 1985 e Israel, 1987).

Estudos com soja inoculada e cultivada em solos com a aplicação de diferentes doses de $\mathrm{P}_{2} \mathrm{O}_{5}$, foram efetuados por Lins et al. (1985) e Pereira (1986), que observaram, que as menores concentrações de $\mathrm{P}_{2} \mathrm{O}_{5}$ nos solos, ocorridas nos tratamentos que aplicaram as menores doses de $\mathrm{P}$, reduziram a massa e o número de nódulos formados por planta e consequentemente a quantidade de $\mathrm{N}$ fixado.

Israel (1985) demonstrou que o processo de fixação apresenta grande resposta ao P. Além do aumento da produção do material seco da parte aérea e das raízes, aumentaram a infecção, o desenvolvimento dos nódulos e a atividade da nitrogenase, medidas pelo número e pelo peso dos nódulos e o acúmulo de $\mathrm{N}$, respectivamente.

No entanto, Sanders (1969) não encontrou aumentos no número e na massa de material fresco de nódulos, com a aplicação de 30 e $60 \mathrm{~kg} \mathrm{ha}^{-1}$ de $\mathrm{P}_{2} \mathrm{O}_{5}$ em um solo com elevado teor do nutriente. Além disso, a aplicação de $\mathrm{P}$ reduziu a produção do material seco das raízes. $\mathrm{O}$ único efeito considerado benéfico, ocorreu sobre a distribuição dos nódulos que concentraram-se na parte superior das raizes.

Existe uma boa correlação entre $\mathrm{N}$ e $\mathrm{P}$ na planta relacionada diretamente com a quantidade de fosfato adicionado ao solo. Esse efeito pode ser atribuído ao desenvolvimento do sistema radicular (Duncan \& Ohlrogge, 1958), à eficiência dos nódulos e ao metabolismo da planta. Doses crescentes de superfosfato elevaram os teores de $\mathrm{N}$ na parte aérea de nove leguminosas tropicais (Andrew \& Robins, 1969b).

A relação entre $\mathrm{N}$ e $\mathrm{P}$ é também responsável pela redução da inibição do $\mathrm{N}$ mineral sobre a nodulação. Gates \& Wilson (1974) verificaram que a aplicação de N limitou a nodulação em baixos níveis de $\mathrm{P}$ no solo, porém o efeito do $\mathrm{N}$ foi estimulante da nodulação quando altas doses de $\mathrm{P}$ foram aplicadas. 
Gates \& Muller (1979) observaram que um balanço favorável entre N, P e S manteve os nódulos com estrutura firme e persistente até o final do ciclo. Relataram ainda, que a inibição da nodulação pelo $\mathrm{N}$ pode ser anulada pela adição de $\mathrm{P}$ e S. Quando os níveis desses dois nutrientes estão adequados, a produção e a nodulação não são influenciadas pelo suprimento de $\mathrm{N}$-mineral.

Freire (1978) verificou que, as plantas inoculadas e adubadas com $20 \mathrm{~kg} \mathrm{ha}^{-1} \mathrm{de}$ $\mathrm{N}$ na semeadura, responderam com aumentos da produção de material seco de nódulos, raízes e parte aérea, quando adubadas com doses crescentes de $\mathrm{P}$ em solos com níveis baixos desse elemento. 


\section{MATERIAL E MÉTODOS}

\subsection{Local de condução do experimento e características do solo}

Um experimento em vasos foi conduzido durante noventa dias na casa-devegetação do Departamento de Ciência do Solo da ESALQ/USP, utilizando-se terra da camada de 0-20 cm de um latossolo vermelho-amarelo, distrófico, textura média, com baixa concentração de P. A amostra de terra foi coletada de uma área da fazenda Sertãozinho pertencente ao Departamento de Genética da ESALQ/USP, cujas características químicas são apresentadas na tabela 1.

Tabela 1- Análise química da amostra de terra da camada de $0-20 \mathrm{~cm}$ do latossolo vermelho amarelo após a peneiragem

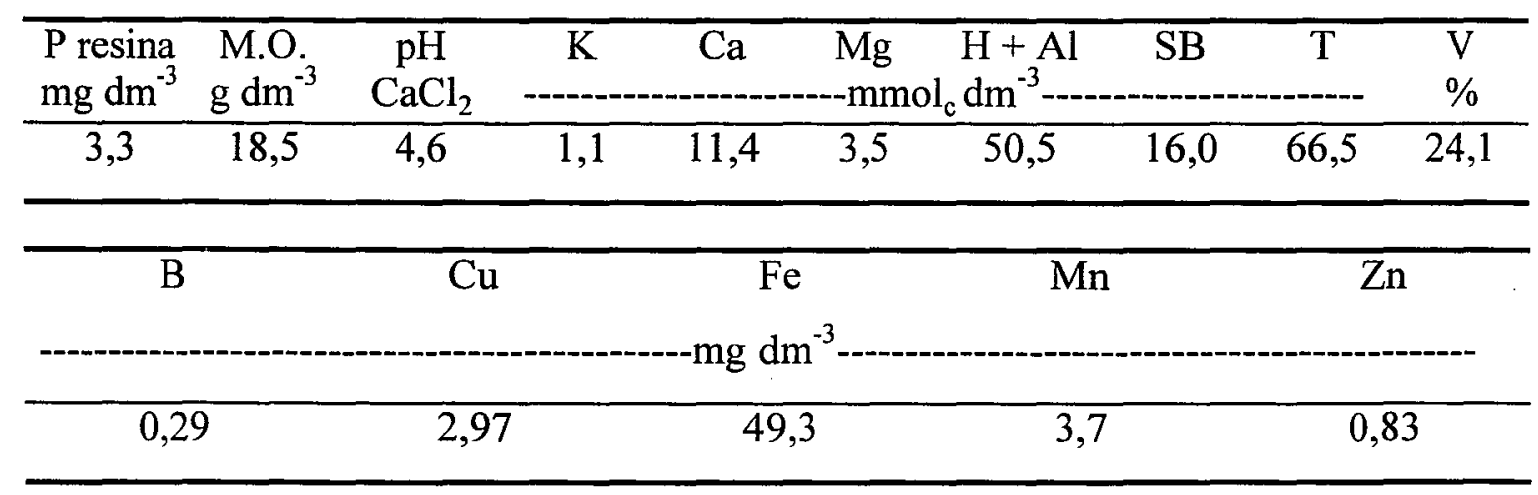

\subsection{Tratamentos}

Empregou-se o delineamento experimental de blocos casualizados, com o esquema fatorial $4 \times 3 \times 2$, com três repetições e duas épocas de avaliação. Foram 
utilizadas quatro doses de nitrogênio $\left(0,5,7 ; 11,4 \mathrm{e} 17,1 \mathrm{mg} \mathrm{kg}^{-1}\right.$ de $\mathrm{N}$ na forma de uréia); três doses de fósforo $\left(15,2 ; 22,7\right.$ e $30,3 \mathrm{mg} \mathrm{kg}^{-1}$ de $\mathrm{P}_{2} \mathrm{O}_{5}$ na forma de superfosfato triplo) e dois cultivares de soja (IAC-8 e IAC-14).

Em cada avaliação foram colhidas todas as plantas de cada vaso, necessitandose assim, o dobro do número de vasos para o experimento completo $(72 \times 2=144)$. Os vasos referentes às duas avaliações caracterizaram-se por apresentarem volumes de terra diferentes. Desse modo, os vasos avaliados quatro e oito semanas após a emergência, contiveram 5 e $9,5 \mathrm{~kg}$ de terra respectivamente.

A casualização dos blocos ocorreu na forma de sorteio, mantendo-se uma movimentação diária dos vasos em sistema de rotação e translação, para uniformizar a quantidade de luz para todos os vasos.

\subsection{Preparo do solo}

O solo foi coletado em setembro de 1995 e então, peneirado para se eliminar as pedras, raízes e outros materiais grosseiros. Posteriormente, realizou-se a amostragem para a análise quimíca e determinação da densidade aparente da amostra de terra e a transferência da terra peneirada para sacos plásticos pretos utilizados como vasos. Toda aplicação de fertilizantes e corretivos aos solos realizadas, basearam-se em mg (kg solo seco) ${ }^{-1}$, fazendo-se necessário portanto o cálculo da densidade, que foi de $1,319 \mathrm{mg} \mathrm{ml}^{-1}$.

A calagem foi realizada individualmente para cada vaso, trinta dias antes do semeadura, em dezembro de 1995. A dose de calcário utilizada foi equivalente a $1,62 \mathrm{~g}$ $\mathrm{kg}^{-1}$ e acondicionada separadamente em papel alumínio. Todo o calcário aplicado foi distribuído e homogeneizado com o volume total de terra de cada vaso, e a umidade do solo foi elevada a $60 \%$ da capacidade de campo do solo através de adição de água destilada, para acelerar a reação do calcário.

As doses dos nutrientes fixos em todos os tratamentos, foram aplicadas na semeadura, em quantidades iguais para todos os vasos com mesma quantidade de solo, 
seguindo a sistemática: pesagem, separação das quantidades a serem aplicadas, aplicação e distribuição homogênea, da mesma maneira que foi realizada para o calcário. Essa aplicação de nutrientes forneceu quantidades equivalentes a $22,7 \mathrm{mg} \mathrm{kg}^{-1}$ de $\mathrm{K}_{2} \mathrm{O}$ na forma de $\mathrm{KCl}, 7,6 \mathrm{mg} \mathrm{kg}^{-1}$ de $\mathrm{S}$ na forma de $\mathrm{CaSO}_{4}$ solúvel e uma solução contendo o equivalente às seguintes quantidades dos micronutrientes sob as respectivas formas: 0,5 $\mathrm{mg} \mathrm{kg}{ }^{-1}$ de $\mathrm{B}\left(\mathrm{H}_{3} \mathrm{BO}_{3}\right) ; 0,8 \mathrm{mg} \mathrm{kg}^{-1}$ de $\mathrm{Cu}\left(\mathrm{CuCl}_{2}\right) ; 7,3 \mathrm{mg} \mathrm{kg}{ }^{-1}$ de $\mathrm{Mn}\left(\mathrm{MnCl}_{2} .4 \mathrm{H}_{2} \mathrm{O}\right)$; $0,05 \mathrm{mg} \mathrm{kg}^{-1}$ de $\mathrm{Mo}\left(\mathrm{H}_{2} \mathrm{MoO}_{4} \cdot \mathrm{H}_{2} \mathrm{O}\right)$ e $2,0 \mathrm{mg} \mathrm{kg}^{-1}$ de $\mathrm{Zn}\left(\mathrm{ZnCl}_{2}\right)$.

\subsection{Tratos culturais}

Na semeadura, dia 15 de janeiro de 1996, foram semeadas 8 e 10 sementes, respectivamente para os vasos de menor e maior volume. As sementes, cedidas pela Seção de Leguminosas do IAC, foram inoculadas com uma mistura das estirpes de $B$. japonicum SEMIA 5099, SEMIA 587 e CB1089 provenientes do Departamento de Microbiologia do CENA/USP, na forma de inoculante turfoso, na base de $25 \mathrm{~g}$ de inoculante por $\mathrm{kg}$ de semente. $\mathrm{O}$ desbaste ocorreu dez dias após a emergência, deixandose quatro plantas em cada vaso.

Adotou-se um sistema de rega diário, para uniformizar-se a umidade do solo em torno de $60 \%$ da capacidade de campo, evitando-se tanto períodos de encharcamento quanto de secamento. $O$ controle da evapotranspiração diária foi realizado através de pesagem por amostragem de 10 vasos por bloco, sendo um bloco completamente pesado a cada cinco dias. 


\subsection{Avaliações e determinações}

As avaliações foram realizadas quatro e oito semanas após a emergência, coincidindo a $2^{\underline{a}}$ avaliação com a época de florescimento pleno das plantas. $\mathrm{Na} 1^{\underline{a}}$ avaliação colheu-se todas as quatro plantas de cada vaso em um dia e na $2^{\mathbf{a}}$, devido à maior dificuldade para a lavagem das raízes foi colhido um bloco por dia.

Todas as plantas de cada vaso foram separadas em folhas, hastes, raízes e nódulos. $\mathrm{Na} 2^{\underline{a}}$ avaliação, por ser a época de avaliação para a diagnose foliar, a folha diagnóstica com pecíolo $(+3)$ foi colhida separadamente. Esse procedimento foi necessário para que a análise química fosse realizada separadamente, uma vez que ocorrem diferenças de concentração de nutrientes entre as partes analisadas. Para as duas avaliações, as folhas foram separadas das hastes na inserção do pecíolo e as hastes separadas das raízes na região do colo. A folha diagnóstica amostrada foi a terceira folha completamente madura, localizada na haste principal da planta.

Foram avaliados em cada vaso, o número de nódulos, a massa de material seco de nódulos e a massa média de material seco por nódulo, obtida pela divisão da massa de material seco pelo número dos nódulos produzidos em cada vaso, as massas de material seco da parte aérea e raízes, os teores de $\mathrm{N}$ e $\mathrm{P}$ na folha diagnóstica e o acúmulo destes nutrientes na parte aérea, raízes e o total das plantas.

Foram realizadas amostragens de terra ao final de cada avaliação, para verificar as alterações nas propriedades químicas, decorrentes dos tratamentos aplicados. No entanto, após a $1^{\underline{a}}$ avaliação, foi realizada uma análise de terra por tratamento,

misturando-se amostras das três repetições e ao final da $2^{\underline{a}}$ avaliação foram realizadas amostragens e análises individuais de cada vaso, resultando em três por tratamento. 


\subsection{Métodos analíticos}

Todas as análises de solo necessárias ao experimento foram realizadas no Laboratório de Análise de Solo do Setor de Nutrição Mineral de Plantas do Departamento de Química da ESALQ/USP, seguindo-se a metodologia proposta por Raij \& Quaggio (1983), complementada pela metodologia de extração dos micronutrientes cobre, ferro, manganês e zinco (Lindsay \& Norvell, 1978) e pela metodologia de extração de boro (Abreu et al., 1994).

O preparo das amostras de material vegetal a serem analisadas, a obtenção dos extratos e as determinações analíticas foram realizadas no Laboratório de Análise de Plantas do Setor de Nutrição Mineral de Plantas do Departamento de Química da ESALQ/USP, conforme a metodologia descrita por Sarruge \& Haag (1974).

A lavagem das raizes foi feita sobre uma tela tipo sombrite de malha fina, apoiada sobre uma peneira, passando-se água corrente para retirar por completo o solo, sem contudo, perder-se ou danificar-se os nódulos. A seguir, as raízes assim como as folhas e as hastes foram lavadas com $\mathrm{HCl} 0,1 \mathrm{~N}$ e então com água destilada, para ser realizada a análise química desse material.

Todas as raizes lavadas foram armazenadas em sacos plásticos e mantidas sob refrigeração para evitar a perda de água, até a completa lavagem de todas as raízes, a separação e a contagem dos nódulos e a pesagem desse material enquanto ainda fresco.

A seguir, todo o material coletado e lavado foi acondicionado em sacos de papel e secos em estufa a $65^{\circ} \mathrm{C}$, para determinar-se a seguir, as massas de material seco produzidas. Todo o material seco e pesado foi então moído finamente em moinho tipo Wiley, para a análise química dos teores de $\mathrm{N}$ e $\mathrm{P}$.

A obtenção dos extratos foi feita por digestão ácida a quente, sendo utilizada a digestão sulfúrica para o obtenção do extrato para a determinação de $\mathrm{N}$, pelo método semi-micro-Kjeldahl e a digestão nítrico-perclórica, para a obtenção do extrato para a determinação de $\mathrm{P}$, e leitura pelo método colorimétrico do vanado-molibdato de amônio. 


\subsection{Análise estatística}

Os dados obtidos foram analisados conforme o delineamento experimental utilizando-se o programa estatístico SAS para a análise da variância, através do Teste $F$, para o nível de significância de 5\%, que apresentou o seguinte quadro (Tabela 2).

Quadro 1 - Quadro geral da análise da variância

\begin{tabular}{|c|c|c|c|c|}
\hline Causa da Variação & G.L. & S.Q. & Q.M. & Valor $\mathrm{F}$ \\
\hline blocos & 2 & & & \\
\hline Cultivar & 1 & & & \\
\hline Dose de N & 3 & & & \\
\hline Cultivar x Dose de N & 3 & & & \\
\hline Dose de P & 2 & & & \\
\hline Cultivar $\mathrm{x}$ Dose de $\mathrm{P}$ & 2 & & & \\
\hline Dose de $\mathrm{N} \times$ Dose de $\mathrm{P}$ & 6 & & & \\
\hline Cultivar x Dose $\mathrm{N} x$ Dose $\mathrm{P}$ & 6 & & & \\
\hline Tratamento & 25 & & & \\
\hline Resíduo & 46 & & & \\
\hline Total & 71 & & & \\
\hline
\end{tabular}

Os resultados foram analisados somente quando apresentaram valores de Teste F significativos ao nível de $5 \%$ de probabilidade. A seguir, os resultados das médias das variáveis, para o fator cultivar, foram comparados pelo teste de Tukey, enquanto para os resultados das médias das variáveis, para os fatores dose de $\mathrm{N}$ e dose de $\mathrm{P}$, foi aplicada a regressão polinomial.

Avaliou-se ainda, as interações entre os fatores de tratamentos e seus desdobramentos, somente quando estas apresentaram valores de $\mathrm{F}$ significativos para análise da variância, uma vez que o programa SAS realiza todos os desdobramentos das interações mesmo que estes não sejam significativos. 


\section{RESULTADOS E DISCUSSÃO}

\subsection{Nodulação}

O número de nódulos produzidos pelas quatro plantas de cada vaso (Tabela 2), foi influenciado pelos fatores cultivar e dose de nitrogênio, apresentando valores significativos para o Teste $\mathrm{F}$.

Tabela 2 - Número de nódulos formados nas primeiras quatro semanas após a emergência.

\begin{tabular}{|c|c|c|c|c|c|c|c|c|c|c|c|}
\hline \multirow{3}{*}{$\begin{array}{c}\mathrm{P}_{2} \mathrm{O}_{5} \\
\mathrm{mg} \mathrm{kg}^{-1}\end{array}$} & \multicolumn{5}{|c|}{ IAC-8 } & \multicolumn{5}{|c|}{ IAC-14 } & \multirow{3}{*}{$\begin{array}{c}\text { média } \\
\text { geral }\end{array}$} \\
\hline & \multicolumn{5}{|c|}{$\mathrm{N}\left(\mathrm{mg} \mathrm{kg}^{-1}\right)$} & \multicolumn{5}{|c|}{$\mathrm{N}\left(\mathrm{mg} \mathrm{kg}^{-1}\right)$} & \\
\hline & 0 & 5,7 & 11,4 & 17,1 & média & 0 & 5,7 & 11,4 & 17,1 & média & \\
\hline 15,2 & 102 & 79 & 79 & 68 & 82 & 37 & 33 & 20 & 20 & 28 & 55 \\
\hline 22,7 & 101 & 66 & 64 & 70 & 75 & 50 & 37 & 42 & 34 & 41 & 58 \\
\hline 30,3 & 113 & 92 & 77 & 61 & 86 & 40 & 47 & 36 & 29 & 38 & 62 \\
\hline média & 105 & 79 & 73 & 66 & 81 & 42 & 39 & 33 & 28 & 36 & \\
\hline \multicolumn{2}{|l|}{ média $\mathrm{g}$} & & & & & 74 & 59 & 53 & 47 & & 58 \\
\hline
\end{tabular}

Houve efeitos significativos dos fatores cultivar, dose de $\mathrm{N}$ e de $\mathbf{P}$ na massa de material seco dos nódulos (Tabela 3), detectados pelo Teste F. 
Tabela 3 - Massa de material seco dos nódulos $\left(\mathrm{mg} \mathrm{vaso}^{-1}\right)$ formada nas primeiras quatro semanas após a emergência.

\begin{tabular}{|c|c|c|c|c|c|c|c|c|c|c|c|}
\hline \multirow[t]{2}{*}{$\begin{array}{c}\mathrm{P}_{2} \mathrm{O}_{5} \\
\mathrm{mg} \mathrm{kg}^{-1}\end{array}$} & \multicolumn{5}{|c|}{ IAC-8 } & \multicolumn{5}{|c|}{ IAC-14 } & \multirow[t]{2}{*}{$\begin{array}{l}\text { média } \\
\text { geral }\end{array}$} \\
\hline & 0 & 5,7 & 11,4 & 17,1 & média & 0 & 5,7 & 11,4 & 17,1 & média & \\
\hline 15,2 & 53,3 & 36,7 & 40,0 & 30,0 & 40,0 & 10,0 & 16,7 & 10,0 & 10,0 & 11,7 & 25,8 \\
\hline 22,7 & 56,7 & 40,0 & 40,0 & 43,3 & 45,0 & 33,3 & 23,3 & 20,0 & 10,0 & 21,7 & 33,3 \\
\hline 30,3 & 66,7 & 40,0 & 46,7 & 40,0 & 48,3 & 26,7 & 16,7 & 16,7 & 13,3 & 18,4 & 33,4 \\
\hline média & 58,9 & 38,9 & 42,2 & 37,8 & 44,4 & 23,3 & 18,9 & 15,6 & 11,1 & 17,2 & \\
\hline média & & & & & & 41,1 & 28,9 & 28,9 & 24,4 & & 30,8 \\
\hline
\end{tabular}

A massa de material seco por nódulo avaliada nessa época (Tabela 4), apresentou efeito significativo (Teste F), para o fator cultivar e a interação dos fatores dose de nitrogênio e dose de fósforo.

Tabela 4 - Massa de material seco por nódulo (mg) formado nas primeiras quatro semanas após a emergência.

\begin{tabular}{|c|c|c|c|c|c|c|c|c|c|c|c|}
\hline \multirow[t]{2}{*}{$\begin{array}{c}\mathrm{P}_{2} \mathrm{O}_{5} \\
\mathrm{mg} \mathrm{kg}^{-1}\end{array}$} & \multicolumn{5}{|c|}{$\frac{\text { IAC-8 }}{\mathrm{N}\left(\mathrm{mg} \mathrm{kg}^{-1}\right)}$} & \multicolumn{5}{|c|}{$\frac{\mathrm{IAC}-14}{\mathrm{~N}\left(\mathrm{mg} \mathrm{kg}^{-1}\right)}$} & \multirow[t]{2}{*}{$\begin{array}{l}\text { média } \\
\text { geral }\end{array}$} \\
\hline & 0 & 5,7 & 11,4 & 17,1 & média & 0 & 5,7 & 11,4 & 17,1 & média & \\
\hline 15,2 & 0,56 & 0,51 & 0,52 & 0,45 & 0,51 & 0,29 & 0,50 & 0,51 & 0,49 & 0,45 & 0,48 \\
\hline 22,7 & 0,56 & 0,62 & 0,62 & 0,61 & 0,60 & 0,68 & 0,67 & 0,52 & 0,30 & 0,54 & 0,57 \\
\hline 30,3 & 0,61 & 0,44 & 0,61 & 0,69 & 0,58 & 0,68 & 0,35 & 0,45 & 0,47 & 0,49 & 0,54 \\
\hline média & 0,58 & 0,52 & 0,58 & 0,58 & 0,57 & 0,55 & 0,51 & 0,49 & 0,42 & 0,49 & \\
\hline & 0,56 & 0,51 & 0,54 & 0,50 & & 0,53 \\
\hline
\end{tabular}

$\mathrm{Na} 2^{\mathrm{a}}$ avaliação, oito semanas após a emergência, o número de nódulos formados (Tabela 5) variou significativamente entre os fatores cultivar e dose de fósforo, evidenciado pelo Teste $\mathrm{F}$. 
Tabela 5 - Número de nódulos formados durante as oito semanas após a emergência.

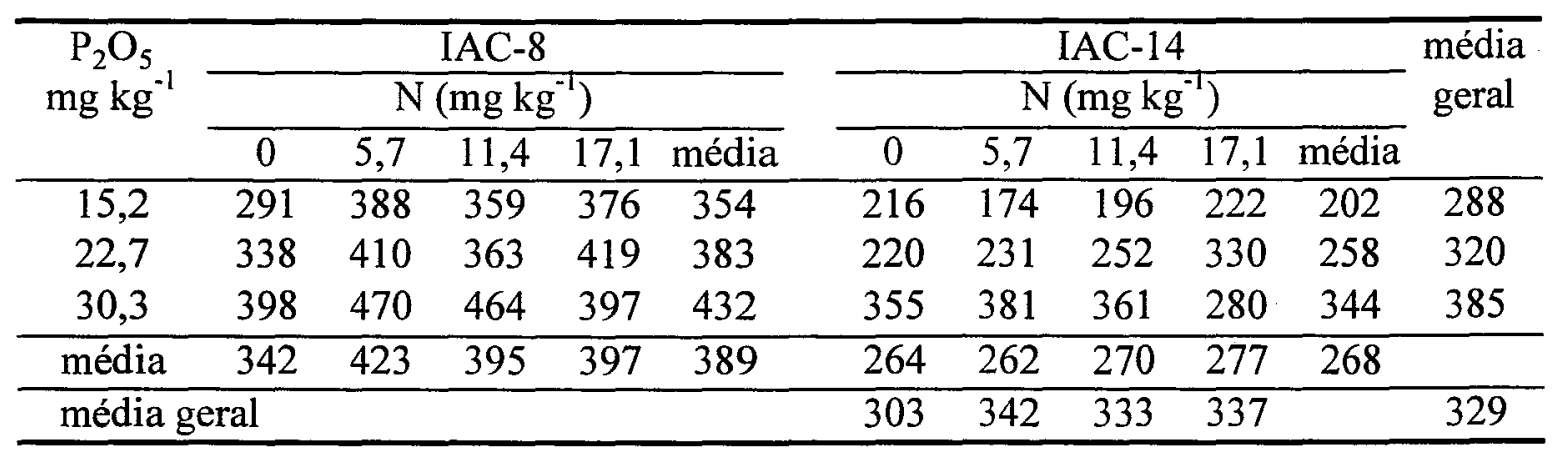

Os resultados de massa de material seco dos nódulos produzidos apresentados na Tabela 6 mostraram na análise da variância (Teste F), efeito significativo apenas das doses de fósforo.

Tabela 6 - Massa de material seco dos nódulos (g vaso ${ }^{-1}$ ) formada durante as oito semanas após a emergência.

\begin{tabular}{|c|c|c|c|c|c|c|c|c|c|c|c|}
\hline \multirow{3}{*}{$\begin{array}{c}\mathrm{P}_{2} \mathrm{O}_{5} \\
\mathrm{mg} \mathrm{kg}^{-1}\end{array}$} & \multicolumn{5}{|c|}{ IAC-8 } & \multicolumn{5}{|c|}{ IAC-14 } & \multirow{3}{*}{$\begin{array}{c}\text { média } \\
\text { geral }\end{array}$} \\
\hline & \multicolumn{5}{|c|}{$\mathrm{N}\left(\mathrm{mg} \mathrm{kg}^{-1}\right)$} & \multicolumn{5}{|c|}{$\mathrm{N}\left(\mathrm{mg} \mathrm{kg}^{-1}\right)$} & \\
\hline & 0 & 5,7 & 11,4 & 17,1 & média & 0 & 5,7 & 11,4 & 17,1 & média & \\
\hline 15,2 & 0,84 & 1,13 & 1,06 & 0,67 & 0,93 & 1,03 & 0,66 & 0,81 & 0,56 & 0,77 & 0,91 \\
\hline 22,7 & 0,82 & 1,16 & 0,92 & 1,10 & 1,00 & 1,05 & 0,91 & 1,09 & 1,20 & 1,06 & 1,03 \\
\hline 30,3 & 1,47 & 1,41 & 1,37 & 1,11 & 1,34 & 1,28 & 1,54 & 1,34 & 1,31 & 1,37 & 1,35 \\
\hline média & 1,04 & 1,23 & 1,12 & 0,96 & 1,09 & 1,12 & 1,04 & 1,08 & 1,02 & 1,07 & \\
\hline \multicolumn{6}{|c|}{ média geral } & 1,08 & 1,14 & 1,10 & 0,99 & & 1,08 \\
\hline
\end{tabular}

Os resultados de massa de material seco por nódulo (Tabela 7) apresentaram diferenças significativas (Teste F) para os fatores cultivar e dose de nitrogênio. 
Tabela 7 - Massa de material seco por nódulo (mg) formada durante as oito semanas após a emergência.

\begin{tabular}{|c|c|c|c|c|c|c|c|c|c|c|c|}
\hline \multirow[t]{2}{*}{$\begin{array}{l}\mathrm{P}_{2} \mathrm{O}_{5} \\
\mathrm{mg} \mathrm{kg}^{-1}\end{array}$} & \multicolumn{5}{|c|}{$\frac{\text { IAC-8 }}{\mathrm{N}\left(\mathrm{mg} \mathrm{kg}^{-1}\right)}$} & \multicolumn{5}{|c|}{$\frac{\text { IAC-14 }}{\mathrm{N}\left(\mathrm{mg} \mathrm{kg}^{-1}\right)}$} & \multirow[t]{2}{*}{$\begin{array}{l}\text { média } \\
\text { geral }\end{array}$} \\
\hline & 0 & 5,7 & 11,4 & 17,1 & média & $\overline{0}$ & 5,7 & 11,4 & 17,1 & média & \\
\hline 15,2 & 2,98 & 2,92 & 2,97 & 1,77 & 2,66 & 4,78 & 3,66 & 4,09 & 2,40 & 3,73 & 3,20 \\
\hline 22,7 & 2,53 & 2,97 & 2,58 & 2,66 & 2,69 & 4,92 & 3,95 & 4,17 & 3,72 & 4,19 & 3,44 \\
\hline 30,3 & 3,72 & 2,97 & 2,97 & 2,77 & 3,11 & 4,07 & 4,04 & 3,67 & 4,65 & 4,11 & 3,61 \\
\hline média & 3,08 & 2,95 & 2,84 & 2,40 & 2,82 & 4,59 & 3,88 & 3,98 & 3,59 & 4,01 & \\
\hline \multicolumn{6}{|c|}{ média geral } & 3,83 & 3,42 & 3,41 & 3,00 & & 3,41 \\
\hline
\end{tabular}

\subsubsection{Efeito do fator cultivar}

A Tabela 8 mostra o número e a massa de material seco dos nódulos produzidos por vaso e a massa de material seco por nódulo para os dois cultivares, quatro semanas após a emergência.

Tabela 8 - Número, massa de material seco de nódulos e massa de material seco por nódulo, dos cultivares IAC-8 e IAC-14, observados quatro semanas após a emergência (médias de 36 vasos).

\begin{tabular}{cccc}
\hline Cultivar & Número de nódulos & $\begin{array}{c}\text { M.S. nódulos } \\
\text { mg vaso }^{-1}\end{array}$ & $\begin{array}{c}\text { M.S. por nódulo } \\
\text { mg }\end{array}$ \\
\hline IAC - 8 & $81 \mathrm{a}$ & $44,4 \mathrm{a}$ & $0,6 \mathrm{a}$ \\
IAC - 14 & $36 \mathrm{~b}$ & $17,2 \mathrm{~b}$ & $0,5 \mathrm{a}$ \\
\hline
\end{tabular}

Médias na vertical seguidas de letras diferentes, diferem entre si ao nível de $5 \%$ para o Teste Tukey

Os dois cultivares estudados apresentaram diferenças significativas entre si quanto à nodulação, principalmente quatro semanas após a emergência, o que concorda com Patterson \& Larue (1983) e Hardarson et al. (1984), que citam a influência genética sobre a nodulação. O cv. IAC-8 apresentou maior nodulação inicial que o "IAC-14". O número de nódulos foi $125 \%$ superior e a massa de material seco dos nódulos produzidos foi em média $158 \%$ maior que a do "IAC-14". A comparação entre os 
cultivares não apresentou diferença significativa (Teste Tukey) para a massa de material seco por nódulo, porém o cv. IAC-8 produziu nódulos 20\% maiores que o "IAC-14".

$\mathrm{Na}$ época da segunda avaliação, no início da fase reprodutiva, a nodulação apresentada pelos dois cultivares (Tabela 9) foi muitas vezes superior aos valores da nodulação observados quatro semanas após a emergência, indicando uma boa relação entre as estirpes de B. japonicum e os cultivares de soja utilizados.

O número de nódulos do cv. IAC-8 foi $45 \%$ superior ao produzido por "IAC14". A diferença na massa de material seco de nódulos produzidos no entanto, foi de $2 \%$ maior para o "IAC-8", não sendo portanto significativa. O cultivar IAC-14 apresentou um desenvolvimento inicial das raízes e da parte aérea menor que o cv. IAC-8. Desse modo, esse cultivar apresentou uma região menor para infecção do rizóbio e também uma menor disponibilidade de fotossintatos necessários ao desenvolvimento dos nódulos. No entanto, o cultivar IAC-14 apresentou um maior desenvolvimento a partir da quarta semana após a emergência e atingiu uma massa de material radicular equivalente ao cv. IAC-8, oito semanas após a emergência, favorecendo a nodulação desse cultivar que apresentou a massa de material seco por nódulo $30 \%$ maior que a "IAC-8". Essa resposta está relacionada com o menor número de nódulos produzidos por esse cultivar (Tabela 9). O cultivar IAC-8 apresentou uma maior eficiência dos processos de infecção e formação de novos nódulos, ao passo que o "IAC-14" promoveu um maior desenvolvimento dos nódulos formados em menor número.

Tabela 9 - Número, massa de material seco de nódulos e massa de material seco por nódulo dos cultivares IAC-8 e IAC-14, observados oito semanas após a emergência (médias de 36 vasos)

\begin{tabular}{cccc}
\hline Cultivar & Número de nódulos & $\begin{array}{c}\text { M.S. nódulos } \\
\text { g vaso }^{-1}\end{array}$ & $\begin{array}{c}\text { M.S. por nódulo } \\
\mathrm{mg}\end{array}$ \\
\hline IAC -8 & $389 \mathrm{a}$ & $1,09 \mathrm{a}$ & $3 \mathrm{~b}$ \\
IAC -14 & $268 \mathrm{~b}$ & $1,06 \mathrm{a}$ & $4 \mathrm{a}$ \\
\hline
\end{tabular}

Médias na vertical seguidas de letras diferentes, diferem entre si ao nível de $5 \%$ para Teste Tukey 


\subsubsection{Efeito do fator dose de nitrogênio}

Quatro semanas após a emergência, o efeito das doses de nitrogênio aplicadas na semeadura foi de inibição da nodulação e expressou-se no menor número e massa de material seco de nódulos produzidos por vaso e também pela tendência de redução da massa de material seco por nódulo (Tabela 10).

Tabela 10 - Número, massa de material seco de nódulos e massa de material seco por nódulo, em função do fator dose de nitrogênio, observados quatro semanas após a emergência (médias de 18 vasos).

\begin{tabular}{cccc}
\hline $\begin{array}{c}\mathrm{N} \\
\mathrm{mg} \mathrm{kg}^{-1}\end{array}$ & Número de nódulos & $\begin{array}{c}\text { M.S. nódulos } \\
\mathrm{mg} \mathrm{vaso}^{-1}\end{array}$ & $\begin{array}{c}\text { M.S. por nódulo } \\
\mathrm{mg}\end{array}$ \\
\hline 0 & 71 & 41,1 & 0,6 \\
5,7 & 63 & 28,9 & 0,5 \\
11,4 & 54 & 28,9 & 0,5 \\
17,1 & 45 & 24,4 & 0,5 \\
\hline
\end{tabular}

A correlação entre o número de nódulos produzidos e a quantidade de $\mathrm{N}$ aplicada foi negativa, ou seja, o aumento das doses diminuiu a nodulação, indicando a inibição desta pelo N-mineral. A correlação ajustou-se a equação linear:

$$
\mathrm{Y}=-1,5 \mathrm{X}+71,1 \quad \mathrm{R}^{2}=93,68 \% ; \mathrm{C} . \mathrm{V} . \%=47,72
$$

A dose $5,7 \mathrm{mg} \mathrm{kg}^{-1}$ de $\mathrm{N}$ reduziu em média $20 \%$, o número de nódulos produzidos, em relação ao tratamento onde não se aplicou o nutriente. Essa tendência de redução ocorreu também para a massa de material seco dos nódulos e massa de material seco por nódulo.

As doses de nitrogênio apresentaram relação linear negativa com a massa de material seco dos nódulos. A menor dose de nitrogênio utilizada produziu 30\% a menos que o tratamento onde $\mathrm{N}$ não foi aplicado, indicando que nessa fase inicial, mesmo doses baixas de $\mathrm{N}$-mineral promovem inibição da nodulação. A equação de regressão que representou a correlação foi: 


$$
\mathrm{Y}=-0,87 \mathrm{X}+38,3 \quad \mathrm{R}^{2}=81,16 \% ; \mathrm{C} . \mathrm{V} . \%=56,84
$$

Em ambos os casos, o elevado coeficiente de variação é observado em função da diferença entre os dois cultivares.

$\mathrm{O}$ efeito negativo do $\mathrm{N}$ sobre a nodulação é bem visível no início do desenvolvimento das plantas, reduzindo a formação de nódulos (Tanner \& Anderson, 1963) e também, apesar de menos acentuado, o desenvolvimento dos nódulos formados. Raggio et al. (1965) e Rabie et al. (1980) verificaram um menor desenvolvimento dos nódulos em plantas que receberam pequenas quantidades de adubação nitrogenada, porém, nesses dois casos, verificou-se um maior crescimento da parte aérea, aumentando a competição entre a parte aérea e o sistema radicular pelos fotossintatos produzidos.

Oito semanas após a emergência, o Teste $\mathrm{F}$ da análise da variância não mostrou efeito significativo da quantidade de $\mathrm{N}$ aplicada, sobre o número e a massa de material seco dos nódulos. Houve variação significativa apenas sobre a massa de material seco por nódulo. Essa equivalência indicou a recuperação da nodulação das plantas adubadas com N (Tabela 11).

Tabela 11 - Número, massa de material seco de nódulos e massa de material seco por nódulo, em função do fator dose de nitrogênio, observados oito semanas após a emergência (médias de 18 vasos).

\begin{tabular}{cccc}
\hline $\begin{array}{c}\mathrm{N} \\
\mathrm{mg} \mathrm{kg}^{-1}\end{array}$ & Número de nódulos & $\begin{array}{c}\text { M.S. nódulos } \\
\mathrm{g}\end{array}$ & $\begin{array}{c}\text { M.S. por nódulo } \\
\mathrm{mg}\end{array}$ \\
\hline 0 & 303 & 1,08 & 3,8 \\
5,7 & 342 & 1,13 & 3,4 \\
11,4 & 333 & 1,10 & 3,4 \\
17,1 & 337 & 0,99 & 3,0 \\
\hline
\end{tabular}

A massa de material seco por nódulo e a quantidade de $\mathrm{N}$ aplicada correlacionaram-se negativamente, ajustando-se a equação linear:

$$
\mathrm{Y}=-0,04 \mathrm{X}+3,79 \quad \mathrm{R}^{2}=90,63 \% ; \mathrm{C} . \mathrm{V} . \%=29,11
$$


A diminuição significativa da massa de material seco por nódulo com o incremento das doses de $\mathrm{N}$ ocorreu porque embora a análise da variância não tenha determinado os efeitos significativos sobre o número e a massa de mateial seco dos nódulos, o aumento percentual sobre do número de nódulos foi superior ao observado sobre a massa de material seco dos nódulos.

Os efeitos negativos do N-mineral sobre a nodulação foram observados somente até a amostragem das primeiras quatro semanas após a emergência, ocorrendo a recuperação da nodulação das plantas adubadas com $\mathrm{N}$ na semeadura, por ocasião do início do florescimento, apresentando ainda tendência de superação sobre as plantas não adubadas.

O N-mineral apresenta alta mobilidade no solo, sendo perdido ou absorvido pelas raízes e microorganismos. Esse fato pode ter feito com que as baixas doses aplicadas não mantivessem, por um período prolongado, concentrações no solo que inibissem a nodulação e, assim, a variação entre os tratamentos ocorrida quatro semanas após a emergência, não foi observada nesta época.

Nesta avaliação, o número de nódulos formados pelas plantas do tratamento que aplicou a menor dose de $\mathrm{N}$ foi $13 \%$ maior que o número produzido pelo tratamento onde não foi aplicado $\mathrm{N}$ e a massa de material seco dos nódulos formados pelos tratamentos que receberam adubação nitrogenada foi de $92 \%$ e $105 \%$ do total produzido pelo tratamento não adubado com $\mathrm{N}$ para a maior e para a menor quantidade de $\mathrm{N}$ aplicadas.

Esses números mostram uma pequena tendência de aumento na nodulação do tratamento que recebeu a menor dose de nitrogênio. Além disso, esses nódulos, por serem mais jovens, devido ao atraso no início da nodulação, podem permanecer ativos por um período maior, durante a fase reprodutiva das plantas, do que os nódulos das plantas não adubadas. Esse adiamento do período de maior atividade na fixação simbiótica do $\mathrm{N}_{2}$ para uma época mais próxima do final do ciclo das plantas, pode até aumentar a quantidade de $\mathrm{N}$ disponível para a produção e seu acúmulo pelas sementes. 


\subsubsection{Efeito do fator dose de fósforo}

A adubação fosfatada apresentou resultados benéficos para a nodulação da soja, comprovando os resultados da literatura. O número, a massa de material seco dos nódulos e a massa de material seco por nódulo formado nas quatro plantas de cada vaso, quatro semanas após a emergência, apresentaram tendência de aumento com as doses de fósforo (Tabela 12), porém os valores de $\mathrm{F}$ mostraram-se significativos apenas para a massa seca dos nódulos.

Tabela 12 - Número, massa de material seco de nódulos e massa de material seco por nódulo, em função do fator dose de fósforo, observadas quatro semanas após a emergência (médias de 24 vasos).

\begin{tabular}{cccc}
\hline $\begin{array}{c}\mathrm{P}_{2} \mathrm{O}_{5} \\
\mathrm{mg} \mathrm{kg}^{-1}\end{array}$ & Número de nódulos & $\begin{array}{c}\text { M.S. nódulos } \\
\mathrm{mg}\end{array}$ & $\begin{array}{c}\text { M.S. por nódulo } \\
\mathrm{mg}\end{array}$ \\
\hline 15,2 & 55 & 25,8 & 0,48 \\
22,7 & 58 & 33,3 & 0,57 \\
30,3 & 62 & 33,4 & 0,54 \\
\hline
\end{tabular}

A correlação linear entre as doses de fósforo aplicadas e a massa de material seco dos nódulos é ajustada pela função da regressão:

$$
\mathrm{Y}=0,5 \mathrm{X}+19,6 \quad \mathrm{R}^{2}=75,00 \% ; \mathrm{C} . \mathrm{V} . \%=58,88
$$

A massa de material seco por nódulo foi crescente até a dose de $22,7 \mathrm{mg} \mathrm{kg}^{-1}$ de $\mathrm{P}_{2} \mathrm{O}_{5}$, mas não mostrou-se significativa. Nessa época de início da nodulação, o efeito do fósforo parece estar mais relacionado com o processo de infecção e formação dos nódulos do que com o desenvolvimento dos nódulos formados.

$\mathrm{O}$ efeito das doses de $\mathrm{P}$ sobre a nodulação foi mais evidente oito semanas após a emergência, quando o número e a massa de material seco dos nódulos aumentaram significativamente com a dose de $\mathrm{P}$ aplicada (Tabela 13). 
Tabela 13 - Número, massa de material seco de nódulos e massa de material seco por nódulo, em função do fator dose de fósforo, observadas oito semanas após a emergência (médias de 24 vasos).

\begin{tabular}{cccc}
\hline $\begin{array}{c}\mathrm{P}_{2} \mathrm{O}_{5} \\
\mathrm{mg} \mathrm{kg}\end{array}$ & Número de nódulos & $\begin{array}{c}\text { M.S. nódulos } \\
\mathrm{g}\end{array}$ & $\begin{array}{c}\text { M.S. por nódulo } \\
\mathrm{mg}\end{array}$ \\
\hline 15,2 & 278 & 0,91 & 3,20 \\
22,7 & 320 & 1,03 & 3,44 \\
30,3 & 385 & 1,35 & 3,61 \\
\hline
\end{tabular}

A correlação entre o número de nódulos e a quantidade de $\mathrm{P}$ aplicada é ajustada pela equação de regressão:

$$
\mathrm{Y}=7,3 \mathrm{X}+162 \quad \mathrm{R}^{2}=98,26 \% ; \text { C.V. } \%=28,37
$$

A massa de material seco de nódulos também apresentou correlação linear com a quantidade de $\mathrm{P}$ aplicada, evidenciando a influência desse nutriente sobre a nodulação e consequentemente sobre a fixação simbiótica de $\mathrm{N}_{2}$. Os resultados observados podem ser expressos pela função de regressão:

$$
\mathrm{Y}=0,03 \mathrm{X}+0,31 \quad \mathrm{R}^{2}=97,74 \% \text { C.V.\% } \% 24,22
$$

As doses de fósforo, apesar de não proporcionarem efeitos significativos, mostraram tendência de aumento da massa de material seco por nódulo. $\mathrm{O} \mathrm{cv}$. IAC-8 produziu nódulos cerca de $30 \%$ menores que o outro cultivar. O maior efeito desse nutriente no entanto, foi aumentar o número de nódulos formados, reforçando a idéia de que ele atua no processo de infecção.

\subsubsection{Efeito da interação entre os fatores dose de nitrogênio e dose de fósforo}

Quatro semanas após a emergência, a massa de material seco por nódulo correlacionou-se significativamente (Teste F) com as doses de nitrogênio, somente no nível $30,3 \mathrm{mg} \mathrm{kg}^{-1}$ de $\mathrm{P}_{2} \mathrm{O}_{5}$ (Figura 1). A maior dose de fósforo não anulou a inibição da nodulação pela aplicação do $\mathrm{N}$-mineral. Todas as doses de nitrogênio aplicadas apresentaram redução da massa de material seco dos nódulos quando comparadas com o 
tratamento no qual não se aplicou $\mathrm{N}$, porém a intensidade da redução verificada foi menor quando aplicou-se $30,3 \mathrm{mg} \mathrm{kg}^{-1}$ de $\mathrm{P}_{2} \mathrm{O}_{5}$. Apesar disso, o número de nódulos formados foi sempre reduzido pelo aumento das doses de nitrogênio aplicadas, reduzindo assim, a massa de material seco por nódulo. Dentre os tratamentos que receberam N, os maiores nódulos no entanto, foram observados na maior dose de nitrogênio aplicada, que teve a formação de nódulos inibida de maneira mais intensiva que a massa de material seco dos nódulos. Dessa forma, os nódulos que se formaram, por estarem em número mais reduzido que nos outros tratamentos, tiveram um desenvolvimento maior. Uma função quadrática demonstra esse resultado.

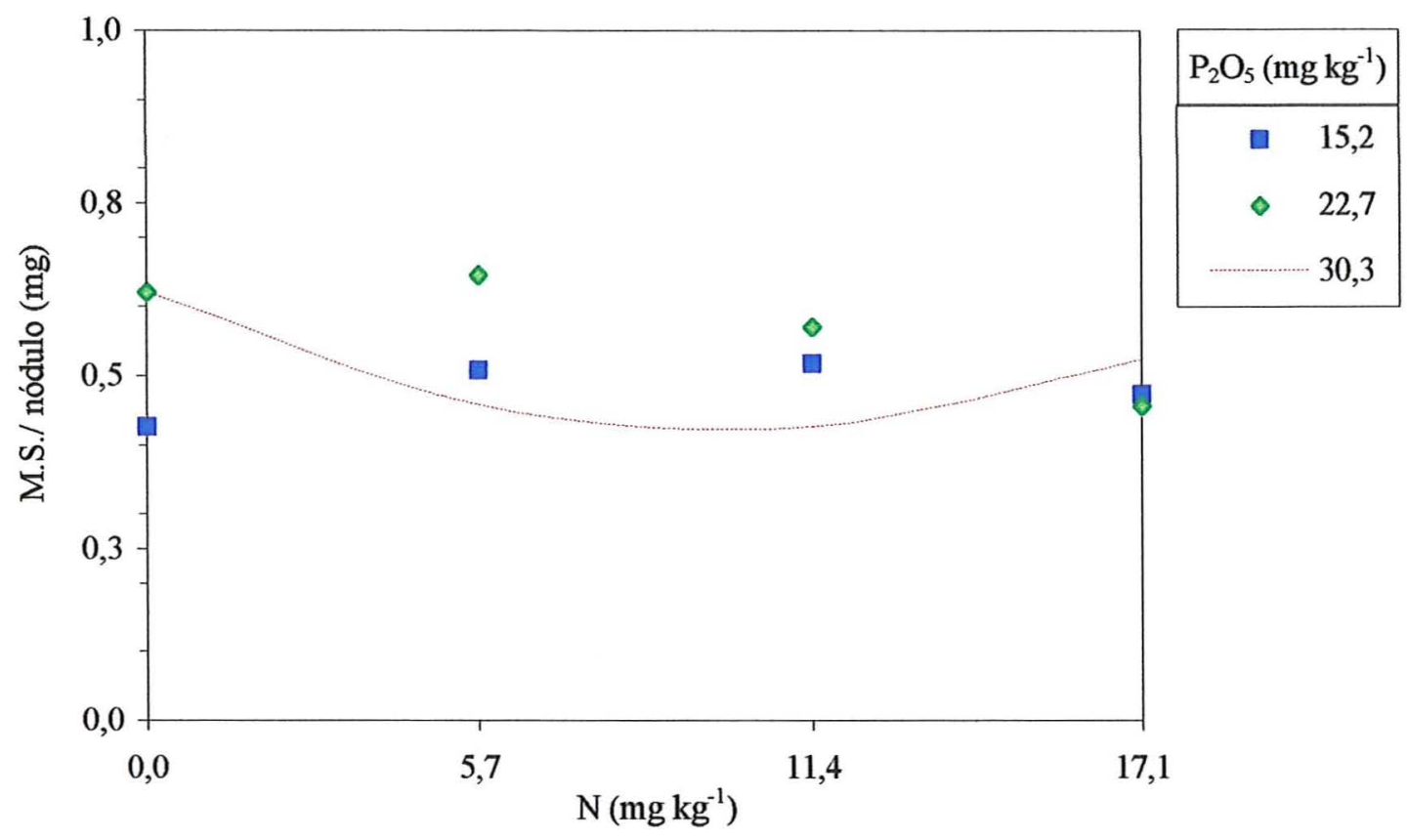

\begin{tabular}{|l|l|l|}
\hline $15,2 \mathrm{mg} \mathrm{kg}^{-1} \mathrm{P}_{2} \mathrm{O}_{5}$ & não significativo & \\
\hline $22,7 \mathrm{mg} \mathrm{kg}^{-1} \mathrm{P}_{2} \mathrm{O}_{5}$ & não significativo & \\
\hline $30,3 \mathrm{mg} \mathrm{kg} \mathrm{P}_{2} \mathrm{O}_{5}$ & $\mathrm{Y}=0,002 \mathrm{X}^{2}-0,04 \mathrm{X}+0,62$ & $\mathrm{R}^{2}=67,14 \% ; \mathrm{CV} \%=25,25$ \\
\hline
\end{tabular}

Figura 1 - Massa de material seco por nódulo em cada dose de fósforo, em função do fator dose de nitrogênio, observadas quatro semanas após a emergência (médias de 6 vasos). 
A regressão para a aplicação de fósforo dentro de cada dose de nitrogênio (Figura 2), apresentou efeito significativo para a massa de material seco por nódulo somente para os níveis 0 e $5,7 \mathrm{mg} \mathrm{kg}^{-1} \mathrm{de} \mathrm{N}$.

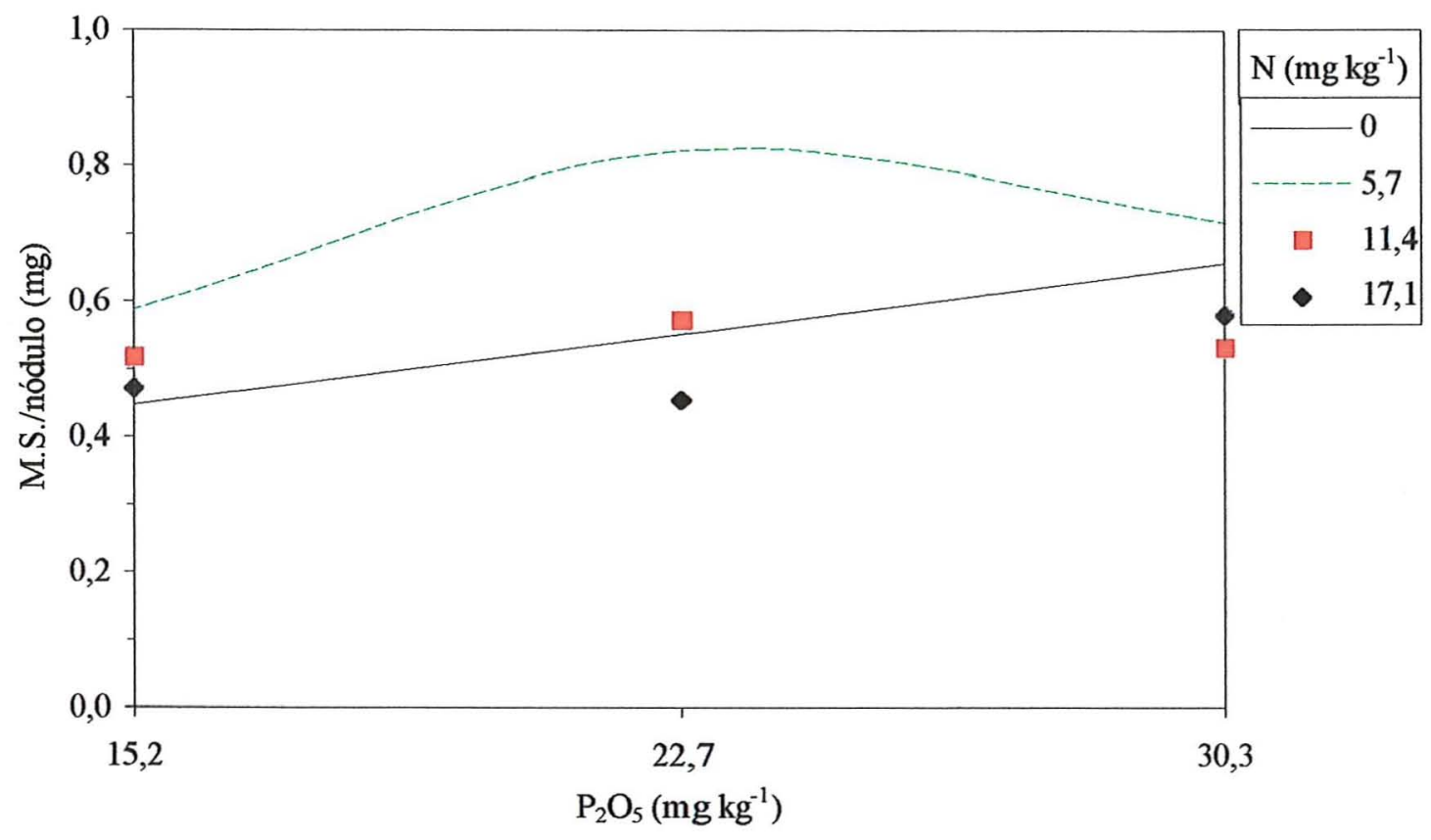

\begin{tabular}{|c|c|c|}
\hline $0 \mathrm{mg} \mathrm{kg}^{-1} \mathrm{~N}$ & $Y=0,01 X+0,23$ & $\mathrm{R}^{2}=82,91 \% ; \mathrm{CV} \%=29,63$ \\
\hline $5,7 \mathrm{mg} \mathrm{kg}^{-1} \mathrm{~N}$ & $Y=-0,003 X^{2}+0,15 X-0,93$ & $\mathrm{R}^{2}=79,22 \% ; \mathrm{CV} \%=28,97$ \\
\hline $11,4 \mathrm{mg} \mathrm{kg}^{-1} \mathrm{~N}$ & não significativo & \\
\hline $17,1 \mathrm{mg} \mathrm{kg}^{-1} \mathrm{~N}$ & não significativo & \\
\hline
\end{tabular}

Figura 2 - Massa de material seco por nódulo em cada dose de nitrogênio, em função do fator dose de fósforo, observadas quatro semanas após a emergência (médias de 6 vasos).

A resposta ao fósforo, quando o nitrogênio não foi aplicado foi linear, por não haver inibição da nodulação. O aumento da dose de fósforo aplicada não anulou a inibição da nodulação pela aplicação de $\mathrm{N}$, porém, quando foram aplicados $5,7 \mathrm{mg} \mathrm{kg}^{-1} \mathrm{de}$ $\mathrm{N}$, a massa de material seco por nódulo foi reduzida para a maior dose de fósforo, por que apresentou uma tendência de redução da inibição da formação dos nódulos, sem 
contudo, promover o mesmo efeito sobre a massa de material seco dos nódulos produzidos.

A inibição da nodulação pela aplicação de pequenas quantidades de $\mathrm{N}$-mineral não foi anulada pela aplicação de doses crescentes de fósforo como afirmaram Gates \& Wilson (1974), no entanto, a tendência de redução da inibição da formação dos nódulos, apresentada pela maior dose de fósforo (Figura 3), assegurou uma maior recuperação da nodulação no início do florescimento (Figura 4).

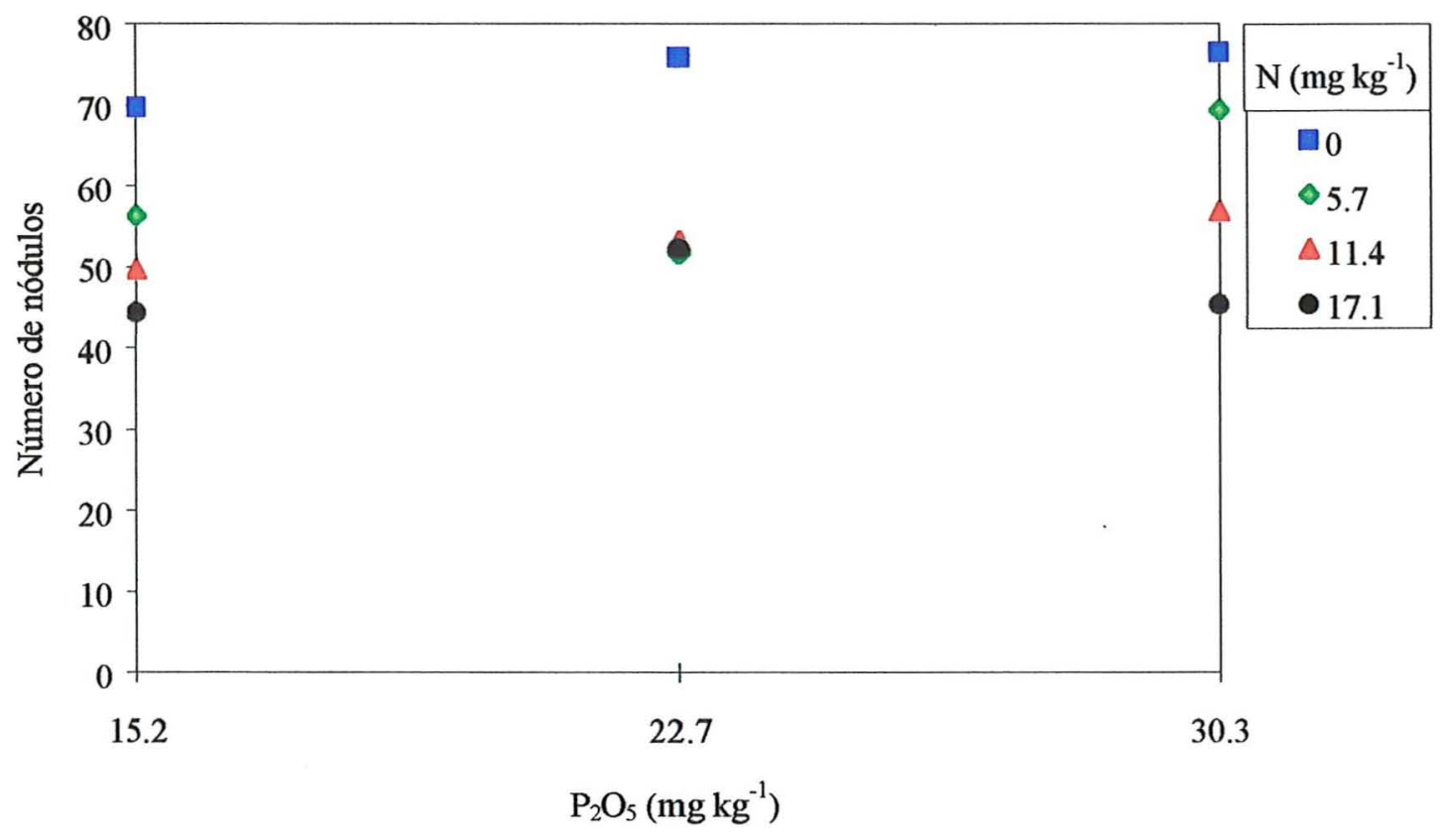

Figura 3 - Número de nódulos formados em cada dose de nitrogênio, em função do fator dose de fósforo, observadas quatro semanas após a emergência (médias de 6 vasos). 


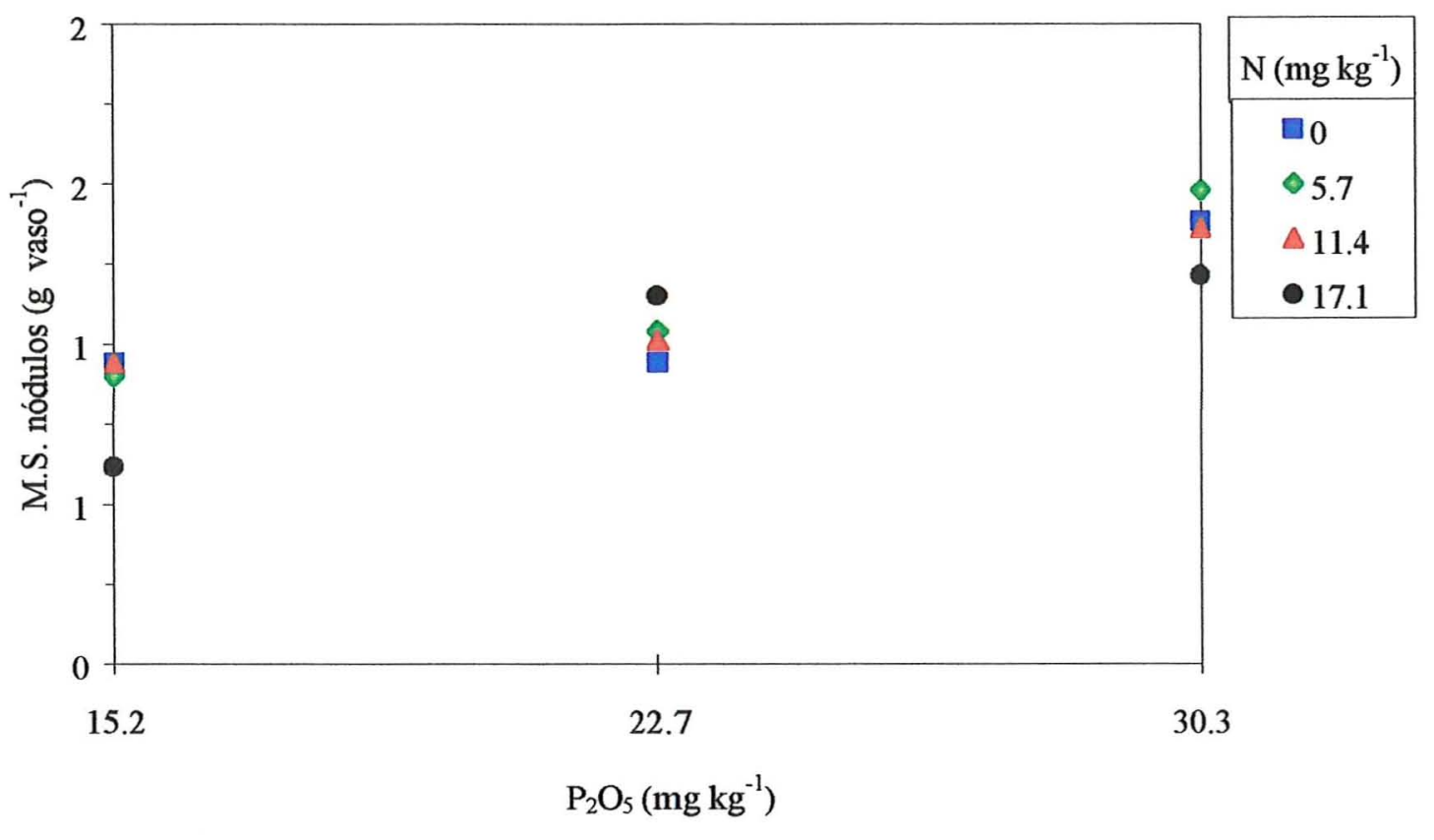

Figura 4 - Massa de material seco dos nódulos em cada dose de nitrogênio, em função do fator dose de fósforo, observadas oito semanas após a emergência (médias de 6 vasos).

\subsection{Massa de material vegetal seco}

A massa de material seco da parte aérea, quatro semanas após a emergência (Tabela 14), foi influenciada significativamente pelos fatores cultivar, dose de nitrogênio e dose de $\mathrm{P}$ isoladamente, evidenciados pelo Teste $\mathrm{F}$. 
Tabela 14 - Massa de material seco da parte aérea $\left(\mathrm{g}\right.$ vaso $^{-1}$ ) observada quatro semanas após a emergência.

\begin{tabular}{|c|c|c|c|c|c|c|c|c|c|c|c|}
\hline \multirow{3}{*}{$\begin{array}{c}\mathrm{P}_{2} \mathrm{O}_{5} \\
\mathrm{mg} \mathrm{kg}^{-1}\end{array}$} & \multirow{2}{*}{\multicolumn{5}{|c|}{$\frac{\text { IAC-8 }}{\mathrm{N}\left(\mathrm{mg} \mathrm{kg}^{-1}\right)}$}} & \multirow{2}{*}{\multicolumn{5}{|c|}{$\frac{\mathrm{IAC}-14}{\mathrm{~N}\left(\mathrm{mg} \mathrm{kg}^{-1}\right)}$}} & \multirow{3}{*}{$\begin{array}{c}\text { média } \\
\text { geral }\end{array}$} \\
\hline & & & & & & & & & & & \\
\hline & 0 & 5,7 & 11,4 & 17,1 & média & 0 & 5,7 & 11,4 & 17,1 & média & \\
\hline 15,2 & 3,87 & 3,20 & 2,56 & 2,95 & 3,15 & 1,60 & 1,76 & 1,46 & 1,44 & 1,57 & 2,38 \\
\hline 22,7 & 3,89 & 2,87 & 2,86 & 3,72 & 3,34 & 2,47 & 1,96 & 2,02 & 1,91 & 2,09 & 2,71 \\
\hline 30,3 & 4,21 & 3,98 & 3,43 & 3,99 & 3,90 & 2,18 & 1,92 & 1,84 & 1,87 & 1,95 & 2,93 \\
\hline média & 3,99 & 3,35 & 2,95 & 3,55 & 3,46 & 2,08 & 1,97 & 1,77 & 1,74 & 1,89 & \\
\hline \multicolumn{6}{|c|}{ édia geral } & 3.04 & 2,66 & 2,36 & 2,65 & & 2,68 \\
\hline
\end{tabular}

Os dados da massa de material seco das raízes (Tabela 15) apresentaram efeitos significativos (Teste F) para os fatores cultivar, dose de nitrogênio e dose de fósforo.

Tabela 15 - Massa de material seco das raízes $\left(\mathrm{g} \mathrm{vaso}^{-1}\right.$ ) observada quatro semanas após a emergência.

\begin{tabular}{|c|c|c|c|c|c|c|c|c|c|c|c|}
\hline \multirow{3}{*}{$\begin{array}{c}\mathrm{P}_{2} \mathrm{O}_{5} \\
\mathrm{mg} \mathrm{kg}^{-1}\end{array}$} & \multirow{2}{*}{\multicolumn{5}{|c|}{$\frac{\text { IAC-8 }}{\mathrm{N}\left(\mathrm{mg} \mathrm{kg}^{-1}\right)}$}} & \multirow{2}{*}{\multicolumn{5}{|c|}{$\frac{\mathrm{IAC}-14}{\mathrm{~N}\left(\mathrm{mg} \mathrm{kg}^{-1}\right)}$}} & \multirow{3}{*}{$\begin{array}{c}\text { média } \\
\text { geral }\end{array}$} \\
\hline & & & & & & & & & & & \\
\hline & 0 & 5,7 & 11,4 & 17,1 & média & 0 & 5,7 & 11,4 & 17,1 & média & \\
\hline 15,2 & 2,00 & 1,70 & 1,46 & 1,69 & 1,71 & 1,37 & 1,41 & 1,16 & 1,34 & 1,32 & 1,52 \\
\hline 22,7 & 2,26 & 1,60 & 1,91 & 2,73 & 2,13 & 2,58 & 1,68 & 2,07 & 1,92 & 2,06 & 2,09 \\
\hline 30,3 & 2,24 & 2,22 & 2,19 & 2,79 & 2,36 & 1,85 & 1,47 & 1,66 & 1,84 & 1,71 & 2,03 \\
\hline média & 2,17 & 1,84 & 1,85 & 2,40 & 2,07 & 1,93 & 1,52 & 1,63 & 1,70 & 1,70 & \\
\hline \multicolumn{6}{|l|}{ média } & 2,05 & 1,68 & 1,74 & 2,05 & & 1,88 \\
\hline
\end{tabular}

Os efeitos dos fatores cultivar, dose de nitrogênio e dose de fósforo, além da interação entre os fatores cultivar e dose de fósforo sobre a massa de material seco total das plantas (Tabela 16) foram estatísticamente significativos (Teste F). 
Tabela 16 - Massa de material seco total das plantas ( $\mathrm{g} \mathrm{vaso}^{-1}$ ) observada quatro semanas após a emergência.

\begin{tabular}{|c|c|c|c|c|c|c|c|c|c|c|c|}
\hline \multirow{3}{*}{$\begin{array}{c}\mathrm{P}_{2} \mathrm{O}_{5} \\
\mathrm{mg} \mathrm{kg}^{-1}\end{array}$} & \multicolumn{5}{|c|}{ IAC-8 } & \multicolumn{5}{|c|}{ IAC-14 } & \multirow{3}{*}{$\begin{array}{c}\text { média } \\
\text { geral }\end{array}$} \\
\hline & \multicolumn{5}{|c|}{$\mathrm{N}\left(\mathrm{mg} \mathrm{kg}^{-1}\right)$} & \multicolumn{5}{|c|}{$\mathrm{N}\left(\mathrm{mg} \mathrm{kg}^{-1}\right)$} & \\
\hline & $\overline{0}$ & 5,7 & 11,4 & 17,1 & média & 0 & 5,7 & 11,4 & 17,1 & média & \\
\hline 15,2 & 5,92 & 4,94 & 4,06 & 4,68 & 4,90 & 2,97 & 3,18 & 2,63 & 2,79 & 2,89 & 3,90 \\
\hline 22,7 & 6,21 & 4,51 & 4,81 & 6,49 & 5,51 & 5,08 & 3,66 & 4,11 & 3,84 & 4,17 & 4,84 \\
\hline 30,3 & 6,52 & 6,23 & 5,67 & 6,83 & 6,31 & 4,06 & 3,41 & 3,51 & 3,73 & 3,68 & 4,89 \\
\hline média & 6,22 & 5,23 & 4,85 & 6,00 & 5,57 & 4,04 & 3,42 & 3,42 & 3,45 & 3,58 & \\
\hline \multicolumn{6}{|c|}{ lia geral } & 5,13 & 4,32 & 4,13 & 4,73 & & 4,58 \\
\hline
\end{tabular}

Oito semanas após a emergência, a massa de material seco da parte aérea (Tabela 17) foi influenciada significativamente (Teste F) pelos fatores cultivar, dose de nitrogênio e dose de fósforo.

Tabela 17 - Massa de material seco da parte aérea $\left(\mathrm{g} \mathrm{vaso}^{-1}\right)$ observada oito semanas após a emergência.

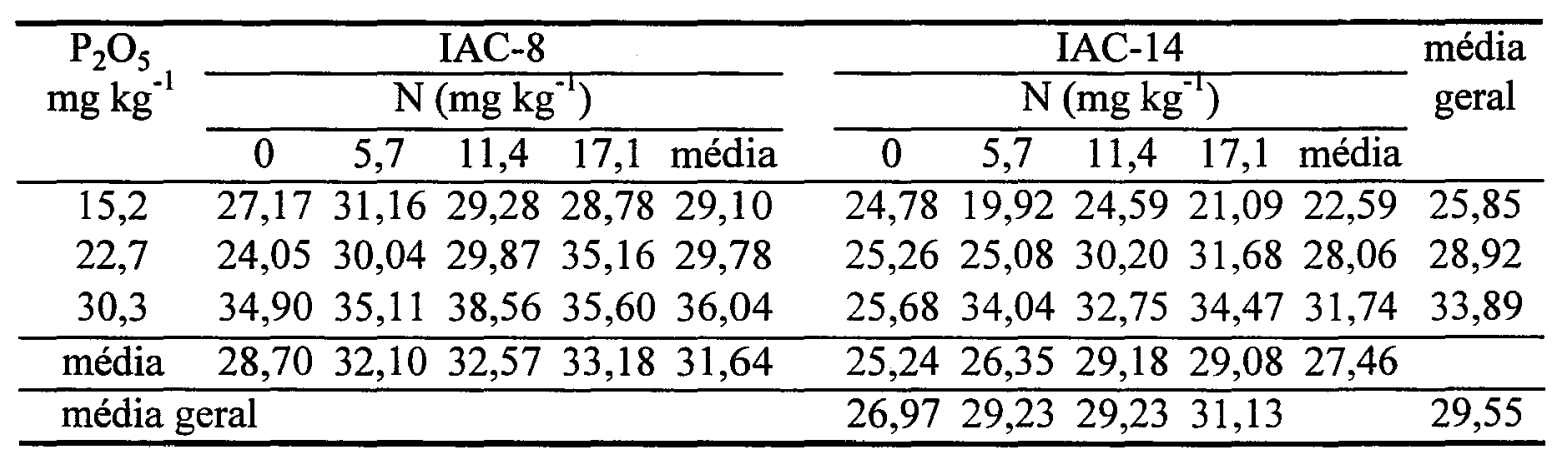

A aplicação do Teste F para a massa de material seco das raízes (Tabela 18) mostrou diferenças significativas para os fatores dose de nitrogênio e dose de fósforo e para a interação dos fatores dose de nitrogênio e dose de fósforo. 
Tabela 18 - Massa de material seco das raízes ( g vaso $^{-1}$ ) observada oito semanas após a emergência.

\begin{tabular}{|c|c|c|c|c|c|c|c|c|c|c|c|}
\hline \multirow[t]{2}{*}{$\begin{array}{c}\mathrm{P}_{2} \mathrm{O}_{5} \\
\mathrm{mg} \mathrm{kg}^{-1}\end{array}$} & \multicolumn{5}{|c|}{$\frac{\mathrm{IAC}^{-8}}{\mathrm{~N}\left(\mathrm{mg} \mathrm{kg}^{-1}\right)}$} & \multicolumn{5}{|c|}{$\frac{\mathrm{IAC}-14}{\mathrm{~N}\left(\mathrm{mg} \mathrm{kg}^{-1}\right)}$} & \multirow[t]{2}{*}{$\begin{array}{l}\text { média } \\
\text { geral }\end{array}$} \\
\hline & 0 & 5,7 & 11,4 & 17,1 & média & 0 & 5,7 & 11,4 & 17,1 & média & \\
\hline 15,2 & 8,2 & 8,5 & 9,7 & 9,5 & 9,0 & 10,1 & 7,7 & 9,0 & 7,2 & 8,5 & 8,8 \\
\hline 22,7 & 7,0 & 9,2 & 9,5 & 13,2 & 9,7 & 8,5 & 8,5 & 10,4 & 11,6 & 9,8 & 9,7 \\
\hline 30,3 & 10,8 & 10,5 & 11,5 & 11,2 & 11,0 & 9,2 & 12,0 & 10,6 & 11,9 & 10,9 & 11,0 \\
\hline média & 8,6 & 9,4 & 10,2 & 11,3 & 9,9 & $\overline{9,3}$ & 9,4 & 10,0 & 10,3 & 9,7 & \\
\hline \multicolumn{2}{|l|}{ média } & & & & & $\overline{9,0}$ & 9,4 & 10,1 & 10,8 & & 9,8 \\
\hline
\end{tabular}

Os resultados da massa de material seco total das plantas (Tabela 19) apresentaram diferenças significativas (Teste F) para os fatores cultivar, dose de $\mathrm{N} \mathrm{e}$ dose de $P$.

Tabela 19 - Massa de material seco total das plantas ( g vaso $^{-1}$ ), observada oito semanas após a emergência.

\begin{tabular}{|c|c|c|c|c|c|c|c|c|c|c|}
\hline \multirow{3}{*}{$\begin{array}{c}\mathrm{P}_{2} \mathrm{O}_{5} \\
\mathrm{mg} \mathrm{kg}^{-1}\end{array}$} & \multirow{2}{*}{\multicolumn{4}{|c|}{$\frac{\text { IAC-8 }}{\mathrm{N}\left(\mathrm{mg} \mathrm{kg}^{-1}\right)}$}} & \multirow{2}{*}{\multicolumn{5}{|c|}{$\frac{\text { IAC-14 }}{\mathrm{N}\left(\mathrm{mg} \mathrm{kg}^{-1}\right)}$}} & \multirow{3}{*}{$\begin{array}{l}\text { média } \\
\text { geral }\end{array}$} \\
\hline & & & & & & & & & & \\
\hline & 0 & 5,7 & 11,4 & 17,1 média & $\overline{0}$ & 5,7 & 11,4 & 17,1 & média & \\
\hline 15,2 & 36,24 & 40,78 & 40,06 & $38,98 \quad 39,02$ & 35,93 & 28,31 & 34,37 & 28,90 & 31,88 & 35,45 \\
\hline 22,7 & 31,81 & 40,36 & 40,24 & $49,42 \quad 40,46$ & 34,79 & 34,52 & 41,71 & 44,53 & 38,89 & 39,67 \\
\hline 30,3 & 47,11 & 47,05 & 51,38 & $\begin{array}{lll}47,93 & 48,37\end{array}$ & 36,11 & 47,61 & 44,69 & 47,65 & 44,01 & 46,19 \\
\hline média & 38,39 & 42,73 & 43,89 & $45,44 \quad 42,61$ & 35,61 & 36,81 & 40,26 & 40,36 & 38,26 & \\
\hline média & eral & & & & 37,00 & 39,77 & 42,07 & 42,90 & & 40,44 \\
\hline
\end{tabular}

\subsubsection{Efeito do fator cultivar}

Os cultivares IAC-8 e IAC-14 possuem ciclo de crescimento diferenciados, que determinam o desenvolvimento dessas plantas. Esse fato foi comprovado pelas diferenças significativas, comprovadas pelo Teste Tukey, observadas para a massa de material seco da parte aérea, das raízes e total das plantas, quatro semanas após a emergência (Figura 5). 


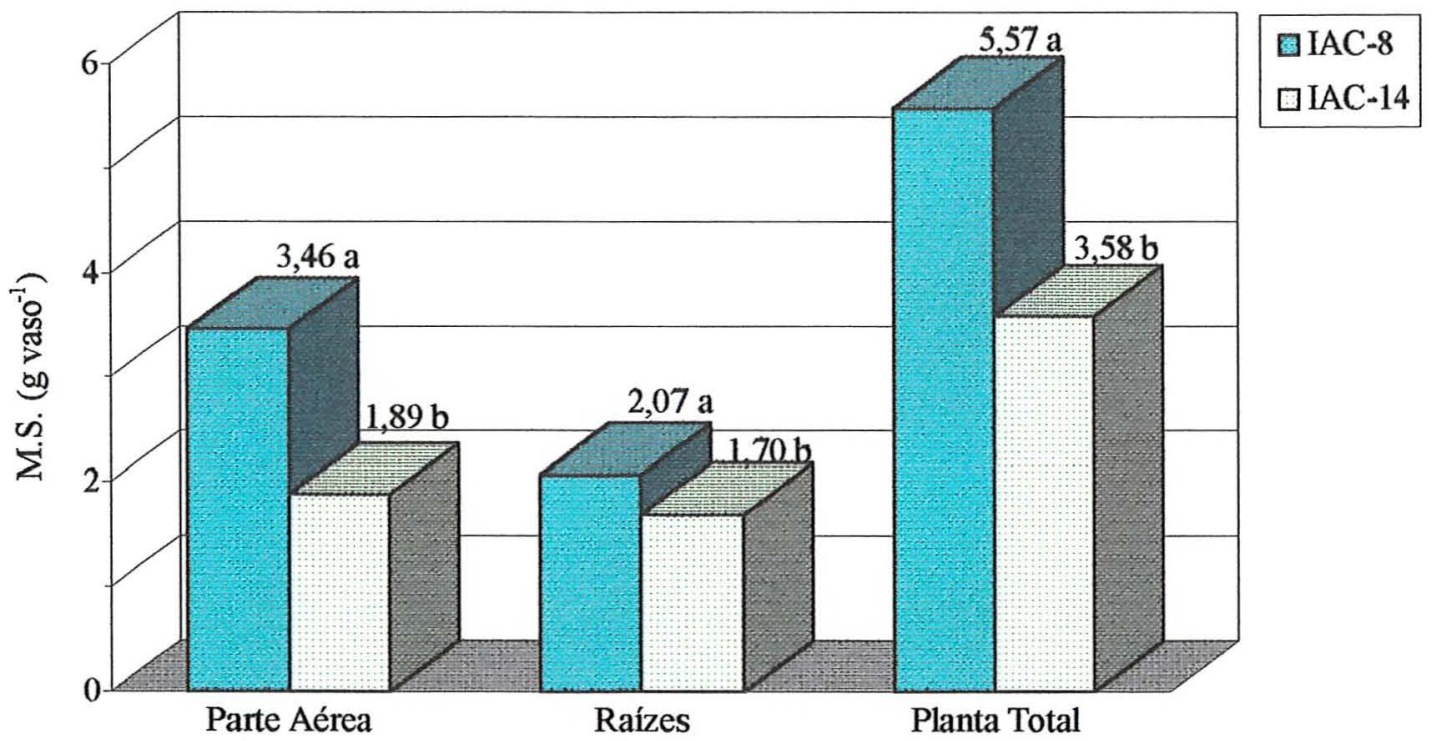

Figura 5 - Massa de material seco da parte aérea, das raízes e total das plantas dos cultivares IAC-8 e IAC-14, observadas quatro semanas após a emergência (médias de 36 vasos).

O cultivar IAC-8 produziu uma massa de material seco da parte aérea $85 \%$ maior que a do "IAC-14". Os resultados dos cultivares referentes à massa de material seco das raízes apresentaram uma diferença de $22 \%$, tendo o cultivar IAC- 8 produzido uma massa maior que a do "IAC-14", confirmando seu maior crescimento nesse período inicial até a primeira avaliação.

O cultivar IAC-8 apresentou uma produção maior que a massa de material seco total das plantas do cv. IAC-14 em todos os níveis de $\mathrm{P}$, porém, as maiores diferenças ocorreram para a maior e a menor dose de fósforo.

O cultivar IAC-8 apresentou um crescimento inicial mais rápido que o cv. IAC14, formando plântulas vigorosas em menor tempo. Esse aspecto deve ter sua importância considerada em condições de cultivo no campo, pois o desenvolvimento das raízes pode garantir para esse cultivar uma maior capacidade de suporte nutricional e resistência ao estresse hídrico nessa época inicial, e o desenvolvimento da parte aérea 
pode aumentar a competitividade com o mato, reduzindo o período de infestação, já que promove uma cobertura mais rápida do solo.

O maior crescimento do cultivar IAC-8, nas primeiras quatro semanas após a emergência, não foi observado ao final das oito semanas após a emergência. Nessa época, a massa de material seco das raízes foi equivalente para os dois cultivares. As massas de material seco da parte aérea e total do cv. IAC-8 foram respectivamente 15 e $11 \%$ maiores que as "IAC-14", um valor significativamente diferente (Teste Tukey). No entanto, a diferença entre os cultivares foi reduzida em relação à primeira avaliação, quatro semanas após a emergência (Figura 6).

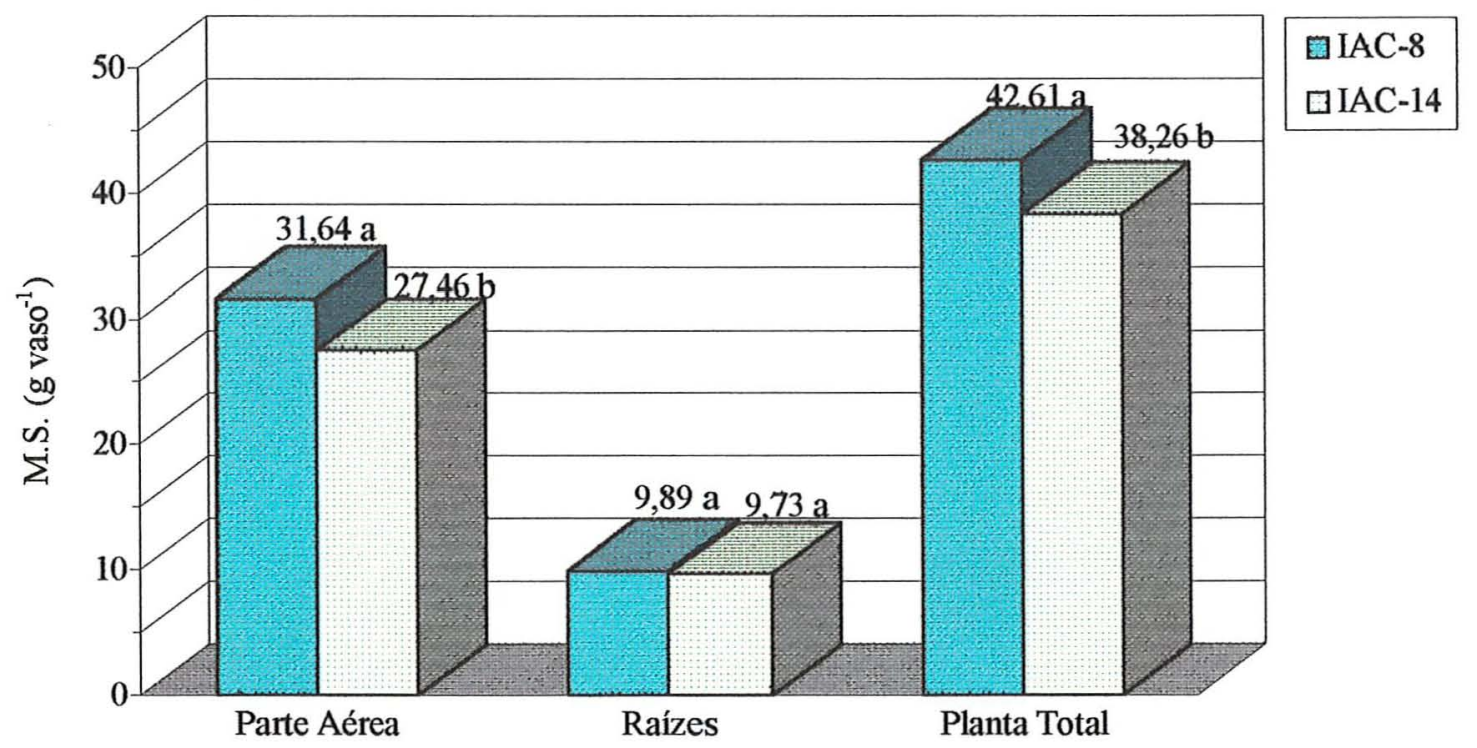

Figura 6 - Massa de material seco da parte aérea, das raízes e total das plantas dos cultivares IAC-8 e IAC-14, observadas oito semanas após a emergência (médias de 36 vasos).

O cultivar IAC-14 teve um maior crescimento nesse segundo período, o que garantiu a sua recuperação. Como a massa de material seco das raízes foi semelhante, a capacidade de fornecimento de nutrientes foi equivalente para os dois cultivares, no início da fase reprodutiva. 


\subsubsection{Efeito do fator dose de nitrogênio}

A produção de material seco, quatro semanas após a emergência, foi reduzida significativamente em todas as partes da planta com o aumento das doses de nitrogênio (Figura 7)

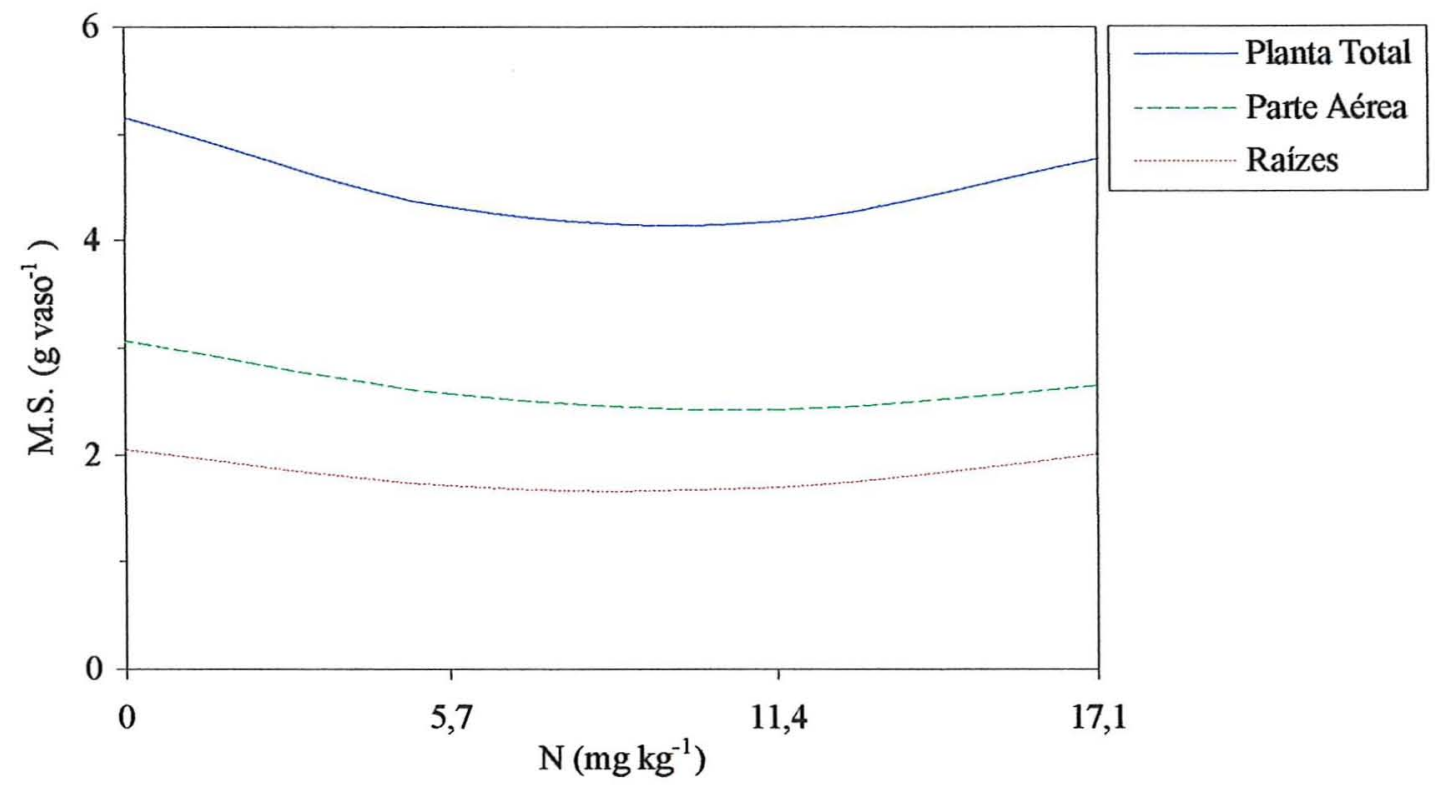

\begin{tabular}{|l|l|l|}
\hline Planta Total & $\mathrm{Y}=0,011 \mathrm{X}^{2}-0,21 \mathrm{X}+5,14$ & $\mathrm{R}^{2}=83,24 \% ; \mathrm{CV} \%=31,27$ \\
\hline Parte Aérea & $\mathrm{Y}=0,01 \mathrm{X}^{2}-0,12 \mathrm{X}+3,06$ & $\mathrm{R}^{2}=53,94 \% ; \mathrm{CV} \%=37,10$ \\
\hline Raízes & $\mathrm{Y}=0,01 \mathrm{X}^{2}-0,09 \mathrm{X}+2,04$ & $\mathrm{R}^{2}=98,30 \% ; \mathrm{CV} \%=30,72$ \\
\hline
\end{tabular}

Figura 7 - Massa de material seco das raízes, da parte aérea e total das plantas em função do fator dose de nitrogênio, observadas quatro semanas após a emergência (médias de 18 vasos).

Esse resultado deve ter sido obtido em função das quantidades de $\mathrm{N}$ absorvidas pelas raízes das plantas que receberam adubação nitrogenada, terem sido inferiores às quantidades de $\mathrm{N}$ fixado, reduzidas pela inibição da nodulação. Entretanto, Harper (1974) verificou um aumento na fixação simbiótica de $\mathrm{N}_{2}$ e com isso um maior desenvolvimento das plântulas na presença de níveis baixos de nitrato. 
A resposta em crescimento da massa de material seco da parte aérea à aplicação de N-mineral correspondeu a uma equação quadrática, na primeira avaliação, quatro semanas após a emergência. A maior massa foi obtida pelo tratamento em que não se aplicou $\mathrm{N}$ e a tendência foi de uma redução equivalente para as doses 5,7 e $17,1 \mathrm{mg} \mathrm{kg}^{-1}$ de $\mathrm{N}$. Neste caso, o maior fornecimento de $\mathrm{N}$ mineral compensou em parte o efeito de 3inibição da nodulação. A dose $11,4 \mathrm{mg} \mathrm{kg}^{-1}$ de $\mathrm{N}$ proporcionou um certo nível de inibição na nodulação e não forneceu $\mathrm{N}$-mineral suficiente, produzindo assim, uma menor quantidade de massa de material seco da parte aérea. Pela equação de regressão, o ponto de mínimo da curva dar-se-ia em $10,7 \mathrm{mg} \mathrm{kg}^{-1}$ de $\mathrm{N}$.

A resposta à aplicação de nitrogênio correspondeu a uma função quadrática para a massa de material seco das raízes. As menores doses de $\mathrm{N}$ apresentaram uma redução no crescimento das raizes.

Para a massa de material vegetal total, assim como para a da parte aérea, o tratamento no qual não foi aplicado $\mathrm{N}$ produziu a maior massa, quatro semanas após a emergência, seguidos dos tratamentos 5,$7 ; 17,1$ e $11,4 \mathrm{mg} \mathrm{kg}^{-1}$ de N.

A aplicação das doses de nitrogênio evidenciou um comportamento das plantas, oito semanas após a germinação, diferente da $1^{\underline{a}}$ avaliação, pois observou-se um crescimento linear da massa de material seco da parte aérea, raízes e total das plantas (Figura 8). A aplicação de nitrogênio na semeadura apresentou, portanto, influência benéfica sobre o crescimento das plantas no final do ciclo vegetativo, apesar desta não ter sido verificada até as primeiras quatro semanas após a emergência. A resposta às doses de nitrogênio proporcionaram aumento da produção da massa de material seco total entre 7 e $15 \%$. 


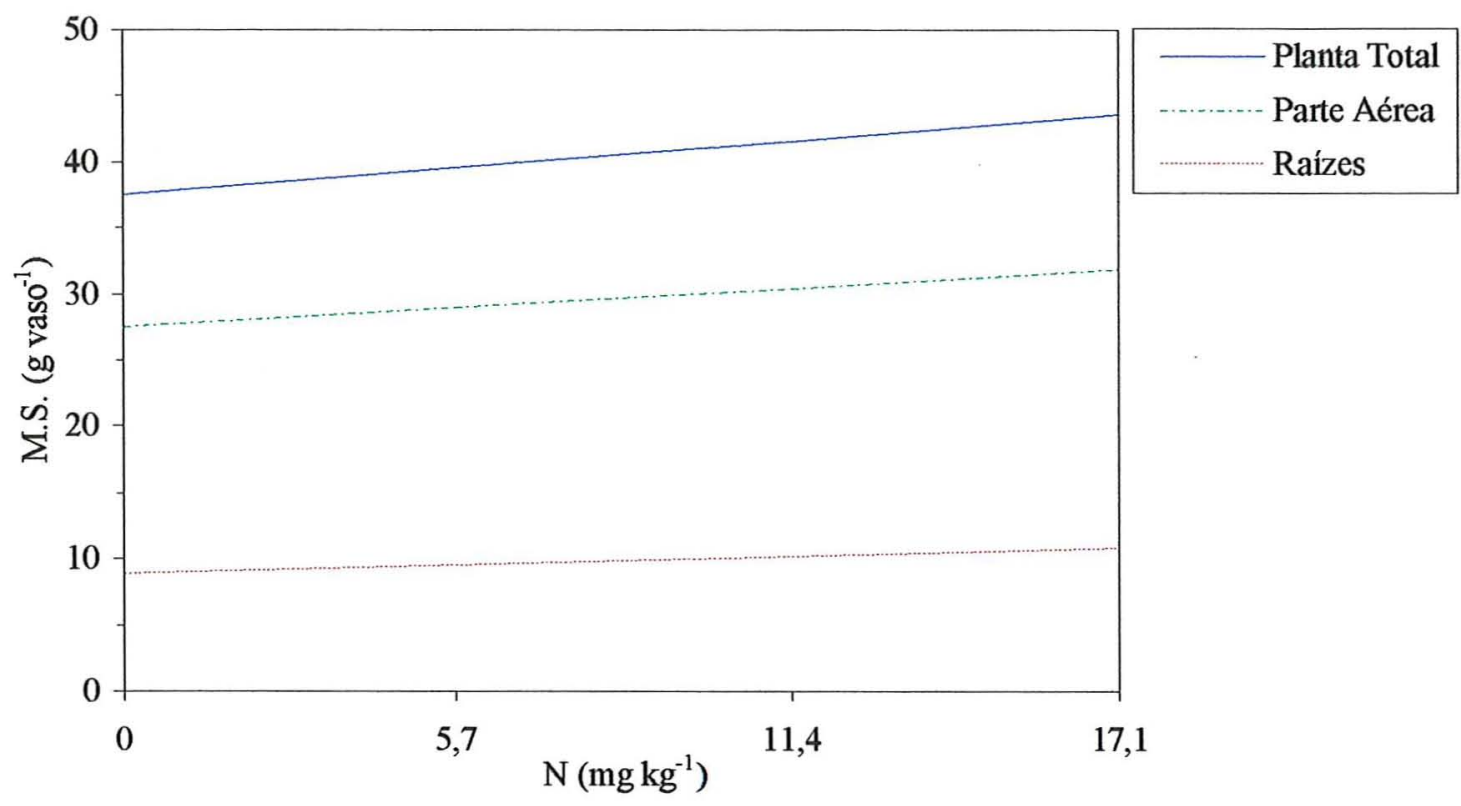

\begin{tabular}{|l|l|l|}
\hline Planta Total & $\mathrm{Y}=0,35 \mathrm{X}+37,4$ & $\mathrm{R}^{2}=95,25 \% ; \mathrm{CV} \%=19,69$ \\
\hline Parte Aérea & $\mathrm{Y}=0,25 \mathrm{X}+27,4$ & $\mathrm{R}^{2}=90,67 \% ; \mathrm{CV} \%=20,07$ \\
\hline Raízes & $\mathrm{Y}=0,11 \mathrm{X}+8,9$ & $\mathrm{R}^{2}=99,29 \% ; \mathrm{CV} \%=22,09$ \\
\hline
\end{tabular}

Figura 8 - Massa de material seco das raízes, da parte aérea e total das plantas, em função do fator dose de nitrogênio, observadas as oito semanas após a emergência (médias de 18 vasos).

A menor quantidade de nitrogênio aplicada produziu um aumento de $8 \%$ na massa de material seco da parte aérea sobre o tratamento não adubado. Essa recuperação aconteceu também para a massa de material seco das raizes, porém, foi significativa somente para o nível $22,7 \mathrm{mg} \mathrm{kg}^{-1}$ do fator dose de fósforo e foi devida a um maior crescimento do número e da massa de material seco dos nódulos, que ocorreram concomitantemente, aumentando o fornecimento de N. A aplicação de pequenas quantidades de nitrogênio promoveu um atraso na nodulação e no crescimento das plantas que, na avaliação oito semanas após a emergência, mostrou-se benéfico, pois as plantas apresentaram um maior desenvolvimento na metade final do ciclo vegetativo. 


\subsubsection{Efeito do fator dose de fósforo}

De forma diferente do fator dose de nitrogênio, as doses de fósforo aumentaram significativamente (Teste F) a massa de material seco da parte aérea, raízes e total das plantas, nas primeiras quatro semanas após a emergência (Figura 9), promovendo uma resposta linear à sua aplicação.

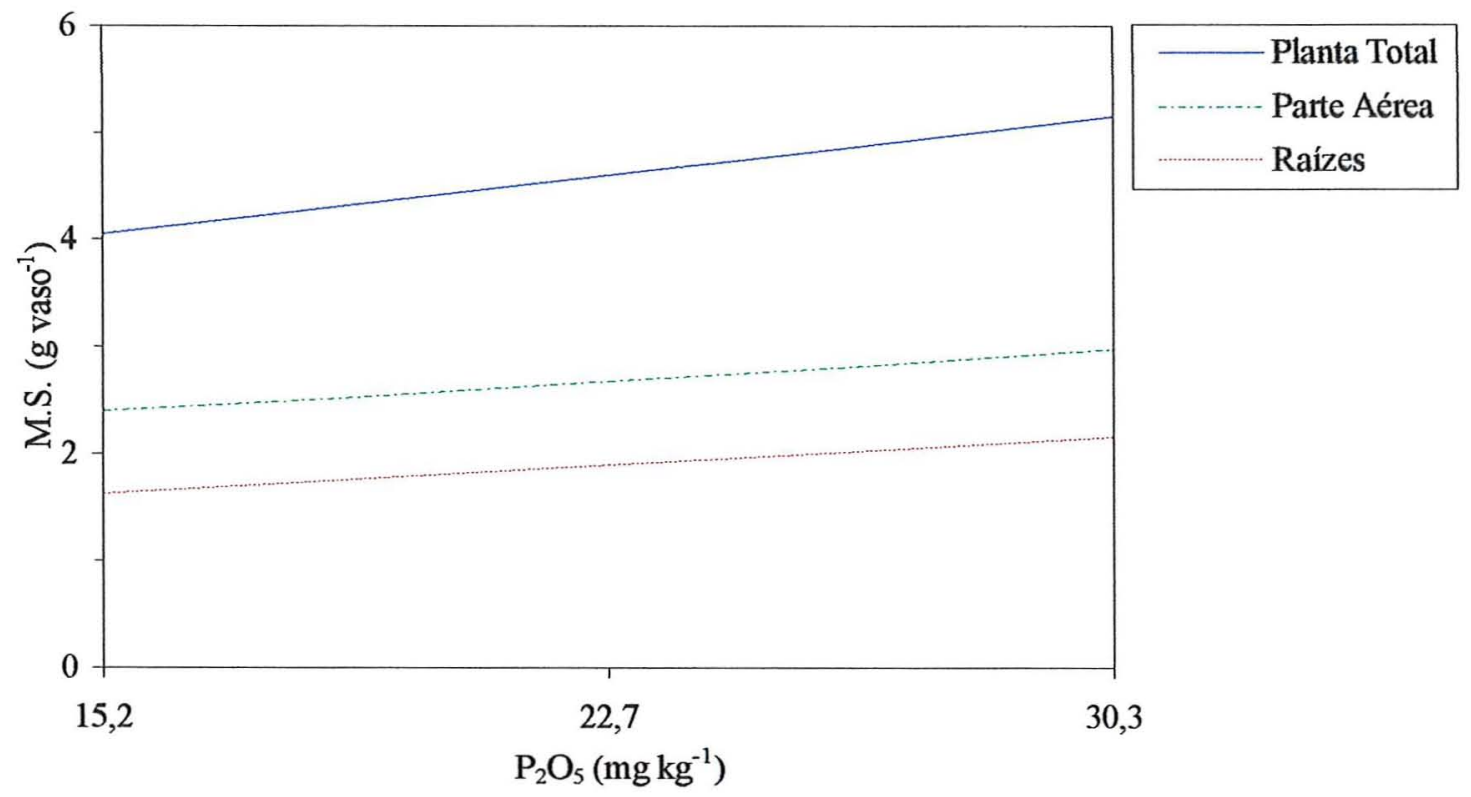

\begin{tabular}{|l|l|l|}
\hline Planta Total & $\mathrm{Y}=0,073 \mathrm{X}+2,93$ & $\mathrm{R}^{2}=85,36 \% ; \mathrm{CV} \%=30,62$ \\
\hline Parte Aérea & $\mathrm{Y}=0,04 \mathrm{X}+1,8$ & $\mathrm{R}^{2}=97,99 \% ; \mathrm{CV} \%=36,87$ \\
\hline Raízes & $\mathrm{Y}=0,03 \mathrm{X}+1,10$ & $\mathrm{R}^{2}=66,40 \% ; \mathrm{CV} \%=29,76$ \\
\hline
\end{tabular}

Figura 9 - Massa de material seco das raízes, parte aérea e total das plantas, em função do fator dose de fósforo, observadas quatro semanas após a emergência (médias de 24 vasos).

As doses de fósforo aumentaram linearmente a massa de material seco total das plantas. Esse fato foi observado para a interação com o cultivar IAC-8, porém, "IAC-14" apresentou maior produção para a dose 22,7 que para a $30,3 \mathrm{mg} \mathrm{kg}^{-1}$ de $\mathrm{P}_{2} \mathrm{O}_{5}$, resultando numa equação quadrática. 
A maior disponibilidade de fósforo no solo estimulou o desenvolvimento radicular, inclusive a formação das estruturas responsáveis pela absorção de nutrientes, os pelos radiculares, que são também a principal região de infecção do rizóbio, para a formação dos nódulos. A maior absorção de fósforo estimulou o crescimento de todas as partes das plantas, aumentando a demanda e também a produção de fotossintatos e, assim, a energia disponível para todos os processos bioquímicos, incluindo a formação e o desenvolvimento dos nódulos e a fixação de $\mathrm{N}_{2}$.

Oito semanas após a emergência, todas as partes das plantas apresentaram respostas significativas à aplicação de fósforo (Figura 10).

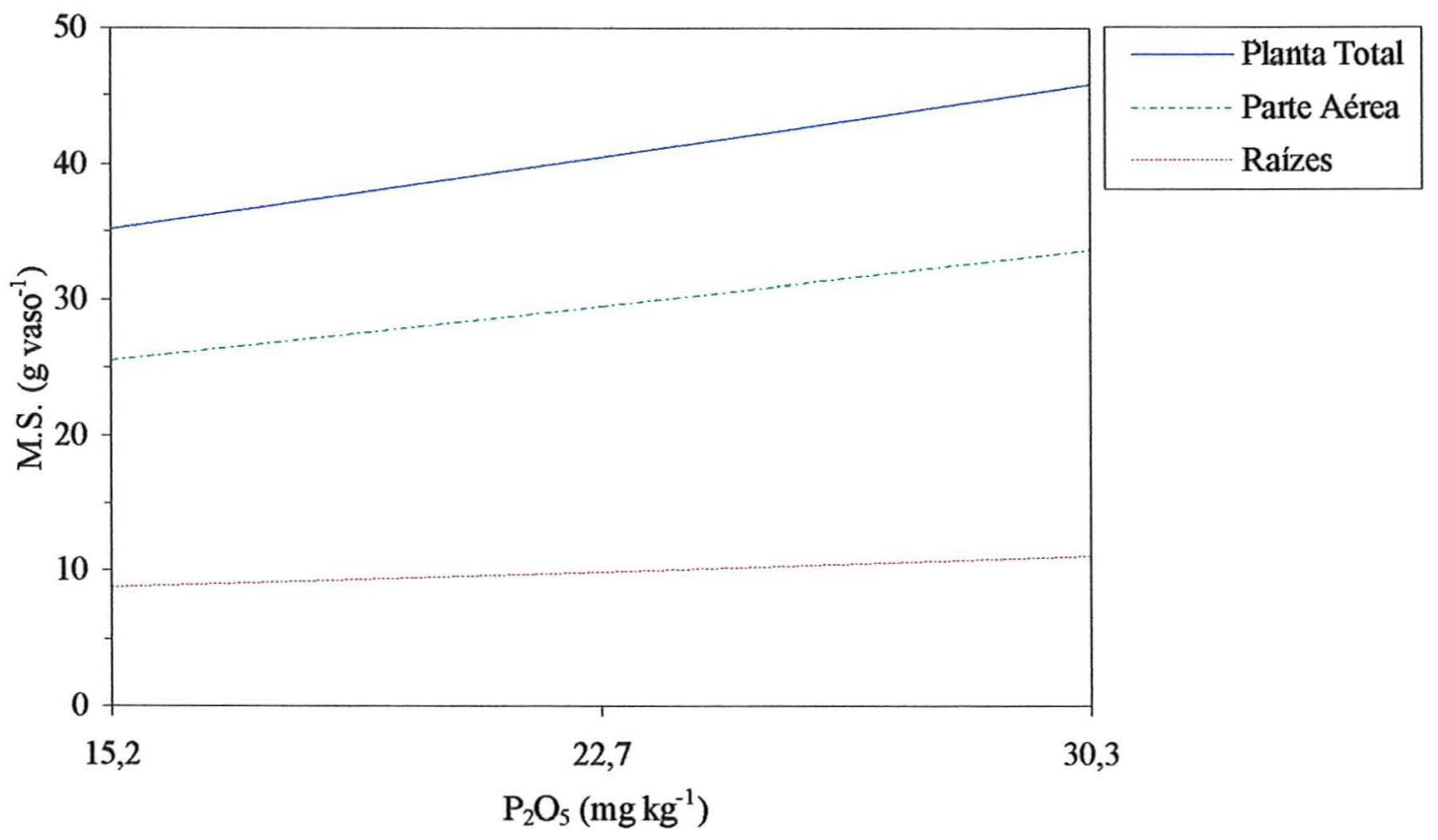

\begin{tabular}{|l|l|l|}
\hline Planta Total & $\mathrm{Y}=0,71 \mathrm{X}+24,25$ & $\mathrm{R}^{2}=98,50 \% ; \mathrm{CV} \%=17,26$ \\
\hline Parte Aérea & $\mathrm{Y}=0,53 \mathrm{X}+17,43$ & $\mathrm{R}^{2}=98,17 \% ; \mathrm{CV} \%=17,47$ \\
\hline Raízes & $\mathrm{Y}=0,15 \mathrm{X}+6,5$ & $\mathrm{R}^{2}=99,54 \% ; \mathrm{CV} \%=21,29$ \\
\hline
\end{tabular}

Figura 10 - Massa de material seco das raízes, da parte aérea e total das plantas, em função do fator dose de fósforo, observadas oito semanas após a emergência (médias de 24 vasos). 
Os efeitos significativos das doses de fósforo sobre a massa de material seco das raízes apresentaram correlação linear para os níveis 5,7 e $17,1 \mathrm{mg} \mathrm{kg}^{-1}$ do fator dose de nitrogênio. As doses de fósforo também aumentaram linearmente a produção de material seco total, mostrando respostas positivas para a soja, quando aplicado na semeadura.

Até o início do florescimento, o crescimento da parte aérea e das raízes foi significativamente linear, porém, o crescimento da parte aérea apresentou maior resposta à aplicação das doses de fósforo, verificado pelos coeficientes de inclinação das retas. $\mathrm{O}$ sistema radicular forma-se primeiramente, concentrando-se na região do solo com fósforo disponível. Um sistema radicular bem desenvolvido, ocupa um volume de solo capaz de fornecer as quantidades de nutrientes exigidos pelas plantas e promove um maior desenvolvimento da parte aérea, elevando então, a relação parte aérea/raízes. Esse aumento da relação com o período de desenvolvimento das plantas, foi acentuado com o aumento das doses de fósforo aplicadas, já que o crescimento das plantas foi também favorecido.

\section{2.4. Efeito da interação entre os fatores cultivar e dose de fósforo}

Quatro semanas após a emergência os resultados da massa de material seco total das plantas (Figura 11) apresentaram efeitos significativos (Teste F) para a aplicação das doses de fósforo nos dois cultivares estudados. 


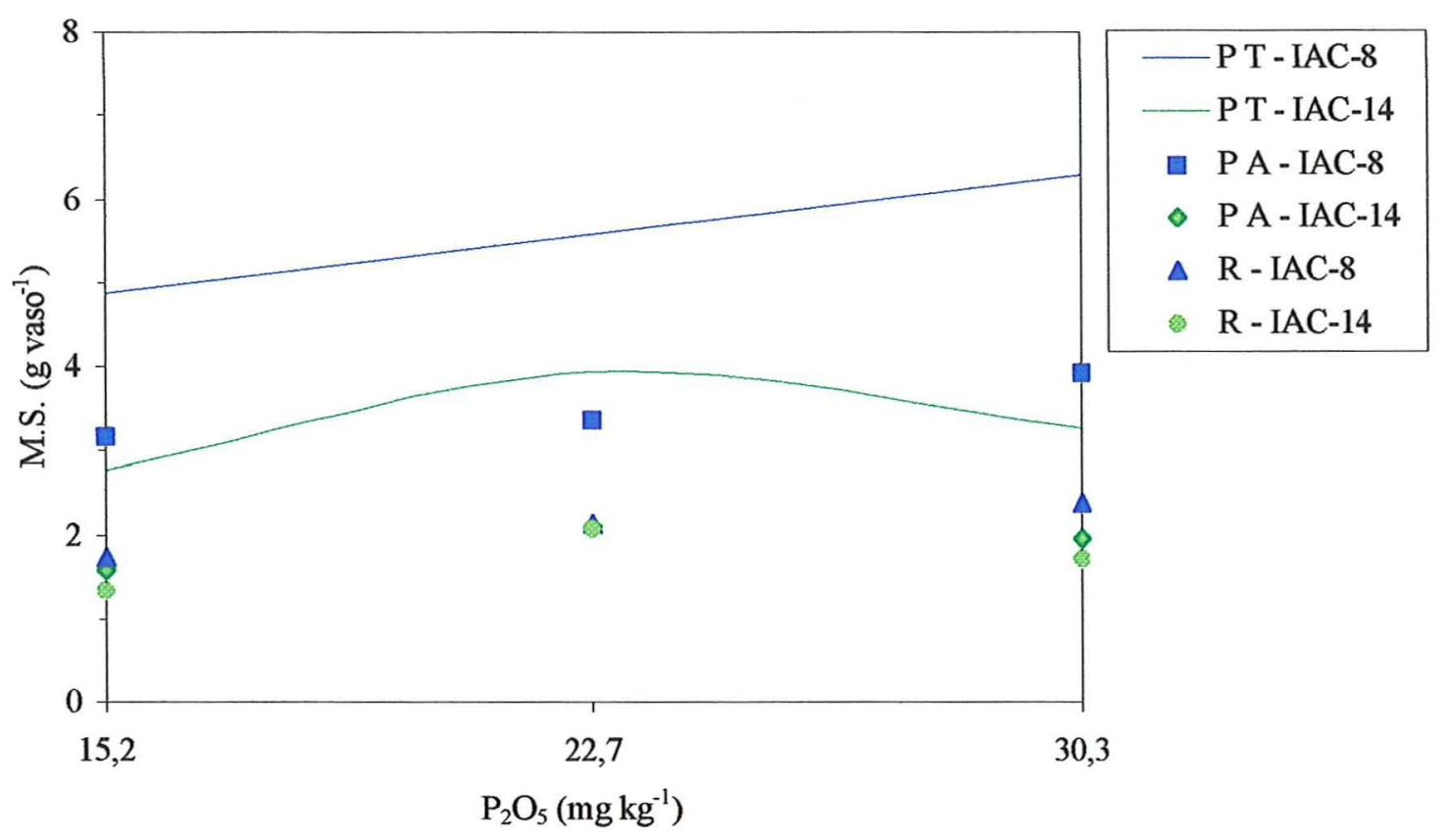

\begin{tabular}{|l|l|l|}
\hline P T- IAC-8 & $\mathrm{Y}=0,09 \mathrm{X}+3,45$ & $\mathrm{R}^{2}=99,32 \% ; \mathrm{CV} \%=18,89$ \\
\hline P T- IAC-14 & $\mathrm{Y}=-0,02 \mathrm{X}^{2}+0,76 \mathrm{X}-5,1$ & $\mathrm{R}^{2}=63,13 \% ; \mathrm{CV} \%=22,26$ \\
\hline P A- IAC-8 & não significativo & \\
\hline P A- IAC-14 & não significativo & \\
\hline R- IAC-8 & não significativo & \\
\hline R- IAC-14 & não significativo & \\
\hline
\end{tabular}

Figura 11 - Massa de material seco das raízes (R), da parte aérea (PA) e total (PT) das plantas nos cultivares IAC-8 e IAC-14, em função do fator dose de fósforo, observadas quatro semanas após a emergência (médias de 12 vasos).

A correlação entre a massa de material seco total das plantas e o cultivar IAC-8 foi positiva e ajustou-se a uma regressão linear, enquanto que a correlação com o cv. IAC-14 apresentou resposta na forma de um regressão quadrática. A Figura 11 mostra que as maiores diferenças entre os cultivares, para a massa de material seco total das plantas, foram verificadas para as doses 15,2 e $30,3 \mathrm{mg} \mathrm{kg}^{-1}$ de $\mathrm{P}_{2} \mathrm{O}_{5}$, níveis em que o desenvolvimento radicular inicial do cultivar IAC-8 foi superior ao do "IAC-14". Quando foi aplicado $15,2 \mathrm{mg} \mathrm{kg}^{-1}$ de $\mathrm{P}_{2} \mathrm{O}_{5}$, o cv. IAC-8 teve um maior aproveitamento da pequena quantidade do fósforo aplicada, enquanto que o $\mathrm{cv}$. IAC-14, que apresentou 
o desenvolvimento inicial mais lento, não teve aproveitamento equivalente (Figura 12). Por outro lado, a aplicação de $30,3 \mathrm{mg} \mathrm{kg}^{-1}$ de $\mathrm{P}_{2} \mathrm{O}_{5}$, maior dose de fósforo, contribuiu para o desenvolvimento mais rápido do cultivar IAC-8, que foi refletido na maior massa de material seco da parte aérea e, consequentemente, na maior massa de material seco total. O mesmo não foi verificado para o cultivar IAC-14, que produziu uma quantidade de massa de material seco das raízes menor do que a dose intermediária, não fazendo portanto, o aproveitamento da maior quantidade de $\mathrm{P}$ aplicada ao solo. Essa redução de crescimento foi verificada também, em menor escala para a massa de material seco da parte aérea, aumentando assim a diferença entre os cultivares para a massa de material seco total.

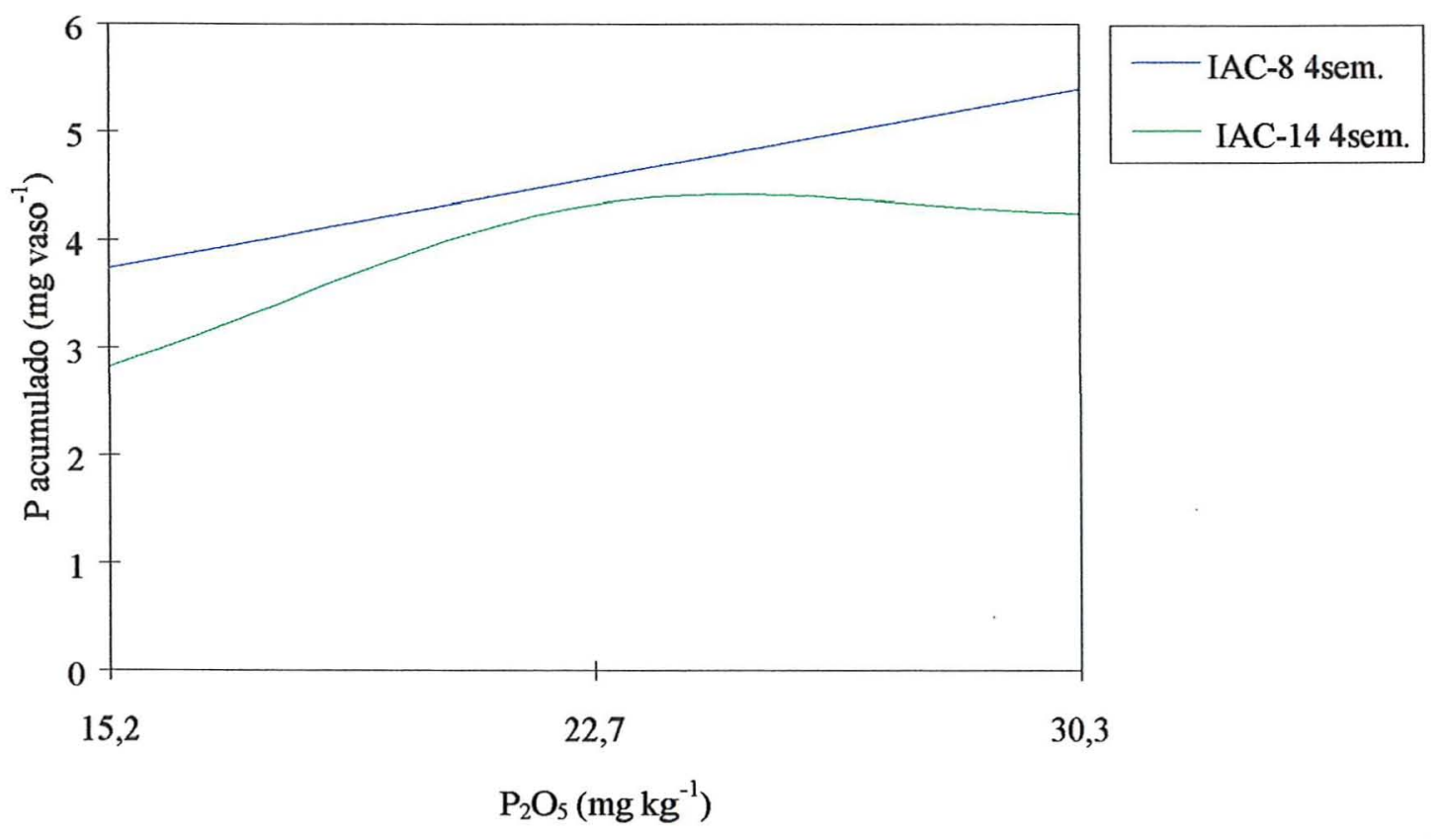

\begin{tabular}{|l|l|l|}
\hline IAC-8 4 sem. & $\mathrm{Y}=0,11 \mathrm{X}+2,06$ & $\mathrm{R}^{2}=95,52 \% ; \mathrm{CV} \%=24,80$ \\
\hline IAC-14 4 sem. & $\mathrm{Y}=-0,01 \mathrm{X}^{2}+0,73 \mathrm{X}-5,04$ & $\mathrm{R}^{2}=40,38 \% ; \mathrm{CV} \%=24,87$ \\
\hline
\end{tabular}

Figura 12 - Quantidade acumulada total de P pelas plantas nos cultivares IAC-8 e IAC14, em função do fator dose de fósforo, observadas quatro semanas após a emergência (médias de 9 vasos). 


\section{2.5. Efeito da interação entre os fatores dose de nitrogênio e dose de fósforo}

Para a massa de material seco das raízes avaliada oito semanas após a emergência, houve efeito significativo positivo (Teste F) das doses de nitrogênio, somente quando aplicou-se $22,7 \mathrm{mg} \mathrm{kg}^{-1} \mathrm{P}_{2} \mathrm{O}_{5}$ (Figura 13), sendo ajustado por uma equação linear.

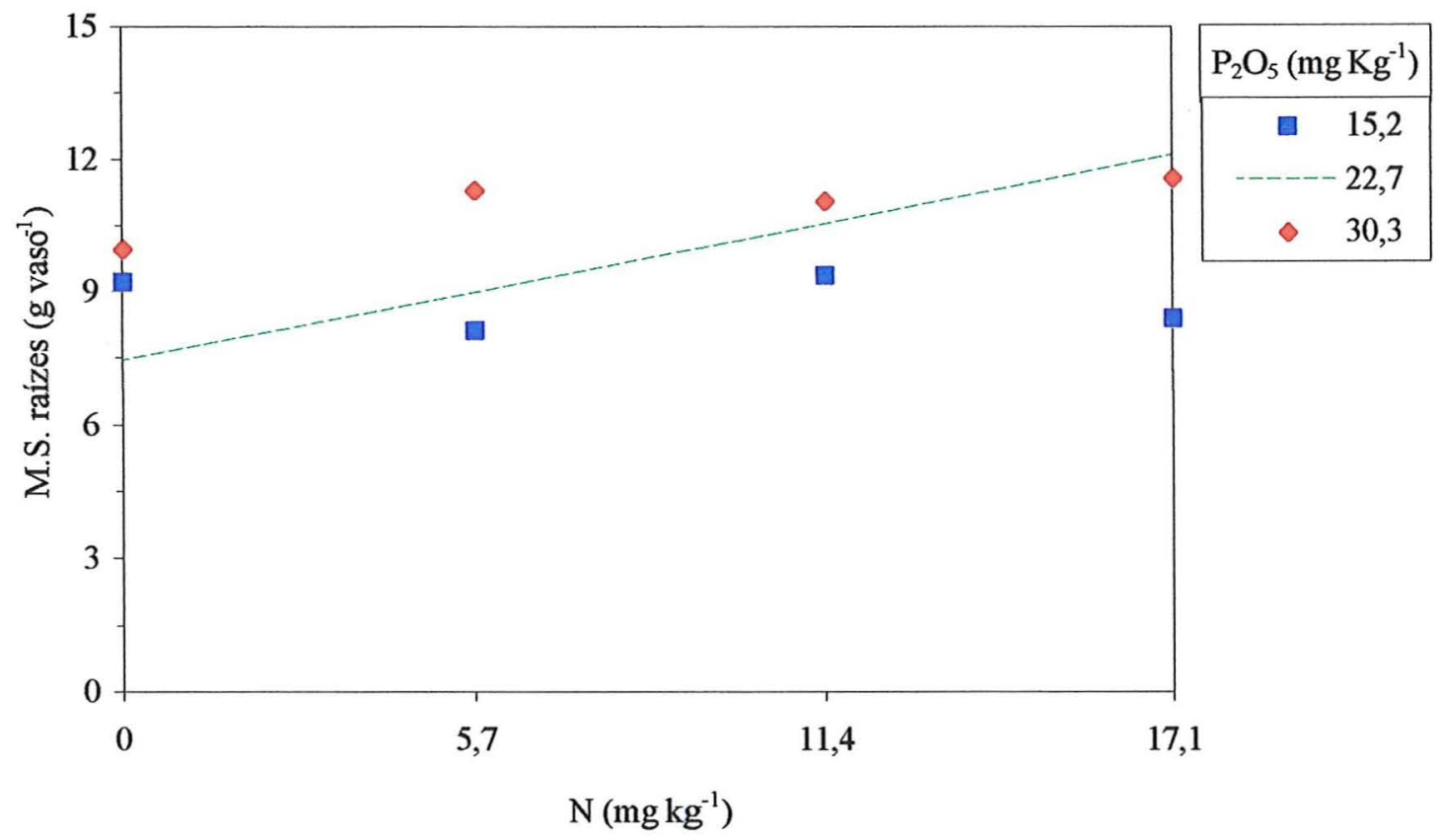

\begin{tabular}{|l|l|l|}
\hline $15,2 \mathrm{mg} \mathrm{kg}^{-1} \mathrm{P}_{2} \mathrm{O}_{5}$ & não significativo & \\
\hline $22,7 \mathrm{mg} \mathrm{kg}^{-1} \mathrm{P}_{2} \mathrm{O}_{5}$ & $\mathrm{Y}=0,27 \mathrm{X}+7,45$ & $\mathrm{R}^{2}=95,46 \% ; \mathrm{CV} \%=23,30$ \\
\hline $30,3 \mathrm{mg} \mathrm{kg}^{-1} \mathrm{P}_{2} \mathrm{O}_{5}$ & não significativo & \\
\hline
\end{tabular}

Figura 13 - Massa de material seco das raízes em cada dose de fósforo, em função do fator dose de nitrogênio, oito semanas após a emergência (médias de 6 vasos)

As doses de $\mathrm{P}$ mostraram uma tendência de aumento da massa de material seco das raízes das plantas dos tratamentos do fator dose de nitrogênio, oito semanas após a 
emergência. Contudo, esse efeito foi significativo (Teste F), apenas quando foram aplicadas as doses 5,7 e 17,1 $\mathrm{mg} \mathrm{kg}^{-1}$ de $\mathrm{N}$ (Figura 14).

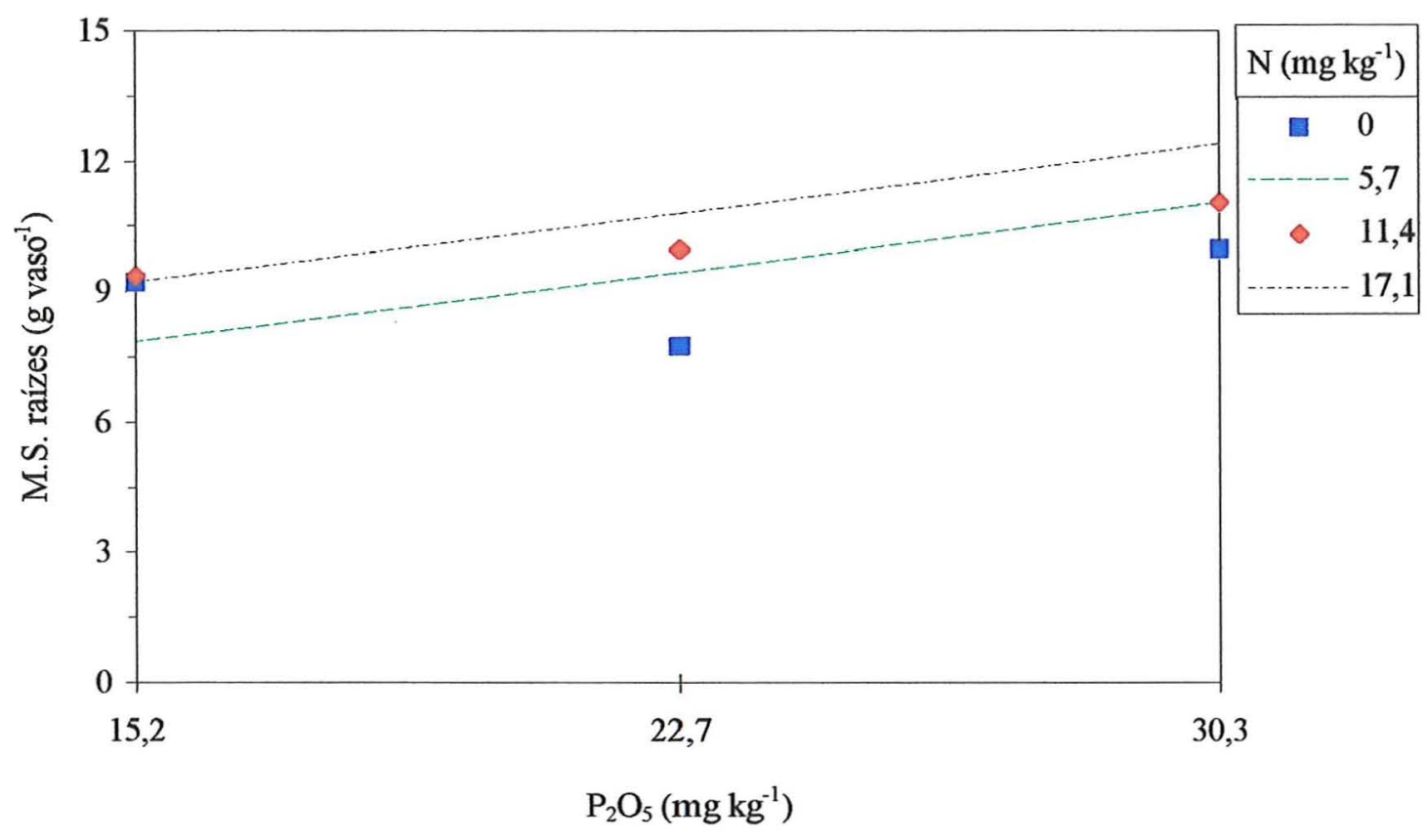

\begin{tabular}{|c|c|c|}
\hline $0 \mathrm{mg} \mathrm{kg}^{-1} \mathrm{~N}$ & não significativo & \\
\hline $5,7 \mathrm{mg} \mathrm{kg}^{-1} \mathrm{~N}$ & $\mathrm{Y}=0,21 * \mathrm{X}+4,7$ & $\mathrm{R}^{2}=91,20 \% ; \mathrm{CV} \%=18,79$ \\
\hline $11,4 \mathrm{mg} \mathrm{kg}^{-1} \mathrm{~N}$ & não significativo & \\
\hline $17,1 \mathrm{mg} \mathrm{kg}^{-1} \mathrm{~N}$ & $Y=0,21 X+6,04$ & $\mathrm{R}^{2}=55,05 \% ; \mathrm{CV} \%=22,92$ \\
\hline
\end{tabular}

Figura 14 - Massa de material seco das raízes em cada dose de nitrogênio, em função do fator dose de fósforo, observadas oito semanas após a emergência (médias de 6 vasos).

\subsection{Teores foliares e quantidade acumulada total de $\mathrm{N}$ e $\mathrm{P}$ pelas plantas}

$\mathrm{Na} 1^{\underline{a}}$ avaliação, quatro semanas após a emergência, a análise da variância (Teste $\mathrm{F}$ ) do $\mathrm{N}$ total acumulado pelas plantas (Tabela 20) mostrou os efeitos significativos dos fatores cultivar e dose de fósforo. 
Tabela $20-\mathrm{N}$ total acumulado pelas plantas $\left(\mathrm{mg} \mathrm{vaso}^{-1}\right)$ observado quatro semanas após a emergência.

\begin{tabular}{|c|c|c|c|c|c|c|c|c|c|c|}
\hline \multirow[t]{2}{*}{$\begin{array}{c}\mathrm{P}_{2} \mathrm{O}_{5} \\
\mathrm{mg} \mathrm{kg}^{-1}\end{array}$} & \multicolumn{4}{|c|}{$\frac{\text { IAC-8 }}{\mathrm{N}\left(\mathrm{mg} \mathrm{kg}^{-1}\right)}$} & \multicolumn{5}{|c|}{$\frac{\text { IAC-14 }}{\mathrm{N}\left(\mathrm{mg} \mathrm{kg}^{-1}\right)}$} & \multirow[t]{2}{*}{$\begin{array}{l}\text { média } \\
\text { geral }\end{array}$} \\
\hline & $\overline{0}$ & 5,7 & 11,4 & $\overline{17,1}$ média & $\overline{0}$ & 5,7 & 11,4 & 17,1 & média & \\
\hline 15,2 & 160,7 & 136,5 & 120,9 & $141,7 \quad 139,9$ & 81,8 & $\overline{94,8}$ & 81,8 & 78,7 & 84,3 & 112,1 \\
\hline 22,7 & 150,7 & 120,5 & 129,6 & $183,0 \quad 145,9$ & 128,1 & 98,7 & 119,9 & 111,8 & 114,6 & 130,3 \\
\hline 30,3 & 160,7 & 174,9 & 152,7 & $194,9 \quad 170,8$ & 105,0 & 104,6 & 105,3 & 110,9 & 106,5 & 138,6 \\
\hline média & 157,4 & 144,0 & 134,4 & $73,2 \quad 152,2$ & 105,0 & 99,4 & 102,3 & 100,4 & 101,8 & \\
\hline \multicolumn{5}{|c|}{ média geral } & 131,2 & 121,7 & 118,4 & 136,8 & & 127,0 \\
\hline
\end{tabular}

$\mathrm{A}$ análise do $\mathrm{P}$ total acumulado pelas plantas nessa avaliação (Tabela 21) apresentou diferenças estatísticamente significativas (Teste F) para os fatores cultivar, dose de nitrogênio e dose de fósforo, e também para a interação dos fatores cultivar e dose de fósforo.

Tabela 21 - P total acumulado pelas plantas $\left(\mathrm{mg} \mathrm{vaso}^{-1}\right)$, observado quatro semanas após a emergência.

\begin{tabular}{|c|c|c|c|c|c|c|c|c|c|c|c|}
\hline \multirow{2}{*}{$\begin{array}{c}\mathrm{P}_{2} \mathrm{O}_{5} \\
\mathrm{mg} \mathrm{kg}^{-1}\end{array}$} & \multicolumn{5}{|c|}{$\frac{\text { IAC-8 }}{\mathrm{J}^{\left(\mathrm{mg} \mathrm{kg}^{-1}\right)}}$} & \multicolumn{5}{|c|}{$\frac{\text { IAC-14 }}{\mathrm{N}\left(\mathrm{mg} \mathrm{kg}^{-1}\right)}$} & \multirow[t]{2}{*}{$\begin{array}{c}\text { média } \\
\text { geral }\end{array}$} \\
\hline & 0 & 5,7 & 11,4 & 17,1 & média & 0 & 5.7 & 11.4 & 171 & média & \\
\hline 15,2 & 4,67 & 4,15 & 2,93 & 3,71 & 3,86 & 2,43 & 2,98 & 2,64 & 2,88 & 2,73 & 3,30 \\
\hline 22,7 & 5,46 & 3,61 & 3,65 & 4,85 & 4,39 & 4,69 & 3,25 & 4,26 & 4,29 & 4,12 & 4,26 \\
\hline 30,3 & 6,05 & 4,82 & 5,28 & 6,06 & 5,55 & 3,63 & 4,14 & 3,39 & 4,35 & 3,88 & 4,71 \\
\hline média & 5,39 & 4,19 & 3,95 & 4,87 & 4,60 & 3,58 & 3,46 & 3,43 & 3,84 & 3,58 & \\
\hline \multicolumn{6}{|l|}{ média } & 4,49 & 3,82 & 3,69 & 4,36 & & 4,09 \\
\hline
\end{tabular}

$\mathrm{O}$ teor de $\mathrm{N}$ na folha diagnóstica (Tabela 22), amostrada 8 semanas após a emergência, não apresentou valor de $\mathrm{F}$ significativo para a análise de variância do modelo experimental. 
Tabela 22 - Teores de $\mathrm{N}$ na folha diagnóstica $\left(\mathrm{g} \mathrm{kg}^{-1}\right)$.

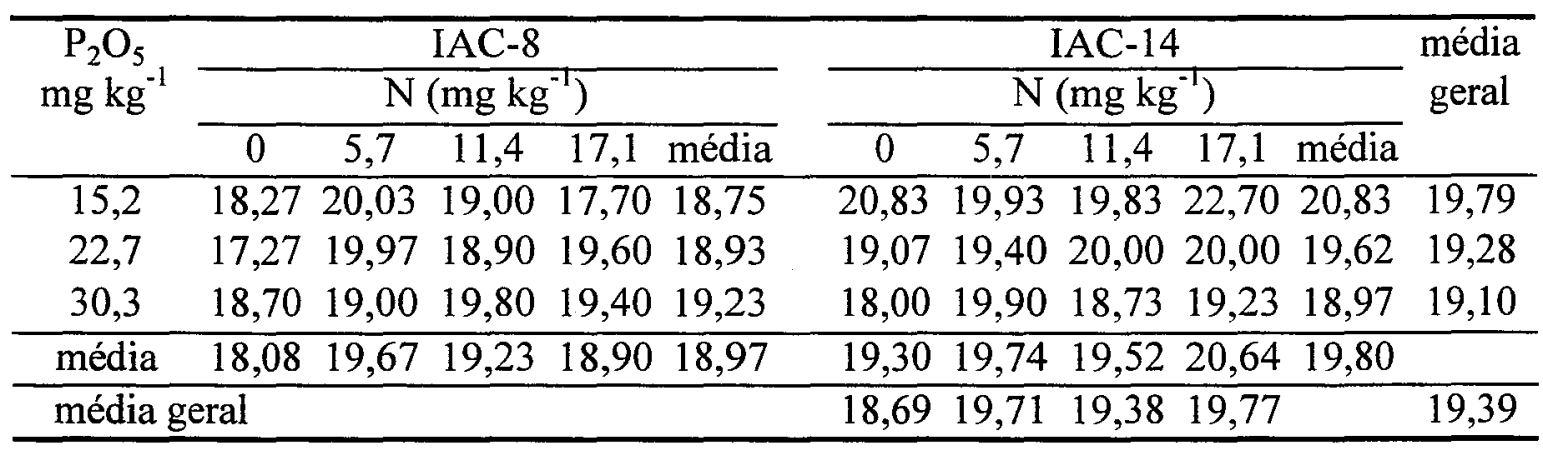

Os resultados apresentados foram bastante inferiores aos apresentados por Peck ${ }^{4}$, citado por Tanaka et al (1993), que são considerados padrões para a cultura no campo, podendo portanto, ocorrer valores menores, em condições de cultivo em vasos em casa-de-vegetação, uma vez que não foram evidenciados sintomas visuais de deficiência.

$\mathrm{A}$ análise do teor de $\mathrm{P}$ na folha diagnóstica (Tabela 23) não apresentou diferença estatísticamente significativa (Teste F) para nenhum dos fatores avaliados, mesmo para as doses de fósforo. No entanto, todos os tratamentos apresentaram também valores baixos para esse nutriente, quando comparados aos valores padrões para cultura no campo, não apresentando porém, sintomas visuais de deficiência.

Tabela 23 - Teores de P na folha diagnóstica em $\left(\mathrm{g} \mathrm{kg}^{-1}\right)$.

\begin{tabular}{|c|c|c|c|c|c|c|c|c|c|c|c|}
\hline \multirow[t]{2}{*}{$\begin{array}{c}\mathrm{P}_{2} \mathrm{O}_{5} \\
\mathrm{mg} \mathrm{kg}^{-1}\end{array}$} & \multicolumn{5}{|c|}{$\frac{\text { IAC-8 }}{\left(\mathrm{mg} \mathrm{kg}^{-1}\right)}$} & \multicolumn{5}{|c|}{$\frac{\text { IAC-14 }}{\mathrm{N}\left(\mathrm{mg} \mathrm{kg}^{-1}\right)}$} & \multirow[t]{2}{*}{$\begin{array}{c}\text { média } \\
\text { geral }\end{array}$} \\
\hline & 0 & 5,7 & 11,4 & 17,1 & média & 0 & 5,7 & 11,4 & 17,1 & $\overline{\text { média }}$ & \\
\hline 15,2 & 0,67 & 0,63 & 0,60 & 0,60 & 0,63 & 0,67 & 0,70 & 0,63 & 0,67 & 0,67 & 0,65 \\
\hline 22,7 & 0,63 & 0,70 & 0,67 & 0,63 & 0,66 & 0,67 & 0,63 & 0,70 & 0,67 & 0,67 & 0,66 \\
\hline 30,3 & 0,63 & 0,67 & 0,67 & 0,70 & 0,67 & 0,67 & 0,67 & 0,67 & 0,67 & 0,67 & 0,67 \\
\hline média & 0,64 & 0,67 & 0,64 & 0,64 & 0,65 & 0,67 & 0,67 & 0,67 & 0,67 & 0,67 & \\
\hline média g & & & & & & 0,66 & 0,67 & 0,66 & 0,66 & & 0,66 \\
\hline
\end{tabular}

\footnotetext{
${ }^{4}$ PECK, T.R. Plant analysis for production agriculture. In: SOIL PLANT ANALYST'S WORKSHOP, 7, Bridgetown, 1979. Proceedings. Bridgetown, 1979, p.1-45.
} 
$\mathrm{Na} 2^{\mathrm{a}}$ avaliação, oito semanas após a emergência, somente o fator dose de fósforo afetou significativamente a quantidade acumulada total de $\mathrm{N}$ pelas plantas (Tabela 24).

Tabela 24 - $\mathrm{N}$ total acumulado pelas plantas $\left(\mathrm{mg} \mathrm{vaso}^{-1}\right)$, observado oito semanas após a emergência.

\begin{tabular}{|c|c|c|c|c|c|c|c|c|c|c|c|}
\hline \multirow[t]{2}{*}{$\begin{array}{c}\mathrm{P}_{2} \mathrm{O}_{5} \\
\mathrm{mg} \mathrm{kg}^{-1}\end{array}$} & \multicolumn{5}{|c|}{$\frac{\text { IAC-8 }}{\mathrm{J}\left(\mathrm{mg} \mathrm{kg}^{-1}\right)}$} & \multicolumn{5}{|c|}{$\frac{\text { IAC-14 }}{N\left(\mathrm{mg} \mathrm{kg}^{-1}\right)}$} & \multirow[t]{2}{*}{$\begin{array}{c}\text { média } \\
\text { geral }\end{array}$} \\
\hline & $\overline{0}$ & 5,7 & 11,4 & 17,1 & édia & $\overline{0}$ & 5,7 & 11,4 & 17,1 & Tédia & \\
\hline 15,2 & 600,7 & 695,6 & 684,0 & 641,7 & 655,5 & 648,4 & 537,3 & 672,7 & 537,8 & 599,0 & 627,3 \\
\hline 22,7 & 533,7 & 749,5 & 682,9 & 813,1 & 694,8 & 621,8 & 571,6 & 741,7 & 831,6 & 691,7 & 693,2 \\
\hline 30,3 & 825,8 & 811,7 & 889,4 & 788,4 & 828,8 & 652,3 & 885,3 & 786,5 & 835,5 & 789,9 & 809,4 \\
\hline média & 653,4 & 752,2 & 752,1 & 747,7 & 726,4 & 640,8 & 664,8 & 733,6 & 735,0 & 693,5 & \\
\hline média & & & & & & 647,1 & 708,5 & 742,9 & 741,3 & & 710,0 \\
\hline
\end{tabular}

Os efeitos dos fatores dose de nitrogênio e dose de fósforo na quantidade acumulada total de P pelas plantas, oito semanas após a emergência (Tabela 25) foram estatísticamente significativos, evidenciados pelo Teste $\mathrm{F}$.

Tabela 25 - P total acumulado pelas plantas (mg vaso ${ }^{-1}$ ), observado oito semanas após a emergência.

\begin{tabular}{|c|c|c|c|c|c|c|c|c|c|c|c|}
\hline \multirow[t]{2}{*}{$\begin{array}{c}\mathrm{P}_{2} \mathrm{O}_{5} \\
\mathrm{mg} \mathrm{kg}^{-1}\end{array}$} & \multicolumn{5}{|c|}{$\frac{\text { IAC-8 }}{\sqrt{\left(\mathrm{mg} \mathrm{kg}^{-1}\right)}}$} & \multicolumn{5}{|c|}{$\frac{\mathrm{IAC}-14}{\mathrm{~N}\left(\mathrm{mg} \mathrm{kg}^{-1}\right)}$} & \multirow[t]{2}{*}{$\begin{array}{c}\text { média } \\
\text { geral }\end{array}$} \\
\hline & 0 & 5,7 & 11,4 & 17,1 & édia & $\overline{0}$ & 5,7 & 11,4 & 17,1 & $\overline{\text { édia }}$ & \\
\hline 15,2 & 26,45 & 28,23 & 29,14 & 27,96 & 27,94 & 28,65 & 23,23 & 28,66 & 22,95 & 25,87 & 26,91 \\
\hline 22,7 & 22,23 & 31,50 & 29,52 & 36,55 & 29,95 & 26,37 & 25,77 & 31,71 & 34,94 & 29,70 & 29,82 \\
\hline 30,3 & 35,00 & 32,73 & 37,52 & 36,18 & 35,36 & 27,90 & 36,66 & 32,88 & 36,46 & 33,47 & 34,41 \\
\hline média & 27,89 & 30,82 & 32,06 & 33,56 & 31,08 & 27,64 & 28,56 & 31,08 & 31,45 & 29,68 & \\
\hline \multicolumn{6}{|c|}{ média geral } & 27,77 & 29,69 & 31,57 & 32,50 & & 30,38 \\
\hline
\end{tabular}




\subsubsection{Efeito do fator cultivar}

Quatro semanas após a emergência, o cultivar IAC-8 extraiu 150\% do total de $\mathrm{N}$ e $129 \%$ do total de $\mathrm{P}$ acumulados por "IAC-14" (Tabela 26), devido a sua maior produção de massa de material seco, mostrando maiores diferenças da quantidade acumulada na maior e na menor dose de fósforo, sendo equivalente ao "IAC-14" na dose intermediária.

Tabela 26 - Quantidade acumulada total de $\mathrm{N}$ e de P pelas plantas dos cultivares IAC-8 e IAC-14, observadas quatro semanas após a emergência (médias de 36 vasos).

\begin{tabular}{|c|c|c|}
\hline Cultivar & $\mathrm{N}$ acumulado & $P$ acumulado \\
\hline IAC - 8 & $152 \mathrm{a}$ & $5 a$ \\
\hline IAC - 14 & $102 \mathrm{~b}$ & $4 b$ \\
\hline
\end{tabular}

Médias na vertical seguidas de letras diferentes, diferem entre si ao nível de $5 \%$ para Teste Tukey

O crescimento inicial maior do cultivar IAC-8, que proporcionou a maior quantidade acumulada de $\mathrm{N}$, pode explicar a diferença entre os cultivares, no número e na massa de material seco de nódulos formados até a quarta semana após a emergência, uma vez que o teor de $\mathrm{N}$-mineral do solo com esse cultivar deve ter se reduzido mais rapidamente até níveis não inibidores da nodulação.

A análise da folha diagnóstica e a quantidade acumulada total de $\mathrm{N}$ e de $\mathrm{P}$ durante as oito semanas após a emergência revelou um equilíbrio na nutrição entre os dois cultivares (Tabela 27). 
Tabela 27 - Teores de $\mathrm{N}$ e $\mathrm{P}$ na folha diagnóstica e quantidade acumulada total de $\mathrm{N}$ e de P pelas plantas dos cultivares IAC-8 e IAC-14, observados oito semanas após a emergência (médias de 36 vasos).

\begin{tabular}{|c|c|c|c|c|}
\hline \multirow[b]{2}{*}{ Cultivar } & \multicolumn{2}{|c|}{ Folha Diagnóstica } & \multicolumn{2}{|c|}{ Planta Total } \\
\hline & teor de N & teor de P & $\mathrm{N}$ acumulado & $\begin{array}{l}\mathrm{P} \text { acumulado } \\
\text { aso }\end{array}$ \\
\hline $\mathrm{IAC}-8$ & $18,97 \mathrm{~b}$ & $0,65 \mathrm{a}$ & $726 \mathrm{a}$ & $31 \mathrm{a}$ \\
\hline IAC - 14 & $19,80 \mathrm{a}$ & $0,67 \mathrm{a}$ & $694 a$ & $30 a$ \\
\hline
\end{tabular}

Médias na vertical seguidas de letras diferentes, diferem entre si ao nível de $5 \%$ para Teste Tukey

Os teores encontrados foram baixos, quando comparados com os apresentados pela literatura, porém nenhuma planta dos vasos apresentou sintoma de deficiência de qualquer nutriente. Além disso, as plantas apresentaram um desenvolvimento satisfatório, o que não é característico nos casos de deficiências.

O cultivar IAC-8 apresentou teor de N 4\% menor do que "IAC-14". No entanto esse valor não foi significativo, para se afirmar que o cv. IAC-14 apresentou maior eficiência na fixação de $\mathrm{N}_{2}$.

A diferença não significativa na quantidade acumulada de N entre "IAC-8" e "IAC-14" foi de 5\% a mais para o "IAC-8", mostrando a recuperação do "IAC-14". Não houve diferença na quantidade acumulada total de $\mathrm{P}$ pelas plantas para o fator cultivar, já que a massa e o teor de $\mathrm{P}$ na planta também não variaram entre os dois cultivares.

A equivalência entre os cultivares, quanto ao acúmulo de $\mathrm{N}$ e de $\mathrm{P}$, também ocorreu com a nodulação e a massa de material seco das raízes, indicando que uma nutrição adequada de $\mathrm{N}$ e de $\mathrm{P}$, no caso da soja, depende do desenvolvimento do sistema radicular e da nodulação.

\subsubsection{Efeito do fator dose de nitrogênio}

A quantidade total de $\mathrm{N}$ acumulado não apresentou diferenças significativas em função das doses de nitrogênio aplicadas, quando avaliada quatro e oito semanas após a 
germinação. No entanto, a aplicação de $\mathrm{N}$ apresentou efeitos significativos sobre a quantidade total de $\mathrm{P}$ acumulado na duas avaliações (Figura 15).

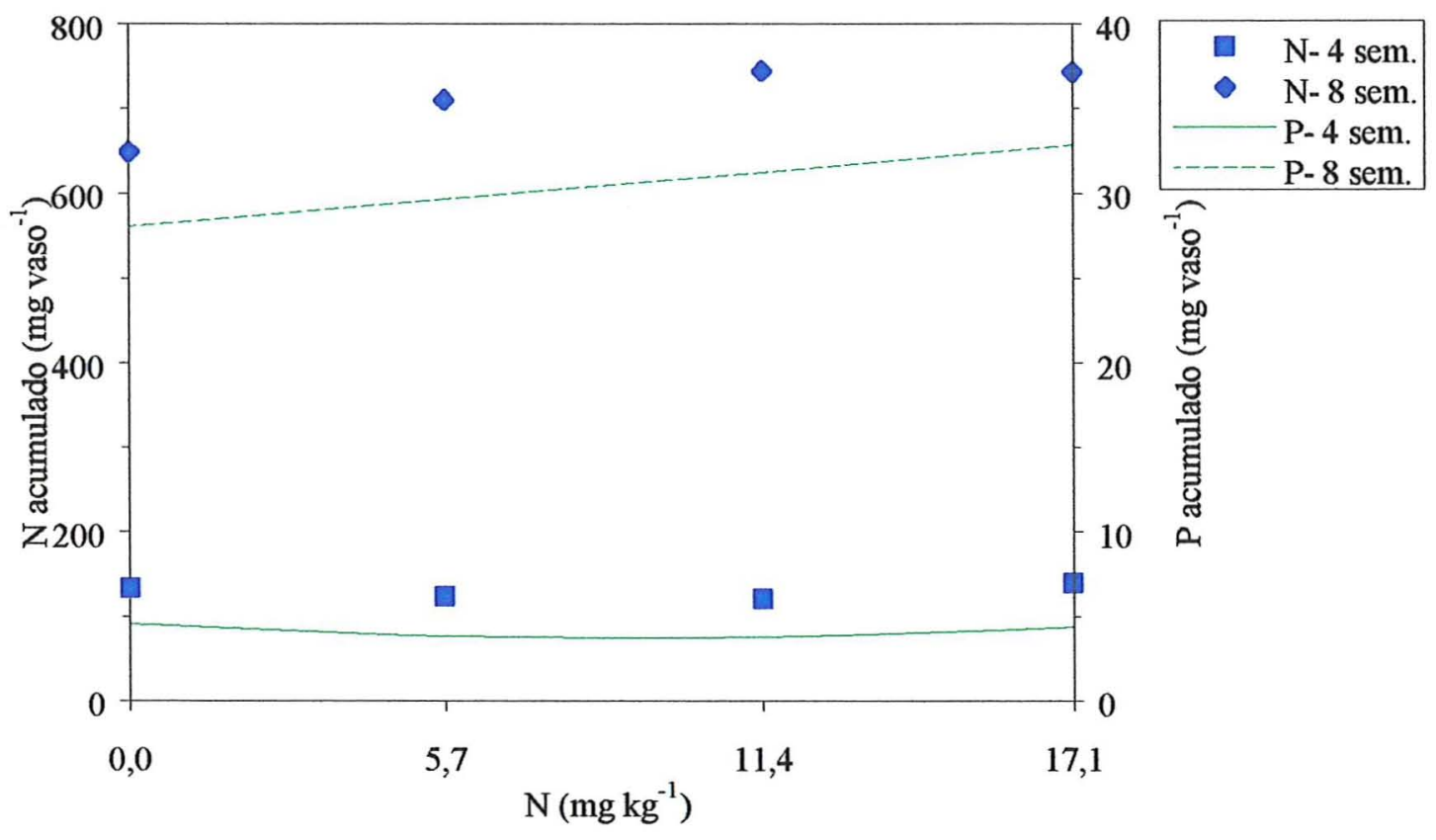

\begin{tabular}{|l|l|l|}
\hline $\mathrm{N}-4$ semanas & não significativo & \\
\hline $\mathrm{P}-4$ semanas & $\mathrm{Y}=0,01 \mathrm{X}^{2}-0,18^{*} \mathrm{X}+4,5$ & $\mathrm{R}^{2}=96,21 \% ; \mathrm{CV} \%=31,07$ \\
\hline $\mathrm{N}-8$ semanas & não significativo & \\
\hline $\mathrm{P}-8$ semanas & $\mathrm{Y}=0,28 \mathrm{X}+28$ & $\mathrm{R}^{2}=97,84 \% ; \mathrm{CV} \%=19,27$ \\
\hline
\end{tabular}

Figura 15 - Quantidade acumulada total de $\mathrm{N}$ e de $\mathrm{P}$ pelas plantas, em função do fator dose de nitrogênio, observadas quatro e oito semanas após a emergência (médias de 18 vasos).

$\mathrm{Na}$ época da primeira avaliação, apesar de não mostrar diferenças significativas, as doses de nitrogênio mostraram uma tendência de redução da fixação em relação ao tratamento em que não se aplicou $\mathrm{N}$, que apresentou em média $131,2 \mathrm{mg}$ de $\mathrm{N}$ vaso ${ }^{-1}$. Somente o tratamento $17,1 \mathrm{mg} \mathrm{kg}^{-1}$ de $\mathrm{N}$ acumulou $136,8 \mathrm{mg}$ de $\mathrm{N}$ vaso ${ }^{-1}$, uma quantidade $4 \%$ maior do que o tratamento no qual não se aplicou $\mathrm{N}$, justamente por ter sido a maior dose de $\mathrm{N}$ aplicada e assim, a única que compensou a redução do $\mathrm{N}$ fixado pelo fornecimento de $\mathrm{N}$-mineral. Os tratamentos 5,7 e $11,4 \mathrm{mg} \mathrm{kg}^{-1}$ de $\mathrm{N}$, que 
apresentaram uma quantidade de $\mathrm{N}$ total menor que o tratamento no qual não se aplicou $\mathrm{N}$-mineral, reduziram a fixação e não tiveram a quantidade acumulada de $\mathrm{N}$ compensada pela adubação.

Quatro semanas após a emergência, a quantidade de $\mathrm{P}$ acumulada pelas plantas adubadas com $\mathrm{N}$ foi reduzida em relação ao tratamento que não recebeu o nutriente na semeadura. $\mathrm{O}$ fator que contribuiu para essa redução foi o menor desenvolvimento das raízes, proporcionando um menor volume de solo explorado, o que resultou no menor acúmulo de massa de material seco total das plantas adubadas.

Não houve diferença significativa para a quantidade total de $\mathrm{N}$ acumulado oito semanas após a emergência, quanto à dose de nitrogênio aplicada, porém, desta vez, todas as doses apresentaram tendência de superação sobre o tratamento no qual não foi aplicado $\mathrm{N}$, o que pode indicar uma maior atividade dos nódulos das plantas adubadas com baixas doses de nitrogênio na semeadura, a partir do final da inibição da nodulação pelo $\mathrm{N}$ aplicado. Essa tendência pode evoluir para uma diferença significativa ao longo da fase reprodutiva, pois a formação de novos nódulos nessa fase é reduzida.

A quantidade acumulada de $\mathrm{P}$ pelas plantas foi elevada em função da aplicação de $\mathrm{N}$, da mesma forma que a massa de material seco das raízes e total das plantas, por ocasião da segunda avaliação.

A folha diagnóstica, amostrada oito semanas após a emergência, tem os teores de $\mathrm{N}$ e de $\mathrm{P}$ apresentados na Tabela 28. Nessa época, a nodulação e o sistema radicular de todos os tratamentos estavam equilibrados e dessa forma, a aplicação de $\mathrm{N}$ na semeadura, não alterou significativamente os teores de $\mathrm{N}$ e de $\mathrm{P}$ encontrados, porém, os teores de $\mathrm{N}$ apresentaram tendência de elevação, com o incremento das doses de nitrogênio. 
Tabela 28 - Teores de N e P na folha diagnóstica, em função do fator dose de nitrogênio, observados oito semanas após a emergência (médias de 18 vasos).

\begin{tabular}{ccc}
\hline $\mathrm{N}$ & teor de $\mathrm{N}$ & teor de $\mathrm{P}$ \\
$\mathrm{mg} \mathrm{kg}$ & & \\
\hline 0 & 18,69 & 0,66 \\
5,7 & 19,71 & 0,67 \\
11,4 & 19,38 & 0,66 \\
17,1 & 19,77 & 0,66 \\
\hline
\end{tabular}

\subsubsection{Efeito do fator dose de fósforo}

As quantidades totais de $\mathrm{N}$ e de $\mathrm{P}$ acumuladas pelas plantas foram elevadas significativamente, pelas doses de fósforo nas duas épocas avaliadas, em função do aumento da massa de material seco total das plantas, uma vez que os teores foram equivalentes (Figura 16).

Quatro semanas após a emergência, a resposta para a quantidade de $\mathrm{N}$ acumulada foi linear para as doses de fósforo, respondendo com aumentos de 16 e $24 \%$ sobre a menor dose para as doses 22,7 e $30,3 \mathrm{mg} \mathrm{kg}^{-1}$ de $\mathrm{P}_{2} \mathrm{O}_{5}$ respectivamente. As plantas dos cultivares IAC-8 e IAC-14 responderam à aplicação de fósforo, com aumento da quantidade acumulada. A dose $22,7 \mathrm{mg} \mathrm{kg}^{-1}$ de $\mathrm{P}_{2} \mathrm{O}_{5}$ foi a que proporcionou maior quantidade acumulada de P para o "IAC-14".

$\mathrm{Na}$ segunda avaliação, as quantidades totais de $\mathrm{N}$ e de $\mathrm{P}$ acumulados apresentaram, como na primeira, respostas lineares à aplicação de $\mathrm{P}$, porém os incrementos nas quantidades acumuladas foram maiores. A resposta ao $\mathrm{N}$ relacionou-se com a maior diferença na nodulação das plantas dos tratamentos com aplicação de $\mathrm{P}$ e a resposta ao $\mathrm{P}$ relacionou-se com o volume do sistema radicular, que estando mais desenvolvido, garantiu a exploração de um volume maior de solo, aumentando a diferença entre os tratamentos. As plantas que receberam a maior dose de $\mathrm{P}$ acumularam $129 \%$ do total das plantas do tratamento $15,2 \mathrm{mg} \mathrm{kg}^{-1}$ de $\mathrm{P}_{2} \mathrm{O}_{5}$. O incremento na quantidade de $\mathrm{P}$ fornecida foi importante para a nutrição nitrogenada das leguminosas, 
uma vez que aumentou a nodulação e a fixação simbiótica do $\mathrm{N}_{2}$ total das plantas, mantendo a quantidade fixada por grama de material seco, ou seja a concentração de $\mathrm{N}$ nas plantas.

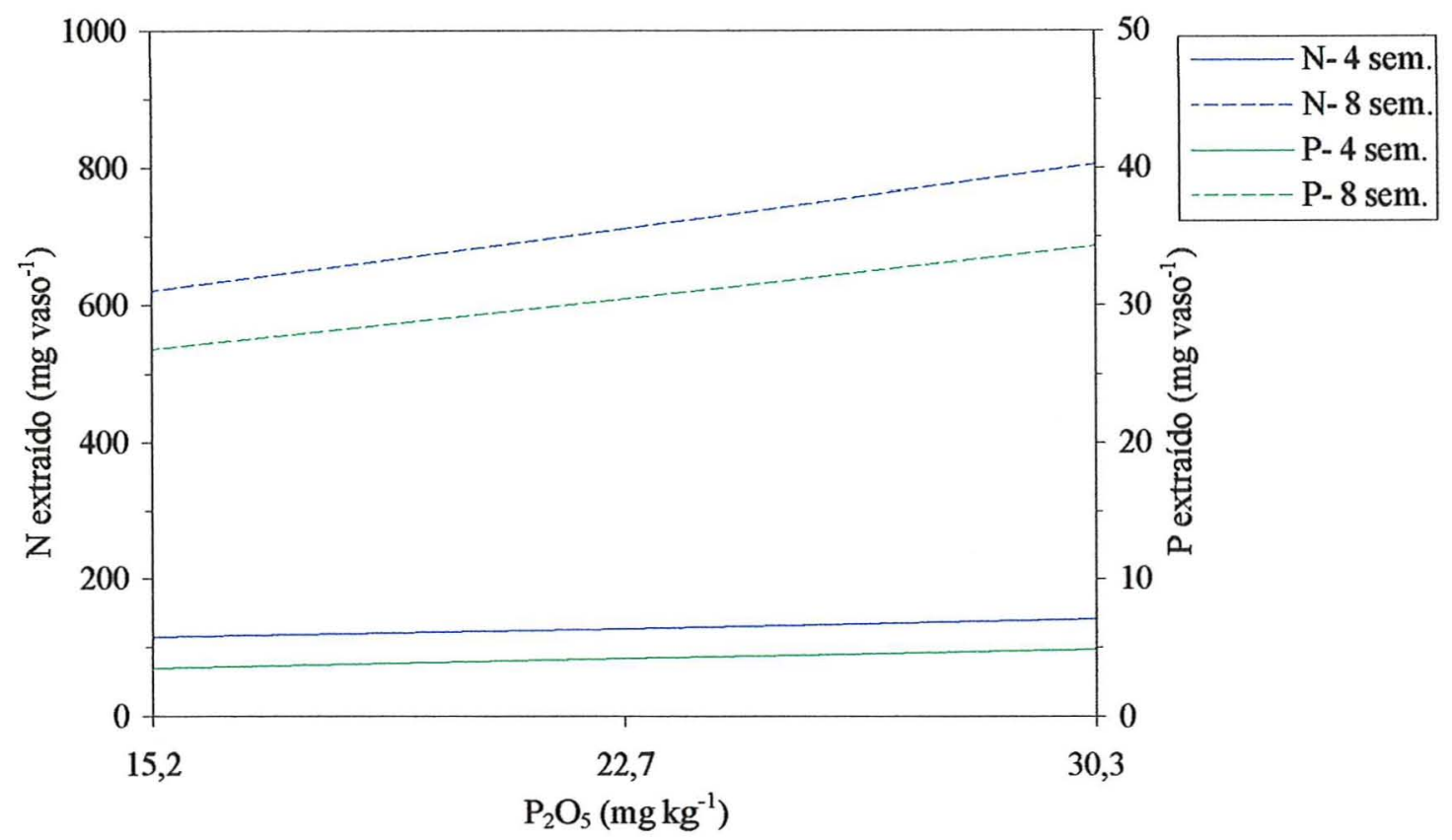

\begin{tabular}{|l|l|l|}
\hline $\mathrm{N}-4$ semanas & $\mathrm{Y}=1,75 \mathrm{X}+87,12$ & $\mathrm{R}^{2}=95,62 \% ; \mathrm{CV} \%=28,40$ \\
\hline $\mathrm{P}-4$ semanas & $\mathrm{Y}=0,09 \mathrm{X}+1,96$ & $\mathrm{R}^{2}=96,03 \% ; \mathrm{CV} \%=28,57$ \\
\hline $\mathrm{N}-8$ semanas & $\mathrm{Y}=12,1 \mathrm{X}+435,6$ & $\mathrm{R}^{2}=97,54 \% ; \mathrm{CV} \%=18,43$ \\
\hline $\mathrm{P}-8$ semanas & $\mathrm{Y}=0,5 \mathrm{X}+19,1$ & $\mathrm{R}^{2}=98,36 \% ; \mathrm{CV} \%=17,40$ \\
\hline
\end{tabular}

Figura 16 - Quantidade acumulada total de $\mathrm{N}$ e de $\mathrm{P}$ pelas plantas, em função do fator dose de fósforo, observadas quatro e oito semanas após a emergência (médias de 24 vasos).

Os teores de $\mathrm{N}$ e de $\mathrm{P}$ na folha diagnóstica (Tabela 29) não foram influenciados pelas doses de fósforo. Os teores obtidos, mesmo nas maiores doses aplicadas são considerados baixos quando comparados com os da literatura, mas a tendência apresentada pelas crescentes doses de $\mathrm{P}$ foi de diminuição do teor de $\mathrm{N}$ nas folhas. 
Tabela 29 - Teores de N e P na folha diagnóstica, em função do fator dose de fósforo, observados oito semanas após a emergência (médias de 24 vasos).

\begin{tabular}{|c|c|c|}
\hline $\begin{array}{c}\mathrm{P}_{2} \mathrm{O}_{5} \\
\mathrm{mg} \mathrm{kg}^{-1}\end{array}$ & teor de $\mathrm{N}$ & teor de $\mathrm{P}$ \\
\hline 15,2 & 19,79 & 0,65 \\
\hline 22,7 & 19,28 & 0,66 \\
\hline 30,3 & 19,10 & 0,67 \\
\hline
\end{tabular}

\subsubsection{Efeito da interação entre os fatores cultivar e dose de fósforo}

Quatro semanas após a emergência, os resultados da quantidade acumulada total de $\mathrm{P}$ pelas plantas (Figura 17) apresentaram efeitos significativos da aplicação das doses de fósforo nos dois cultivares estudados.

As quantidades totais de $\mathrm{P}$ acumuladas pelas plantas dos dois cultivares, em função das doses de fósforo aplicadas foram influenciadas da mesma maneira que as massas de material seco totais. O cultivar IAC-8 apresentou resposta linear à aplicação de fósforo, porém a concentração foi elevada nas maiores doses, uma vez que a quantidade acumulada de fósforo teve um aumento maior que a massa de material seco total. O cultivar IAC-14 apresentou a mesma resposta quadrática para a quantidade acumulada e para a massa de material seco total, mantendo a concentração de fósforo na planta, independente da dose de fósforo aplicada. 


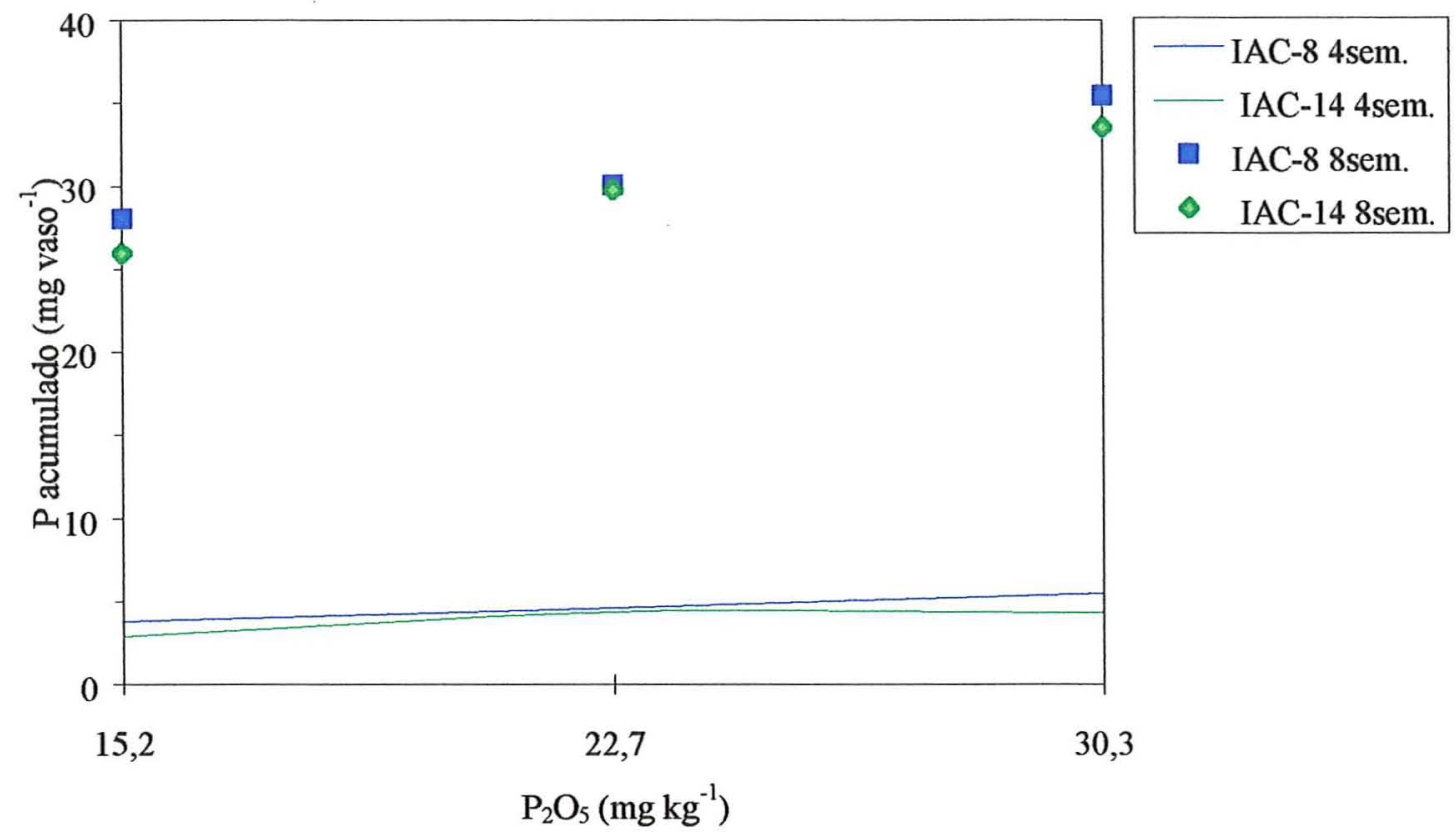

\begin{tabular}{|l|l|l|}
\hline IAC-8 4 sem. & $\mathrm{Y}=0,11 \mathrm{X}+2,06$ & $\mathrm{R}^{2}=95,52 \% ; \mathrm{CV} \%=24,80$ \\
\hline $\mathrm{IAC}-144$ s & $\mathrm{Y}=-0,01 \mathrm{X}+0,73 \mathrm{X}-5,04$ & \\
\hline
\end{tabular}

\begin{tabular}{|l|l|l|}
\hline IAC-14 4 sem. & $\mathrm{Y}=-0,01 \mathrm{X}^{2}+0,73 \mathrm{X}-5,04$ & $\mathrm{R}^{2}=40,38 \% ; \mathrm{CV} \%=24,87$ \\
\hline
\end{tabular}

IAC-8 8 sem. $\quad$ não significativo

IAC-14 8 sem. não significativo

Figura 17 - Quantidade acumulada total de P pelas plantas nos cultivares IAC-8 e IAC14 , em função do fator dose de fósforo, observadas quatro e oito semanas após a emergência (médias de 9 vasos).

\subsection{Análise de terra}

Os resultados da análise de terra, quatro semanas após a emergência, mostraram equivalência entre os níveis dos fatores dose de $\mathrm{N}$ e dose de $\mathrm{P}$ para os parâmetros de solo avaliados. Somente o nível de P no solo apresentou tendência para a diferenciação em função das doses aplicadas de nitrogênio (Tabela 30) e de fósforo (Tabela 31). 
Tabela 30 - Análise de terra, quatro semanas após a emergência, em função do fator dose de nitrogênio (Médias de 18 vasos).

\begin{tabular}{|c|c|c|c|c|c|c|c|}
\hline $\begin{array}{c}\mathrm{N} \\
\mathrm{mg} \mathrm{kg}^{-1}\end{array}$ & $\begin{array}{l}\text { P resina } \\
\mathrm{mg} \mathrm{dm}^{-3}\end{array}$ & $\begin{array}{l}\text { M.O. } \\
\mathrm{g} \mathrm{dm}^{-3}\end{array}$ & $\begin{array}{c}\mathrm{pH} \\
\mathrm{CaCl}_{2}\end{array}$ & $\mathrm{~K}$ & $\mathrm{Ca}$ & $\begin{array}{c}\mathrm{Mg} \\
\mathrm{dm}^{-3}-.\end{array}$ & $\mathrm{H}+\mathrm{Al}$ \\
\hline 0 & 8,23 & 25,22 & 5,60 & 0,87 & 23,00 & 14,07 & 19,87 \\
\hline 5,7 & 9,10 & 24,57 & 5,61 & 1,00 & 22,55 & 14,37 & 19,87 \\
\hline 11,4 & 11,30 & 24,68 & 5,62 & 1,02 & 21,85 & 14,70 & 20,58 \\
\hline 17,1 & 9,52 & 25,37 & 5,58 & 0,97 & 23,80 & 15,77 & 19,93 \\
\hline
\end{tabular}

Tabela 31 - Análise de terra, quatro semanas após a emergência, em função do fator dose de fósforo (Médias de 24 vasos).

\begin{tabular}{|c|c|c|c|c|c|c|c|}
\hline $\begin{array}{r}\mathrm{P}_{2} \mathrm{O}_{5} \\
\mathrm{mg} \mathrm{kg}^{-1}\end{array}$ & $\begin{array}{l}\text { P resina } \\
\mathrm{mg} \mathrm{dm}^{-3}\end{array}$ & $\begin{array}{l}\text { M.O. } \\
\mathrm{g} \mathrm{dm}^{-3}\end{array}$ & $\begin{array}{c}\mathrm{pH} \\
\mathrm{CaCl}_{2}\end{array}$ & $\bar{K}$ & $\mathrm{Ca}$ & $\begin{array}{r}\mathrm{Mg} \\
\mathrm{Im}^{-3}-\end{array}$ & $\overline{\mathrm{H}+\mathrm{Al}}$ \\
\hline 15,2 & 7,89 & 25,14 & 5,59 & 1,01 & 23,00 & 14,83 & 19,88 \\
\hline 22,7 & 9,45 & 24,88 & 5,59 & 0,95 & 23,23 & 14,90 & 19,95 \\
\hline 30,3 & 11,28 & 24,86 & 5,62 & 0,93 & 22,18 & 14,45 & 20,36 \\
\hline
\end{tabular}

Os resultados da análise de terra na segunda avaliação, em função das doses de $\mathrm{N}$ (Tabela 32) não apresentaram valores estatísticamente significativos (Teste F). Os resultados referentes às doses de $\mathrm{P}$ (Tabela 33), amostrados oito semanas após a emergência, seguiram a tendência observada na primeira avaliação e mostraram efeito significativo da aplicação de doses de $\mathrm{P}$ apenas apenas para o nível de $\mathrm{P}$ no solo.

Tabela 32 - Análise de solo, oito semanas após a emergência, em função do fator dose de nitrogênio (Médias de 18 vasos).

\begin{tabular}{|c|c|c|c|c|c|c|c|}
\hline $\begin{array}{c}\mathrm{N} \\
\mathrm{mg} \mathrm{kg}^{-1}\end{array}$ & $\begin{array}{l}\text { P resina } \\
\mathrm{mg} \mathrm{dm}^{-3}\end{array}$ & $\begin{array}{l}\text { M.O. } \\
\mathrm{g} \mathrm{dm}^{-3} \\
\end{array}$ & $\begin{array}{c}\mathrm{pH} \\
\mathrm{CaCl}_{2}\end{array}$ & $\overline{\mathrm{K}}$ & $\begin{array}{l}\mathrm{Ca} \\
--\mathrm{mm}\end{array}$ & $\begin{array}{r}\mathrm{Mg} \\
\mathrm{dm}^{-3}-\end{array}$ & $\overline{\mathrm{H}+\mathrm{Al}}$ \\
\hline$\overline{0}$ & 6,32 & 16,24 & 5,97 & 0,50 & 23,27 & 13,92 & 21,57 \\
\hline 5,7 & 6,71 & 17,32 & 5,94 & 0,59 & 21,58 & 12,54 & 21,91 \\
\hline 11,4 & 6,87 & 17,02 & 5,88 & 0,63 & 22,08 & 11,90 & 22,27 \\
\hline 17,1 & 6,41 & 16,21 & 5,88 & 0,52 & 23,17 & 11,88 & 22,23 \\
\hline
\end{tabular}


Tabela 33 - Análise de solo, oito semanas após a emergência, em função do fator dose de fósforo (Médias de 24 vasos).

\begin{tabular}{|c|c|c|c|c|c|c|c|}
\hline $\begin{array}{c}\mathrm{P}_{2} \mathrm{O}_{5} \\
\mathrm{mg} \mathrm{kg}^{-1}\end{array}$ & $\begin{array}{l}\text { P resina } \\
\mathrm{mg} \mathrm{dm}^{-3}\end{array}$ & $\begin{array}{l}\text { M.O. } \\
\mathrm{g} \mathrm{dm}^{-3}\end{array}$ & $\begin{array}{c}\mathrm{pH} \\
\mathrm{CaCl}_{2}\end{array}$ & $\mathrm{~K}$ & $\begin{array}{c}\mathrm{Ca} \\
---\mathrm{mn}\end{array}$ & $\begin{array}{l}\mathrm{Mg} \\
\mathrm{lm}^{-3}-.\end{array}$ & $\mathrm{H}+\mathrm{Al}$ \\
\hline 15,2 & 5,66 & 16,83 & 5,95 & 0,55 & 22,33 & 12,87 & 21,52 \\
\hline 22,7 & 6,44 & 16,42 & 5,91 & 0,54 & 23,34 & 12,61 & 21,88 \\
\hline 30,3 & 7,63 & 16,85 & 5,89 & 0,58 & 21,90 & 12,20 & 22,58 \\
\hline
\end{tabular}

A equação de regressão que expressa esse resultado é:

$$
0,004 X^{2}-0,03 X+5,31 \quad R^{2}=99,9 \% ; C . V .=28 \%
$$

Entre as duas avaliações ocorreu um aumento do $\mathrm{pH}$, indicando que ainda houve reação do calcário aplicado, o que manteve o nível de Ca no solo.

No entanto, antes do plantio, o pH do solo um mês após a calagem era de 5,80 em média, mostrando que houve um abaixamento do $\mathrm{pH}$ no início do desenvolvimento das plantas e um leve aumento no decorrer do experimento.

\subsection{Considerações gerais}

Quando o N-mineral foi aplicado na semeadura, as plantas avaliadas, quatro semanas após a emergência, apresentaram resultados de nodulação geralmente menores que o tratamento no qual não foi aplicado $\mathrm{N}$, indepedente da dose de fósforo aplicada. Além da nodulação, a produção de massa de material seco também foi reduzida, contrariando a hipótese inicial de que a disponibilidade de $\mathrm{N}$ estimularia o crescimento vegetativo inicial das plantas, apesar de inibir a nodulação. A tendência, verificada pelo aumento da dose de fósforo aplicada em conjunto com as menores doses de nitrogênio, foi a de reduzir a inibição da nodulação e, também a diferença de produção de massa de material seco entre o tratamento que não recebeu adubação nitrogenada e os que receberam as menores doses. 
$\mathrm{O}$ crescimento das plantas, entre as duas avaliações realizadas, mostrou uma recuperação tanto da nodulação (Tabela 34 ) quanto da massa de material seco produzida pelas plantas adubadas com $\mathrm{N}$ na semeadura (Tabela 35 ).

Tabela 34 - Número, massa de material seco de nódulos e massa de material seco por nódulo, em função do fator dose de $\mathrm{N}$, observados entre as duas avaliações (médias de 18 vasos).

\begin{tabular}{cccc}
\hline $\begin{array}{c}\mathrm{N} \\
\mathrm{mg} \mathrm{kg}^{-1}\end{array}$ & Número de nódulos & $\begin{array}{c}\text { M.S. nódulos } \\
\mathrm{g}\end{array}$ & $\begin{array}{c}\text { M.S. por nódulo } \\
\mathrm{mg}\end{array}$ \\
\hline 0 & & 1,04 & 3,3 \\
5,7 & 229 & 1,10 & 2,9 \\
11,4 & 283 & 1,07 & 2,9 \\
17,1 & 280 & 0,97 & 2,5 \\
\hline
\end{tabular}

Tabela 35 - Massa de material seco da parte aérea, das raizes e total das plantas, em função do fator dose de nitrogênio, observadas entre as duas avaliações (médias de 18 vasos).

\begin{tabular}{cccc}
\hline $\begin{array}{c}\mathrm{N} \\
\mathrm{mg} \mathrm{kg}^{-1}\end{array}$ & Parte aérea & Raízes & Planta total \\
\hline 0 & 23,93 & 6,90 & 31,87 \\
5,7 & 26,57 & 7,74 & 35,45 \\
11,4 & 26,87 & 8,36 & 37,94 \\
17,1 & 28,48 & 8,72 & 38,17 \\
\hline
\end{tabular}

$\mathrm{Na}$ época do florescimento, oito semanas após a emergência, as plantas dos tratamentos que receberam as duas maiores doses de fósforo aplicadas, as doses $5,7 \mathrm{e}$ $11,4 \mathrm{mg} \mathrm{kg}^{-1}$ de $\mathrm{N}$, tenderam sempre a superar a nodulação e a produção de massa de material seco do tratamento que não recebeu adubação nitrogenada na semeadura.

As pequenas quantidades de $\mathrm{N}$, aplicadas na semeadura, poderiam ter suas concentrações no solo reduzidas em um curto período de tempo, possibilitando a recuperação das plantas cultivadas nesses tratamentos. De alguma forma, que não pôde ser identificada pela avaliação realizada quatro semanas após a emergência, essa 
aplicação de N-mineral na semeadura favoreceu, a partir da redução da concentração de $\mathrm{N}$-mineral no solo, a nodulação e o crescimento dessas plantas, que atingiram, na época do florescimento, um porte maior e um sistema radicular mais vigoroso, apresentando nodulação equivalente à do tratamento no qual não foi aplicado $\mathrm{N}$.

Sinclair e Wit (1976) estudaram o relacionamento entre o comprimento do período de enchimento dos grãos e a disponibilidade de fotossintatos e de $\mathrm{N}$ para as plantas e concluíram que, o aumento da relação fotossintatos $/ \mathrm{N}$ nas plantas promoveu uma redução desse período, e que ao contrário, a maior disponibilidade de $\mathrm{N}$ poderia aumentá-lo e, assim, contribuir para o aumento da produção de grãos. Desse modo, plantas que apresentarem nessa fase, uma maior quantidade de $\mathrm{N}$ acumulado pelas plantas e disponível através do processo de translocação e, também, uma maior massa de nódulos com grande atividade apresentarão um potencial maior de produção.

Os nódulos formados, nas plantas dos tratamentos que receberam adubação nitrogenada, foram formados mais recentemente, devido ao atraso provocado pela inibição por $\mathrm{N}$, devendo deslocar o período de maior atividade desses nódulos para depois do florescimento, numa época mais próxima do final do ciclo, o que pode garantir uma maior fixação, podendo até aumentar a quantidade de $\mathrm{N}$ e também de $\mathrm{P}$, na fase de maior exigência das plantas, disponível para a translocação para os grãos e, embora os trabalhos já realizados não tenham verificado aumentos na produção com a aplicação de $\mathrm{N}$ na semeadura, pode haver incrementos na concentração de proteína dos grãos.

Quando o nível no solo ou a adubação fornecer uma quantidade de fósforo que permita uma produção elevada, a aplicação de doses pequenas de nitrogênio na semeadura não garantirá aumento da produção de grãos, porém deve melhorar a condição vegetativa das plantas, podendo aumentar a nodulação. Por isso, se a dose utilizada não implicar em aumento no custo de produção da soja, sua aplicação deve ser realizada. 


\section{CONCLUSÕES}

Nas condições em foi realizado este trabalho e, de acordo com os resultados obtidos, pode-se concluir que:

- O desenvolvimento do sistema radicular e da parte aérea, além da nodulação e do acúmulo de $\mathrm{N}$ e de $\mathrm{P}$ foram afetados devido aos cultivares testados.

- O cultivar IAC-14 apresentou um desenvolvimento inicial lento, porém no início do florescimento, apresentou massa de material seco total das plantas e dos nódulos e acúmulo de $\mathrm{N}$ e de $\mathrm{P}$ equivalentes ao do cv. IAC-8.

- A aplicação de doses baixas de nitrogênio na semeadura promoveu a inibição da nodulação e do desenvolvimento inicial do sistema radicular e da parte aérea, no entanto, na época do florescimento, as doses equivalentes a 5,7 e $11,4 \mathrm{mg} \mathrm{kg}^{-1} \mathrm{de} \mathrm{N}$ apresentaram um efeito benéfico para o crescimento vegetativo e uma tendência positiva para a nodulação e para a fixação simbiótica do $\mathrm{N}_{2}$.

- O acúmulo de $\mathrm{P}$ em função da aplicação de $\mathrm{N}$ apresentou comportamento semelhante ao acúmulo de material vegetal seco total das plantas.

- As doses de fósforo aplicadas proporcionaram incremento do acúmulo de material vegetal seco, dos nutriente $\mathrm{N}$ e $\mathrm{P}$ e da nodulação da soja.

- Os efeitos negativos iniciais da aplicação de $\mathrm{N}$ na semeadura, apresentaram tendência de redução com o aumento da dose de fósforo aplicada.

- A análise de terra apresentou efeito positivo da aplicação de P somente para o valor de P disponível no solo. 


\section{REFERÊNCIAS BIBLIOGRÁFICAS}

ABREU, C.A. de; ABREU, M.F. de; RAIJ, B.van; BATAGLIA, O.C. Extraction of boron from soil by microwave heating for ICP-AES determination. Communication in Soil Science and Plant Analysis, v. 25, n. 19-20, p. 3321-33, 1994.

ALLOS, H.F.; BARTHOLOMEW, W.V. Replacement of symbiotic fixation by available nitrogen. Soil Science, v. 87, n. 2, p.61-6, 1959.

ANDREW, C.S.; ROBINS, M.F. The effect of phosphorus on the growth and chemical composition of some tropical pasture legumes. I. Growth and critical percentages of phosphorus. Australian Journal of Agricultural Research, v. 20, n. 4, p. 665-74, jul. 1969a.

ANDREW, C.S.; ROBINS, M.F. The effect of phosphorus on the growth and chemical composition of some tropicals pasture legumes. II. Nitrogen, calcium, magnesium, potassium and sodium contents. Australian Journal of Agricultural Research, v. 20, n. 4, p. 675-85, jul. 1969 b.

BEARD, B.H.; HOOVER, R.M. Effect of nitrogen on nodulation and yield of irrigated soybeans. Agronomy Journal, v. 63, n. 5, p. 815-6, set. 1971.

BELL, F; NUTMAN, P.S. Experiments on nitrogen fixation by nodulated lucerne.

Plant and Soil, special v., p. 231-64, 1971

BETHENFALVAY, G.J.; YODER, J.F. The Glycine-Glomus-Rhizobium symbiosis.I. Phosphorus effect on nitrogen fixation and mycorrhizal infection. Physiologia Plantarum, v. 52, n. 1, p. 141-6, mai. 1981. 
BEZDICEK, D.F.; MULFORD, A.F.; MAGEE, B.H. Influence of organic nitrogen on soil nitrogen, nodulation, nitrogen fixation and yield of soybeans. Soil Science Soc. of America Proceedings, v. 38, n. 1, p.268-73, jan./fev. 1978.

BONETTI, R.. Efeito do $\mathrm{N}$ do solo na fixação simbiótica do $\mathrm{N}_{2}$ e na utilização de fertilizantes nitrogenados em soja (Glycine $\max (\mathrm{L})$ Merrill). Piracicaba, 1982. 138p. Dissertação (mestrado) - Escola Superior de Agricultura "Luiz de Queiroz"- USP.

BONETTI, R.; MONTANHEIRO, M.N.S.; SAITO, S.M.T. The effects of phosphate and soil moisture on the nodulation and growth of Phaseolus vulgaris. Journal of Agricultural Science, v. 103, n. 1, p. 95-102, ag. 1984.

CHILD, J.J.; LARUE, T.A. A simple technique for the establishment of nitrogenase in soybean callus culture. Plant Physiology, v. 53, n. 1, p. 88-90, jan. 1974.

CHO, M.J.; HARPER, J.E. Effect of inoculation and nitrogen on isoflavanoid concentration in wild-type and nodulation-mutant soybean roots. Plant Physiology, v. 95, n. 2, p. 835-40, fev. 1991.

DUNCAN, W.G.; OHLROGGE, A.J. Principles of nutrient uptake from fertilizers bands. II. Root development in the band. Agronomy Journal, v. 50, n. 10, p. 605-8, out. 1958 .

EAGLESHAM, A.R.J.; HASSOUNA, S.; SEEGERS, R. Fertilizer-N effects on N fixation by cowpea and soybean. Agronomy Journal, v. 75, n. 1, p.11-6, jan. 1983. FONSECA, S.M. Fixação biológica de $\mathrm{N}_{2}$ e absorção de ${ }^{15} \mathrm{~N}$ mineral em variedades de feijoeiro (Phaseolus vulgaris L.). Piracicaba, 1985. 116p. Dissertação (mestrado). Escola Superior de Agricultura "Luiz de Queiroz"- USP.

FRANCO, A.A.; NEVES, M.C.P. Fatores limitantes à fixação biológica de nitrogênio. In: CARDOSO, E.J.B.N.; TSAI, S.M.; NEVES, M.C.P. Microbiologia do solo. Campinas: Soc. Bras. de Ciência do Solo, 1992. p.219-30.

FRANCO, A.A; PEREIRA, J.C.; NEYRA, C.A. Seasonal patterns of nitrate reductase and nitrogenase activities in Phaseolus vulgaris L. Plant Physiology, v. 63, n. 3, p. 421-4, mar. 1979. 
FRANCO, A.R.; FONSECA, O.O.; MARRIEL, I.E. Efeito do nitrogênio mineral na atividade da nitrogenase e nitrato redutase, durante o ciclo da soja no campo. Rev. Bras. Ciência do Solo, v. 2, n. 2, p.110-4, mai./ago. 1978.

FREIRE, F.M. Produção de matéria seca, nodulação e absorção de nutrientes pela soja (Glycine $\max (\mathrm{L})$ Merrill) em função de níveis de fósforo e zinco, em solos de Minas Gerais. Piracicaba, 1978. 74p. Dissertação (Mestrado) - Escola Superior de Agricultura "Luiz de Queiroz"- USP.

GALLARDO, F.O.A. Resposta de soja inoculada com Bradyrhizobium japonicum à aplicação de N-nítrico em diferentes fases de seu ciclo. Viçosa, 1989. 45p. Tese (Mestrado) - Universidade Federal de Viçosa.

GATES, C.T.; MULLER, W.J. Nodule and plant development in the soybean (Glycine max (L.) Merrill: Growth response to nitrogen, phosphorus and sulfur. Australian Journal of Botany, v. 27, n. 3, p. 203-15, jun. 1979.

GATES, C.T; WILSON, J.R. The interaction of nitrogen and phosphorus on the growth, nutrient status and nodulation of Stylosanthes lumilis H.B.K. (Townsville Stylo). Plant and Soil, v.41, p.325-33, 1974.

GIBSON, A.H. Energy production and utilization in nitrogen fixation. In: INTERNATIONAL SYMPOSIUM ON NITROGEN FIXATION, 4, Camberra, 1980. Current Perspectives in nitrogen fixation. International Symposium on Nitrogen Fixation, 4, Proceedings. Amsterdam: Elsevier, 1981. p.127-8.

GIBSON, A.H.; HARPER J.E. Nitrate effect on nodulation of soybean by Bradyrhizobium japonicum. Crop Science, v. 25, n. 3, p.497-501, mai./jun. 1985.

GIBSON, A. H.; NUTMAN, P.S. Studies on the physiology of nodule formation. VII. A reppraisal of the effect of preplanting. Annals of Botany, v. 24, n. 96, p. 420-33, out. 1960.

GIBSON, A.H.; PAGAM, J.D. Nitrate effects of the nodulation of legumes inoculated with nitrate reductase deficient mutants of rhizobium. Planta, v. 134, p.17-22, 1977. 
HANWAY, J.J.; WEBER, C.R. Accumulation of nitrogen, phosphorus, and potassium by soybean (Glycine max (L.) Merrill) plants. Agronomy Journal, v. 68, n. 2, p. 319-24, mai./jun. 1971.

HARDARSON, G.; ZAPATA, F.; DANSO, S.K.A. Effect of plant genotype and nitrogen fertilizer on symbiotic nitrogen fixation by soybeans cultivars. Plant and Soil, v. 82, n. 3, p. 397-405, 1984.

HARDY, R.W.F.; BURNS, R..C.; HEBERT,R.R.; HOLSTEN, R.D.; JACKSON, E.K. Biological nitrogen fixation: a key to world protein. Plant and Soil, special v., p.561-90, 1971.

HARPER, J.E. Soil and symbiotic nitrogen requeriments for optimum soybean production. Crop Science, v. 14, n. 2, p. 255-60, mar./abr. 1974.

HARPER, J.E. Nitrogen metabolism. In: WILCOX, J.R. (ed.). Soybeans Improvement, production and uses. 2 ed. Madison: American Society of Agronomy, Inc., 1987. v.16, cap. 13, p.498-534.

HARPER, J.E.; HAGEMAN, R.H. Canopy and seasonal profiles of nitrate redutase in soybeans(Glycine $\max$ (L) Merrill). Plant Physiology, v. 49, n. 2, p.146-154, fev. 1972.

HATFIELD, J.L.; EGLI, D.B.; LEGGETT, J.E.; PEASLEE, D.E. Effect of applied nitrogen on the nodulation and early growth of soybean (Glycine max (L) Merrill). Agronomy Journal, v. 66, n. 1, p 112-4, jan./fev. 1974.

HERRIDGE, D.F., BETTS, J.H. Nitrate tolerance in soybean: variation between genotypes. In: INTERNATIONAL SYMPOSIUM ON NITROGEN FIXATION, 6 , Corvallis, 1985. Nitrogen fixation research progress. International Symposium on Nitrogen Fixation, 6, Proceedings. Dordrecht: Martinus Nijhoff Publishers, 1985. p. 32.

HOLSTEN, R.D.; BURNS, R.C.; HARDY, W.F.; HERBERT, R.R. Establishment of symbiosis between rhizobium and plant cells "in vitro". Nature, v. 232, n. 5307, p.173-6, jul. 1971. 
ISRAEL, D.W. Effects of phosphorus nutrition on symbiotic dinitrogen fixation in soybeans plants. In: INTERNATIONAL SYMPOSIUM ON NITROGEN FIXATION, 6, Corvallis, 1985. Nitrogen fixation research progress. International Symposium on Nitrogen Fixation, 6, Proceedings. Dordrecht: Martinus Nijhoff Publishers, 1985. p. 343.

ISRAEL, D.W. Investigation of the role of phosphorus in symbiotic dinitrogen fixation. Plant Physiology, v. 84, n. 3, p. 835-40, jul. 1987.

JAKOBSEN, I. The role of phosphorus in nitrogen fixation by young pea plants (Pisum sativum). Physiologia Plantarum, v. 64, n. 2, 190-6, jun. 1985.

KLUCAS, R.V. Studies on soybean nodule senescence. Plant Physiology, v. 54, n. 4, p. 612-16, out. 1974.

KOLLING, J. STAMMEL, J.G.; KORNELIUS, E. Efeitos da calagem e da adubação fosfatada sobre a nodulação, nitrogênio total no tecido e produção de matéria seca de leguminosas forrageiras de clima tropical. Agronomia Sulriograndense, v. 10, n. 2, p. 267-80, 1974.

La FAVRE, A.K.; EAGLESHAM, A.R.S. The effects of high level of N, applied at plantings on nodulation of soybeans (Glycine max (L.) Merrill) by strains of Bradyrhizobium. Plant and Soil, v. 102, n. 2, p.267-70, 1987.

LAWN, R.J.; BRUN, W.A. Symbiotic nitrogen fixation in soybeans. Effect of photosynthetic source-sink manipulation. Crop Science, v. 14, n. 1, p. 11-16. jan/fev. 1974.

LIE, T.A. Enviroment effects of nodulation and symbiotic nitrogen fixation. In: QUISPEL, A. The Biology of nitrogen fixation. Amsterdam: North-Holland Publishing Co., 1974. v. 33, cap 11.6, p. 555-82.

LINDSAY, W.L.; NORVELL, W.A. Development of a DTPA-soil test for zinc, iron, manganese and copper. Soil Science Society of America Journal, v.42, p. 421-8, 1978. 
LINS, I.D.G.; COX, F.Z.; NICHOLAIDES, J.J. Otimizing phosphorus fertilizations rates for soybeans grown on oxisols associated entisols. Soil Science of America Journal, v. 49, n. 6, p.1457-60, nov./dez. 1985.

MAHON, J.D. Root and nodule respiration in relation to acetylen reduction in intact nodulated pea. Plant Physiology, v. 60, n. 6, p.812-6, dez. 1977.

MASCARENHAS, H.A.A.; HIROCE, R.; BRAGA, N.R.; MIRANDA, M.A.C.de; BULISANI, E.A.; POMMER, C.V.; SAWAZAKI, E.; GALLO, P.B.; PEREIRA, J.C.V.N.A. Efeito do $\mathbf{N}$ residual de soja na produção de milho. 2 ed. Campinas: Instituto Agronômico, 1983. 24p. (boletim técnico, 58)

MOOY, C.J.de; PESEK, J. Nodulated responses of soybeans to added phosphorus, potassium and calcium salts. Agronomy Journal, v. 58, n. 3, p. 275-80, mai./jun. 1966.

MULLER, L. Fixação simbiótica do nitrogênio. In: MIYASAKA, S. (ed.). A Soja no Brasil. Campinas: Fund. CARGILL, 1981. p. 401-14.

NANGJU, D. Soybean response to indigenous rhizobia as influenced by cultivar origin. Agronomy Journal, v. 72, n. 3, p.403-6, mai/jun. 1980.

NELSON, A.N.; WEAVER, R.W. Seasonal nitrogen acumulation and fixation by soybean grown at different densities. Agronomy Journal, v. 72, n. 4, p.613-6, jul./ago. 1980.

NOVO, M.C.S.S. Resposta à aplicação de uréia e cloreto de potássio em dois genótipos de soja, inoculados com Bradyrhizobium japonicum, cultivados no inverno. Piracicaba, 1995. 113p. Dissertação (Mestrado) - Escola Superior de Agricultura "Luiz de Queiroz"- USP.

OGHOGHORIE, C.G.O.; PATE, J.S. The nitrate stress syndrome of the nodulated field pea (Pisum arvense L.). Techniques for measurement and evaluation in physiological terms. Plant and Soil, special v., p.185-202, 1971. 
PATTERSON, T.G.; LARUE, T.A. Nitrogen fixation by soybeans; seasonal and cultivar effects and comparisons of estimates. Crop Science, v. 23, n. 3, p.488-92, mai/jun. 1983.

PAZ, L.G. Influência do pH e da nutrição mineral na nodulação e fixação de nitrogênio molecular pelo feijoeiro (Phaseolus vulgaris L.) cultivado em solução nutritiva. Piracicaba, 1978. 186 p. Tese (Doutorado) - Escola Superior de Agricultura "Luiz de Queiroz"- USP.

PEREIRA, P.R.G. Estudo da eficiência de fungos micorrízicos vesículo-arbusculares para a soja em amostra de um latossolo. Viçosa, 1986. 72p. Dissertação (Mestrado) - Universidade Federal de Viçosa.

PHILLIPS, D.A. Factor affecting the reduction of acetylene by rhizobium-soybean cells associations "in vitro". Plant Physiology, v. 53, n. 1, p. 64-72, jan. 1974.

RABIE, R.K.; AKIMA, Y.; KUMAZAWA, Y. Effect of combinated nitrogen on the distribution patterns of photosynthetic assimilates in nodulated soybean plants as revelled by ${ }^{14} \mathrm{C}$. Soil Science and Plant Nutrition, v.26, n. 1, p.78-86, 1980.

RAGGIO, M.; RAGGIO, N.; TORREY, J.C. The interaction of nitrate and carbohidrates in rhizobial root-nodule formation. Plant Physiology, v. 40, n. 4, p.601-6, 1965.

RAIJ, B.van; QUAGGIO, J.A. Métodos de análise de solo para fins de fertilidade. Campinas: Instituto Agronômico, 1983. 31p. (Boletim IAC, 81).

ROBSON, A.D.; O'HARA G.W.; ABBOTT, L.K. Involvement of phophorus on nitrogen fixation by subterranen clover (Trifolium subterraneum L.). Australian Journal of Plant Physiology, v. 8, n. 4 e 5, p. 427-36, 1981.

ROSOLEM, C.A. Nutrição mineral e adubação da soja. 3 ed. Piracicaba: POTAFOS, 1984. $80 \mathrm{p}$. 
RUSCHEL, A.P.; SAITO, S.M.; VOSE ,P.B. Atividade da redutase do nitrato e nitrogenase em relação ao $\mathrm{N}$ absorvido do solo, ${ }^{15} \mathrm{~N}$-fertilizante, fixação simbiótica em soja (Glycine $\max$ (L.) Merrill). Energia Nuclear na Agricultura, v.2, n.1, p.817, jan. 1980.

RUSCHEL, A.P.; SUHET, A.R.; VIANNI, R.; ALMEIDA, D.L. Efeito de diferentes fontes de nitrogênio e da inoculação na produção de sementes, proteína e óleo em dois cultivares de soja. Pesquisa Agropecuária Brasileira, v. 10, n. 11, p. 19-23, 1975.

SAITO, S.M.T.; BONETTI, R.; SALATI, O.; VICTORIA, R.L. Resposta do Phaseolus vulgaris nodulado ao $\mathrm{N}$ combinado em casa-de-vegetação. In: SEMINÁRIO REGIONAL SOBRE O USO DE TÉCNICAS NUCLEARES EM ESTUDOS DAS RELAÇÕES SOLO-PLANTA-ATMOSFERA. Piracicaba, 1981. Resumos dos Trabalhos. Piracicaba: CENA, 1981. P.33.

SANDERS, R. Effect of nitrogen and phosphorus on nodulation and root development of soybeans. Gainesville, 1969. 49 p. Dissertação (Mestrado) - University of Florida.

SANTIAGO, T.M.D. Eficiência da adubação foliar com uréia $\left({ }^{15} \mathrm{~N}\right)$ em soja(Glycine $\max (\mathrm{L})$ Merrill). Piracicaba. 1989. 68p. Dissertação (mestrado) - ESALQ/ USP.

SARRUGE, J.R.; HAAG, H.P. Análises químicas em plantas. Piracicaba: Depto de Química, ESALQ/USP, 1974. 56p.

SIJ, J.W.; TURNER, F.T.; CRAIGMILES, J.P. "Starter nitrogen" fertilization in soybean culture. Communication in Soil Science and Plant Analysis, v. 10, n. 11, p. 1451-7, nov. 1979.

SINCLAIR, T.R.; WIT, C.T.de. Analysis of the carbon and nitrogen limitations to soyabean yield. Agronomy Journal, v. 68, n. 2, p. 219-24, mar./abr. 1976. 
SLOGER, C. Effects of blocking photosynthate to soybean root nodules. In: INTERNATIONAL SYMPOSIUM ON NITROGEN FIXATION, 6, Carvallis, 1985. Nitrogen fixation research progress. International Symposium on Nitrogen Fixation, 6, Proceedings. Dordrecht: Martinus Nijhoff Publishers, 1985. p.343.

SMALL, J.G.C.; LEONARD, O.A. Translocation on ${ }^{14} \mathrm{C}$ labelled photosynthate in nodulated legumes as influenced by nitrate nitrogen. American Journal of Botany, v. 56, n. 2, p. 187-94, fev. 1969.

SPRENT, J.I. Biology of nitrogen fixing organisms. London: McGran-hill, 1979. $195 \mathrm{p}$.

STEPHENS, B.D.; NEYRA, C. Nitrate and nitrite reduction in relation to nitrogenase activity in soybean nodules and Rhizobium japonicum bacteroids. Plant Physiology, v. 71, n. 4, p. 731-5, abr. 1983.

TANAKA, R.T.; MASCARENHAS, H.A.A.; BORKERT, C.M. Nutrição mineral da soja. In: ARANTES, N.E.; SOUZA, P.I.de M.de, eds. Cultura da soja nos cerrados. Potafos, Piracicaba, 1993. p.105-135.

TANNER, I.W.; ANDERSON, J.G. An externed effect of inorganic nitrogen on root nodulation. Nature, v. 198, n. 4877, p. 303-4, abr. 1963.

VARGAS, M.A.T.; PERES, J.R.R.; SUHET, A.R. Adubação nitrogenada, inoculação e épocas de calagem para a soja em um solo sob cerrado. Pesquisa Agropecuária Brasileira, v. 17, n. 8, p. 1127 - 32, ago. 1982.

VEST. G.D.; WEBER, F; SLOGER, C. Nodulation and nitrogen fixation. In: CALDWELL, B.E.; JONHSON, H.W. (ed.) Soybeans: Improvement, production and uses. 1 ed. Madison: American Society of Agronomy, Inc., 1973. v. 16, cap. 10, p. 353-90.

WEBER,C.R. NodulatinG and nonnodulating soybean isolines: II. Response to applied nitrogen and modified soil condictions. Agronomy Journal, v. 58, n. 1, p.46-9, jan./fev. 1966. 
WESTERMAN, R.L.; KURTZ, L.T. Priming effect of ${ }^{15} \mathrm{~N}$-labelled fertilizers on soil nitrogen in field experiments. Soil Science Society of America Proceedings, v. 37, n. 5, p. 725-727, set. 1973.

WHITEAKER, G.; GERLOFF, G.C. GABELMAN, W.H.; LINDGREN, D. Intraspecific differences in growth of soybeans at stress levels of phosphorus. Journal of American Society for Horticultural Science, v. 101, n. 4, p. 472-75, jul. 1976.

WONG, P. Nitrate and Carbohidrate effects on nodulation and nitrogen fixation (acetylen reduction) activity of lentil (Lens sculenta Moench). Plant Physiology, v. 71, n.1, p78-81, jul. 1980. 


\section{APÊNDICE}

A 1 - Quadro da análise da variância para o número de nódulos formados nas primeiras quatro semanas após a emergência.

\begin{tabular}{|lcrrr|}
\hline \multicolumn{1}{|c}{ Causa da Variação } & G.L. & S.Q. & Q.M. & Valor F \\
\hline blocos & 2 & 766 & 383 & 1,7 \\
\hline Cultivar & 1 & 36992 & 36992 & $159,1^{*}$ \\
Dose de N & 3 & 7032 & 2344 & $10,1^{*}$ \\
Cultivar x Dose de N & 3 & 1830 & 610 & 2,6 \\
Dose de P & 2 & 590 & 295 & 1,3 \\
Cultivar x Dose de P & 2 & 1216 & 608 & 2,6 \\
Dose de N x Dose de P & 6 & 959 & 160 & 0,7 \\
Cultivar x Dose N x Dose P & 6 & 653 & 109 & 0,5 \\
\hline Tratamento & 25 & 50038 & 2002 & $8,6^{*}$ \\
Resíduo & 46 & 10697 & 233 & \\
\hline Total & 71 & 60734 & & \\
\hline
\end{tabular}

A 2 - Quadro da análise da variância para a massa de material seco dos nódulos formada nas primeiras quatro semanas após a emergência.

\begin{tabular}{|lcrrr|}
\hline \multicolumn{1}{|c}{ Causa da Variação } & G.L. & S.Q. & Q.M. & Valor F \\
\hline blocos & 2 & 1008 & 504 & $5,5^{*}$ \\
\hline Cultivar & 1 & 13339 & 13339 & $144,1^{*}$ \\
Dose de N & 3 & 2772 & 924 & $10,0^{*}$ \\
Cultivar x Dose de N & 3 & 550 & 183 & 2,0 \\
Dose de P & 2 & 900 & 450 & $4,9^{*}$ \\
Cultivar x Dose de P & 2 & 144 & 72 & 0,8 \\
Dose de N x Dose de P & 6 & 311 & 52 & 0,6 \\
Cultivar x Dose N x Dose P & 6 & 467 & 78 & 0,8 \\
\hline Tratamento & 25 & 19492 & 780 & $8,4^{*}$ \\
Resíduo & 46 & 4258 & 93 & \\
\hline Total & 71 & 23750 & & \\
\hline
\end{tabular}


A 3 - Quadro da análise da variância para a massa de material seco por nódulo formada nas primeiras quatro semanas após a emergência.

\begin{tabular}{|lcccc|}
\hline \multicolumn{1}{|c}{ Causa da Variação } & G.L. & S.Q. & Q.M. & Valor F \\
\hline blocos & 2 & 0,084 & 0,042 & 1,9 \\
\hline Cultivar & 1 & 0,094 & 0,094 & $4,2^{*}$ \\
Dose de N & 3 & 0,038 & 0,013 & 0,6 \\
Cultivar x Dose de N & 3 & 0,060 & 0,020 & 0,9 \\
Dose de P & 2 & 0,101 & 0,050 & 2,2 \\
Cultivar x Dose de P & 2 & 0,004 & 0,002 & 0,1 \\
Dose de N x Dose de P & 6 & 0,324 & 0,054 & $2,4^{*}$ \\
Cultivar x Dose N x Dose P & 6 & 0,267 & 0,045 & 2,0 \\
\hline Tratamento & 25 & 0,972 & 0,039 & 1,8 \\
Resíduo & 46 & 1,035 & 0,022 & \\
\hline Total & 71 & 2,007 & & \\
\hline
\end{tabular}

A 4 - Quadro da análise da variância para o número de nódulos formados durante as oito semanas após a emergência.

\begin{tabular}{|lcrrr|}
\hline \multicolumn{1}{|c}{ Causa da Variação } & G.L. & S.Q. & Q.M. & Valor F \\
\hline blocos & 2 & 8120 & 4060 & 0,8 \\
\hline Cultivar & 1 & 264386 & 264386 & $52,1^{*}$ \\
Dose de N & 3 & 16620 & 5540 & 1,1 \\
Cultivar x Dose de N & 3 & 15197 & 5066 & 1,0 \\
Dose de P & 2 & 149907 & 74954 & $14,8^{*}$ \\
Cultivar x Dose de P & 2 & 12128 & 6064 & $1,2^{*}$ \\
Dose de N x Dose de P & 6 & 45709 & 7618 & 1,5 \\
Cultivar x Dose N x Dose P & 6 & 10919 & 1820 & 0,4 \\
\hline Tratamento & 25 & 522986 & 20919 & $4,1^{*}$ \\
Resíduo & 46 & 233636 & 5079 & \\
\hline Total & 71 & 756621 & & \\
\hline
\end{tabular}


A 5 - Quadro da análise da variância para o massa de material seco dos nódulos formada durante as oito semanas após a emergência.

\begin{tabular}{|lcccc|}
\hline \multicolumn{1}{|c}{ Causa da Variação } & G.L. & S.Q. & Q.M. & Valor F \\
\hline blocos & 2 & 0,12 & 0,06 & 0,9 \\
\hline Cultivar & 1 & 0,01 & 0,01 & 0,2 \\
Dose de N & 3 & 0,19 & 0,06 & 1,0 \\
Cultivar x Dose de N & 3 & 0,22 & 0,07 & 1,2 \\
Dose de P & 2 & 3,17 & 1,58 & $25,0 *$ \\
Cultivar x Dose de P & 2 & 0,17 & 0,08 & 1,3 \\
Dose de N x Dose de P & 6 & 0,59 & 0,10 & 1,6 \\
Cultivar x Dose N x Dose P & 6 & 0,47 & 0,08 & 1,2 \\
\hline Tratamento & 25 & 4,94 & 0,20 & $3,1 *$ \\
Resíduo & 46 & 2,92 & 0,06 & \\
\hline Total & 71 & 7,85 & & \\
\hline
\end{tabular}

A 6 - Quadro da análise da variância para o massa de material seco por nódulo formada durante as oito semanas após a emergência.

\begin{tabular}{|lcrrc|}
\hline \multicolumn{1}{|c}{ Causa da Variação } & G.L. & \multicolumn{1}{c|}{ S.Q. } & Q.M. & Valor F \\
\hline blocos & 2 & 2,1 & 1,0 & 1,8 \\
\hline Cultivar & 1 & 25,7 & 25,7 & $45,1^{*}$ \\
Dose de N & 3 & 6,3 & 2,1 & $3,7^{*}$ \\
Cultivar x Dose de N & 3 & 0,8 & 0,3 & 0,5 \\
Dose de P & 2 & 2,1 & 1,0 & 1,8 \\
Cultivar x Dose de P & 2 & 0,9 & 0,5 & 0,8 \\
Dose de N x Dose de P & 6 & 6,6 & 1,1 & 1,9 \\
Cultivar x Dose N x Dose P & 6 & 4,3 & 0,7 & 1,3 \\
\hline Tratamento & 25 & 48,8 & 2,0 & $3,4^{*}$ \\
Resíduo & 46 & 26,2 & 0,6 & \\
\hline Total & 71 & 74,9 & \\
\hline
\end{tabular}


A 7 - Quadro da análise da variância para a massa de material seco da parte aérea, observada quatro semanas após a emergência.

\begin{tabular}{|lcrrr|}
\hline \multicolumn{1}{|c}{ Causa da Variação } & G.L. & \multicolumn{1}{c|}{ S.Q. } & Q.M. & Valor F \\
\hline blocos & 2 & 1,4 & 0,7 & 2,7 \\
\hline Cultivar & 1 & 45,7 & 45,7 & $181,4^{*}$ \\
Dose de N & 3 & 4,2 & 1,4 & $5,6^{*}$ \\
Cultivar x Dose de N & 3 & 1,5 & 0,5 & 2,0 \\
Dose de P & 2 & 4,0 & 2,0 & $8,0^{*}$ \\
Cultivar x Dose de P & 2 & 1,5 & 0,8 & 3,0 \\
Dose de N x Dose de P & 6 & 0,9 & 0,2 & 0,6 \\
Cultivar x Dose N x Dose P & 6 & 0,8 & 0,1 & 0,5 \\
\hline Tratamento & 25 & 60,0 & 2,4 & $9,5{ }^{*}$ \\
Resíduo & 46 & 11,6 & 0,3 & \\
\hline Total & 71 & 71,5 & & \\
\hline
\end{tabular}

A 8 - Quadro da análise da variância para a massa de material seco das raízes, observada quatro semanas após a emergência.

\begin{tabular}{|lcccc|}
\hline \multicolumn{1}{|c}{ Causa da Variação } & G.L. & S.Q. & Q.M. & Valor F \\
\hline blocos & 2 & 1,1 & 0,6 & 2,4 \\
\hline Cultivar & 1 & 2,5 & 2,5 & $10,7^{*}$ \\
Dose de N & 3 & 2,1 & 0,7 & $3,1^{*}$ \\
Cultivar x Dose de N & 3 & 0,7 & 0,2 & 1,0 \\
Dose de P & 2 & 4,8 & 2,4 & $10,5^{*}$ \\
Cultivar x Dose de P & 2 & 1,0 & 0,5 & 2,3 \\
Dose de N x Dose de P & 6 & 1,4 & 0,2 & 1,0 \\
Cultivar x Dose N x Dose P & 6 & 0,9 & 0,1 & 0,6 \\
\hline Tratamento & 25 & 14,5 & 0,6 & $2,5^{*}$ \\
Resíduo & 46 & 10,6 & 0,2 & \\
\hline Total & 71 & 25,1 & & \\
\hline
\end{tabular}


A 9 - Quadro da análise da variância para a massa de material seco total das plantas, observada quatro semanas após a emergência.

\begin{tabular}{|lcrrc|}
\hline \multicolumn{1}{|c}{ Causa da Variação } & G.L. & \multicolumn{1}{c}{ S.Q. } & Q.M. & Valor F \\
\hline blocos & 2 & 5,1 & 2,5 & $3,6^{*}$ \\
\hline Cultivar & 1 & 71,4 & 71,4 & $101,9^{*}$ \\
Dose de N & 3 & 10,6 & 3,5 & $5,0^{*}$ \\
Cultivar x Dose de N & 3 & 3,1 & 1,0 & 1,5 \\
Dose de P & 2 & 16,9 & 8,5 & $12,1^{*}$ \\
Cultivar x Dose de P & 2 & 5,1 & 2,6 & $3,6^{*}$ \\
Dose de N x Dose de P & 6 & 4,4 & 0,7 & 1,0 \\
Cultivar x Dose N x Dose P & 6 & 3,2 & 0,5 & 0,8 \\
\hline Tratamento & 25 & 119,7 & 4,8 & $6,8^{*}$ \\
Resíduo & 46 & 32,2 & 0,7 & \\
\hline Total & 71 & 151,9 & & \\
\hline
\end{tabular}

A 10 - Quadro da análise da variância para a massa de material seco da parte aérea, observada oito semanas após a emergência.

\begin{tabular}{|lcrcc|}
\hline \multicolumn{1}{|c}{ Causa da Variação } & G.L. & \multicolumn{1}{c}{ S.Q. } & Q.M. & Valor F \\
\hline blocos & 2 & 34,1 & 17,06 & 0,9 \\
\hline Cultivar & 1 & 314,2 & 314,2 & $16,3^{*}$ \\
Dose de N & 3 & 198,3 & 66,1 & $3,4^{*}$ \\
Cultivar x Dose de N & 3 & 16,3 & 5,5 & 0,3 \\
Dose de P & 2 & 791,1 & 395,6 & $20,5{ }^{*}$ \\
Cultivar x Dose de P & 2 & 68,7 & 34,3 & 1,8 \\
Dose de N x Dose de P & 6 & 171,1 & 28,5 & 1,5 \\
Cultivar x Dose N x Dose P & 6 & 159,8 & 26,6 & 1,4 \\
\hline Tratamento & 25 & 1753,5 & 70,1 & $3,6^{*}$ \\
Resíduo & 46 & 889,2 & 19,3 & \\
\hline Total & 71 & 2642,7 & & \\
\hline
\end{tabular}


A 11 - Quadro da análise da variância para a massa de material seco das raízes, observada oito semanas após a emergência.

\begin{tabular}{|lcrrc|}
\hline \multicolumn{1}{|c}{ Causa da Variação } & G.L. & S.Q. & Q.M. & Valor F \\
\hline blocos & 2 & 45,6 & 22,8 & $7,5^{*}$ \\
\hline Cultivar & 1 & 0,4 & 0,4 & 0,1 \\
Dose de N & 3 & 34,5 & 11,5 & $3,8^{*}$ \\
Cultivar x Dose de N & 3 & 6,4 & 2,1 & 0,7 \\
Dose de P & 2 & 57,9 & 29,0 & $9,6^{*}$ \\
Cultivar x Dose de P & 2 & 1,0 & 0,5 & 0,2 \\
Dose de N x Dose de P & 6 & 52,8 & 8,8 & $2,9^{*}$ \\
Cultivar x Dose N x Dose P & 6 & 24,9 & 4,2 & 1,4 \\
\hline Tratamento & 25 & 223,6 & 8,9 & $3,0^{*}$ \\
Resíduo & 46 & 139,3 & 3,0 & \\
\hline Total & 71 & 362,8 & & \\
\hline
\end{tabular}

A 12 - Quadro da análise da variância para a massa de material seco total das plantas, observada oito semanas após a emergência.

\begin{tabular}{|lcrrc|}
\hline \multicolumn{1}{|c}{ Causa da Variação } & G.L. & \multicolumn{1}{c}{ S.Q. } & Q.M. & Valor F \\
\hline blocos & 2 & 135,2 & 67,6 & 1,9 \\
\hline Cultivar & 1 & 341,2 & 341,2 & $9,5^{*}$ \\
Dose de N & 3 & 378,1 & 126,0 & $3,5^{*}$ \\
Cultivar x Dose de N & 3 & 26,9 & 9,0 & 0,3 \\
Dose de P & 2 & 1406,4 & 703,2 & $19,6^{*}$ \\
Cultivar x Dose de P & 2 & 93,0 & 46,5 & 1,3 \\
Dose de N x Dose de P & 6 & 434,3 & 72,4 & 2,0 \\
Cultivar x Dose N x Dose P & 6 & 326,2 & 54,4 & 1,5 \\
\hline Tratamento & 25 & 3141,3 & 125,7 & $3,5 *$ \\
Resíduo & 46 & 1654,5 & 36,0 & \\
\hline Total & 71 & 4795,7 & & \\
\hline
\end{tabular}


A 13 - Quadro da análise da variância para a quantidade de $\mathrm{N}$ total acumulado pelas plantas, observada quatro semanas após a emergência.

\begin{tabular}{|lcccc|}
\hline \multicolumn{1}{|c}{ Causa da Variação } & G.L. & S.Q. & Q.M. & Valor F \\
\hline blocos & 2 & 1673 & 837 & 1,5 \\
\hline Cultivar & 1 & 45804 & 45804 & $83,3^{*}$ \\
Dose de N & 3 & 3894 & 1298 & 2,4 \\
Cultivar x Dose de N & 3 & 3920 & 1307 & 2,4 \\
Dose de P & 2 & 8823 & 4412 & $8,0^{*}$ \\
Cultivar x Dose de P & 2 & 3516 & 1758 & 3,2 \\
Dose de N x Dose de P & 6 & 4376 & 729 & 1,3 \\
Cultivar x Dose N x Dose P & 6 & 2183 & 364 & 0,7 \\
\hline Tratamento & 25 & 74189 & 2968 & $5,4^{*}$ \\
Resíduo & 46 & 25306 & 550 & \\
\hline Total & 71 & 99496 & & \\
\hline
\end{tabular}

A 14 - Quadro da análise da variância para a quantidade de P total acumulado pelas plantas, observada quatro semanas após a emergência.

\begin{tabular}{|lcrrc|}
\hline \multicolumn{1}{|c}{ Causa da Variação } & G.L. & \multicolumn{1}{c|}{ S.Q. } & Q.M. & Valor F \\
\hline blocos & 2 & 5,7 & 2,9 & \multicolumn{1}{c|}{3,1} \\
\hline Cultivar & 1 & 18,9 & 18,9 & $20,5^{*}$ \\
Dose de N & 3 & 8,2 & 2,7 & $3,0^{*}$ \\
Cultivar x Dose de N & 3 & 4,3 & 1,4 & 1,6 \\
Dose de P & 2 & 25,1 & 12,5 & $13,6^{*}$ \\
Cultivar x Dose de P & 2 & 6,0 & 3,0 & $3,3^{*}$ \\
Dose de N x Dose de P & 6 & 6,1 & 1,0 & 1,1 \\
Cultivar x Dose N x Dose P & 6 & 2,8 & 0,5 & 0,5 \\
\hline Tratamento & 25 & 77,2 & 3,1 & $3,3^{*}$ \\
Resíduo & 46 & 42,5 & 0,9 & \\
\hline Total & 71 & 119,7 & & \\
\hline
\end{tabular}


A 15 - Quadro da análise da variância para os teores de $\mathrm{N}$ na folha diagnóstica.

\begin{tabular}{|lcrrr|}
\hline \multicolumn{1}{|c}{ Causa da Variação } & G.L. & \multicolumn{1}{c}{ S.Q. } & Q.M. & Valor F \\
\hline blocos & 2 & 11,3 & 5,6 & 1,9 \\
\hline Cultivar & 1 & 12,5 & 12,5 & $4,3^{*}$ \\
Dose de N & 3 & 13,3 & 4,4 & 1,5 \\
Cultivar x Dose de N & 3 & 8,3 & 2,8 & 1,0 \\
Dose de P & 2 & 6,2 & 3,1 & 1,1 \\
Cultivar x Dose de P & 2 & 16,5 & 8,3 & 2,8 \\
Dose de N x Dose de P & 6 & 3,9 & 0,7 & 0,2 \\
Cultivar x Dose N x Dose P & 6 & 22,2 & 3,7 & 1,3 \\
\hline Tratamento & 25 & 94,2 & 3,8 & 1,3 \\
Resíduo & 46 & 133,8 & 2,9 & \\
\hline Total & 71 & 228,0 & & \\
\hline
\end{tabular}

A 16 - Quadro da análise da variância para os teores de P na folha diagnóstica.

\begin{tabular}{|lcccc|}
\hline \multicolumn{1}{|c}{ Causa da Variação } & G.L. & S.Q. & Q.M. & Valor F \\
\hline blocos & 2 & 0,008 & 0,004 & 0,8 \\
\hline Cultivar & 1 & 0,005 & 0,005 & 1,1 \\
Dose de N & 3 & 0,002 & 0,001 & 0,1 \\
Cultivar x Dose de N & 3 & 0,002 & 0,001 & 0,1 \\
Dose de P & 2 & 0,006 & 0,003 & 0,6 \\
Cultivar x Dose de P & 2 & 0,006 & 0,003 & 0,6 \\
Dose de N x Dose de P & 6 & 0,018 & 0,003 & 0,6 \\
Cultivar x Dose N x Dose P & 6 & 0,018 & 0,003 & 0,6 \\
\hline Tratamento & 25 & 0,063 & 0,003 & 0,5 \\
Resíduo & 46 & 0,213 & 0,005 & \\
\hline Total & 71 & 0,275 & & \\
\hline
\end{tabular}


A 17 - Quadro da análise da variância para a quantidade de $\mathrm{N}$ total acumulado pelas plantas, observada oito semanas após a emergência.

\begin{tabular}{|lcrrc|}
\hline \multicolumn{1}{|c}{ Causa da Variação } & G.L. & \multicolumn{1}{c}{ S.Q. } & \multicolumn{1}{c|}{ Q.M. } & Valor F \\
\hline blocos & 2 & 62921 & 31460 & 2,2 \\
\hline Cultivar & 1 & 19383 & 19383 & 1,3 \\
Dose de N & 3 & 108398 & 36133 & 2,5 \\
Cultivar x Dose de N & 3 & 18038 & 6013 & 0,4 \\
Dose de P & 2 & 407950 & 203975 & $14,0^{*}$ \\
Cultivar x Dose de P & 2 & 8851 & 4426 & 0,3 \\
Dose de N x Dose de P & 6 & 148908 & 24818 & 1,7 \\
Cultivar x Dose N x Dose P & 6 & 148364 & 24727 & 1,7 \\
\hline Tratamento & 25 & 922813 & 36913 & $2,5^{*}$ \\
Resíduo & 46 & 673230 & 14635 & \\
\hline Total & 71 & 1596043 & & \\
\hline
\end{tabular}

A 18 - Quadro da análise da variância para a quantidade de P total acumulado pelas plantas, observada oito semanas após a emergência.

\begin{tabular}{|lcrrc|}
\hline \multicolumn{1}{|c}{ Causa da Variação } & G.L. & \multicolumn{1}{c}{ S.Q. } & Q.M. & Valor F \\
\hline blocos & 2 & 27,2 & 13,6 & 0,6 \\
\hline Cultivar & 1 & 35,4 & 35,4 & 1,5 \\
Dose de N & 3 & 238,5 & 79,5 & $3,4^{*}$ \\
Cultivar x Dose de N & 3 & 12,4 & 4,1 & 0,2 \\
Dose de P & 2 & 687,6 & 343,8 & $14,6^{*}$ \\
Cultivar x Dose de P & 2 & 12,0 & 6,0 & 0,3 \\
Dose de N x Dose de P & 6 & 293,1 & 48,9 & 2,1 \\
Cultivar x Dose N x Dose P & 6 & 239,9 & 40,0 & 1,7 \\
\hline Tratamento & 25 & 1546,1 & 61,8 & $2,6^{*}$ \\
Resíduo & 46 & 1086,8 & 23,6 & \\
\hline Total & 71 & 2633,0 & & \\
\hline
\end{tabular}


A 19 - Quadro da análise da variância para a quantidade de P no solo, observada oito semanas após a emergência.

\begin{tabular}{|lcrrc|}
\hline \multicolumn{1}{|c}{ Causa da Variação } & G,L, & \multicolumn{1}{c|}{ S,Q, } & Q,M, & Valor F \\
\hline blocos & 2 & 176,3 & 88,2 & $112,2^{*}$ \\
\hline Cultivar & 1 & 2,8 & 2,8 & 3,6 \\
Dose de N & 3 & 3,6 & 1,2 & 1,5 \\
Cultivar x Dose de N & 3 & 1,6 & 0,5 & 0,7 \\
Dose de P & 2 & 47,1 & 23,6 & $30,0^{*}$ \\
Cultivar x Dose de P & 2 & 1,1 & 0,5 & 0,7 \\
Dose de N x Dose de P & 6 & 6,1 & 1,0 & 1,3 \\
Cultivar x Dose N x Dose P & 6 & 7,9 & 1,3 & 1,7 \\
\hline Tratamento & 25 & 246,6 & 9,9 & $12,5^{*}$ \\
Resíduo & 46 & 36,2 & 0,8 & \\
\hline Total & 71 & 282,7 & & \\
\hline
\end{tabular}

